Universidade de Brasília - UnB

Instituto de Psicologia - IP

Programa de Pós-Graduação em Psicologia Social,

do Trabalho e das Organizações - PSTO

\title{
Além da diversão: Jogos digitais, carga cognitiva e comportamento prosocial
}

Mauricio Miranda Sarmet

Brasília

2016 
Universidade de Brasília - UnB

Instituto de Psicologia - IP

Programa de Pós-Graduação em Psicologia Social,

do Trabalho e das Organizações - PSTO

\title{
Além da diversão: Jogos digitais, carga cognitiva e comportamento prosocial
}

\author{
Mauricio Miranda Sarmet
}

Tese de Doutorado apresentada ao Instituto de Psicologia da Universidade de Brasília, como requisito parcial à obtenção de título de Doutor em Psicologia Social, do Trabalho e das

Organizações.

Orientador: Prof. Dr. Ronaldo Pilati

Brasília 
Universidade de Brasília

Instituto de Psicologia

Programa de Pós-graduação em Psicologia Social, do Trabalho e das Organizações

Tese aprovada pela seguinte banca examinadora:

Prof. Dr. Ronaldo Pilati Rodrigues (Presidente)

Universidade de Brasília - UnB

Prof. Dr. Claudio Vaz Torres (Membro)

Universidade de Brasília - UnB

Profa. Dra. Goiara Mendonça de Castilho

Universidade de Brasília - UnB

Prof. Dr. Marcos Emanoel Pereira

Universidade Federal da Bahia - UFBA

Prof. Dr. Carlos Eduardo Pimentel

Universidade Federal da Paraíba - UFPB

Brasília, setembro de 2016. 


\section{Agradecimentos}

Muitas vezes, o fim de uma jornada significa o início de outra. Este é um momento em que lembro de todos que participaram, direta ou indiretamente, desta conquista. Neste sentido, gostaria de externar meus sinceros agradecimentos:

À Universidade de Brasília, na figura de seus servidores, pelo suporte durante todos os anos de minha formação. A UnB foi minha segunda casa durante vários anos, que serão guardados na memória com muito carinho. Nela fiz grandes amigos e excepcionais colegas de profissão.

À CAPES pelo suporte financeiro fundamental para o desenvolvimento deste trabalho. Ao Instituto Federal de Educação, Ciência e Tecnologia da Paraíba pelo apoio nas fases finais do trabalho e pelas perspectivas futuras de trabalho.

Ao meu orientador e amigo, Ronaldo Pilati, que aceitou a árdua tarefa de orientar meu trabalho, sempre me dando a autonomia necessária que um trabalho desta natureza requer. Obrigado por compartilhar, por este período, o mundo complexo dos games e do comportamento prosocial.

Ao grupo de pesquisa Pro_games (Beatriz Dantas, Daniel Castro, Fabio Lacerda, Guilherme Raposo, Julia Gisler, Matheus Moreto, Nagy Sardinha, Stéfanie Crispim e Tainah Santos), que acompanhou e ajudou de forma fundamental a construir este trabalho. Obrigado pelas discussões, pelo trabalho árduo no planejamento, coleta e análise de dados. Obrigado, principalmente, por compartilhar comigo a curiosidade e o amor pelo mundo dos games.

Aos meus colegas do Laboratório de Psicologia Social, pelas inúmeras discussões produtivas sobre psicologia social, produção de conhecimento, método e técnicas de análises de dados. Não menos importante, pelas divertidas conversas sobre os mais diversos assuntos. André Rabelo, Camila Gastal, Gabriela Campelo, Gabriela Ribeiro, João Modesto, Lucas 
Caldas, Raíssa Damasceno, Raquel Sousa, Renan Saraiva, Victor Keller e Víthor Franco, obrigado!

Aos colegas que acompanharam meu trabalho e me apoiaram em diversos momentos. Fabio Iglesias e Carla Antloga, obrigado pelas conversas sobre a natureza, os prazeres e as angústias da vida acadêmica. Muito do que decidi fazer, hoje, é um reflexo do que conversamos. Alexandre Silvino e Tiago Barros, irmãos de armas, obrigado por sustentar comigo a parede de escudos, mesmo já tendo suportado as próprias batalhas.

Por fim, e não menos importante, agradeço à família pela compreensão durante todo este processo; aos meus pais, pelo amor incondicional (mesmo quando não compreendiam totalmente o que eu fazia). Às minhas irmãs, Luciana e Simone, por me ensinarem que estaremos juntos, não importa o rumo que a vida nos levar. À Yvanna, minha esposa, por tudo. Tudo mesmo. Aos meus filhos, Gabriel e Luíza, pela alegria do aprendizado constante e pela perspectiva de um futuro semelhante a um bom jogo: cheio de desafios, de alegrias e de recompensas ao longo da experiência. 


\section{Sumário}

Página

Lista de Tabelas................................................................................. ix

Lista de Figuras............................................................................. $\mathrm{x}$

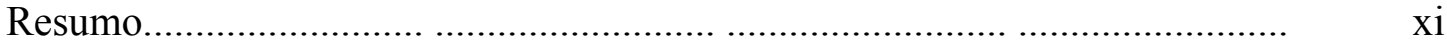

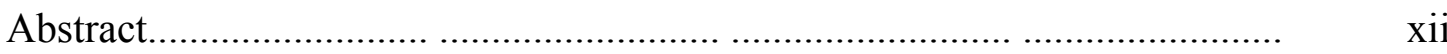

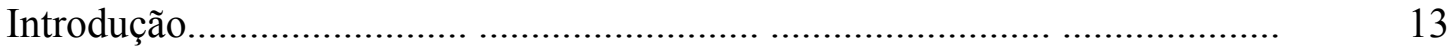

Fundamentação teórica.......................................................................... 17

Comportamento Prosocial.............................................................. 17

Modelo Geral de Aprendizagem (General learning model - GLM)........ 21

Evidências empíricas sobre o GLM.................................................... 25

Impacto dos jogos no funcionamento cognitivo.................................... 29

Estudo sobre variáveis mediadoras................................................... 32

Aprofundando o estudo de jogos: investigação de processos psicológicos e desenvolvimento de ferramentas de pesquisa.................... 34

Considerações sobre a seleção dos jogos digitais.............................. 35

Investigação de processos automáticos e controlados......................... 36

Experimento 1 - Influência do papel desempenhado em jogo no comportamento prosocial..................................................................... $\quad 39$

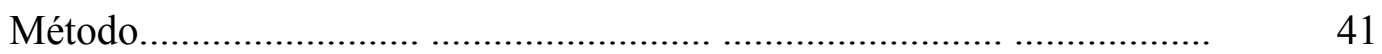

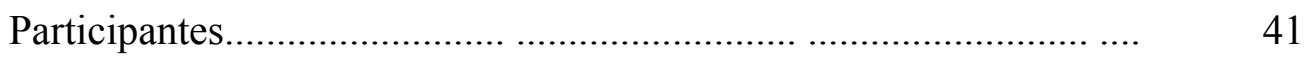

Instrumentos e materiais....................................................... 41

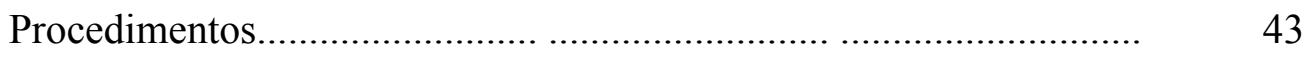

Procedimentos de análise de dados............................................... 45

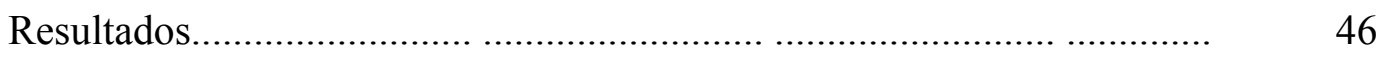

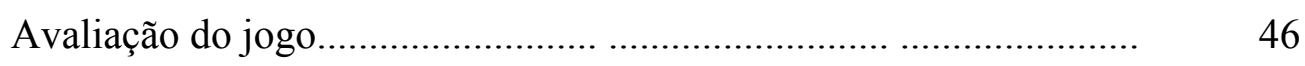

Análises acerca do comportamento prosocial e da intenção de ajuda $\quad 46$

Análises adicionais.................................................................. 48

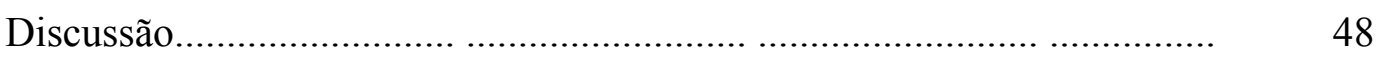

Experimento 2 - Influência do papel desempenhado em jogo no comportamento prosocial e na acessibilidade cognitiva................................ 50

Método.............................................................................. 51

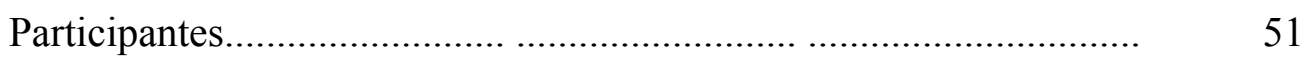

Instrumentos e Materiais............................................................ 51

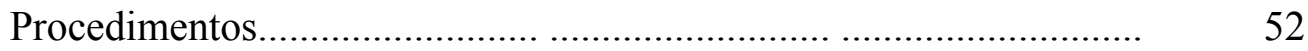




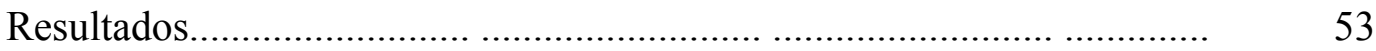

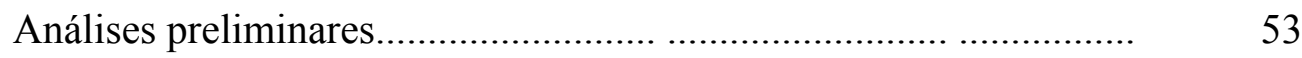

Análise do efeito sobre o comportamento prosocial, intenção de ajuda, afetos positivos e negativos e acessibilidade a cognições prosociais.

Análises adicionais.................................................................. 55

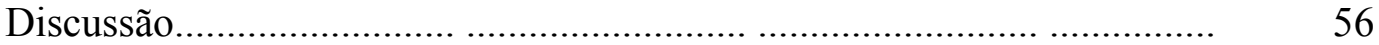

Experimento 3 - Influência do papel em jogo no autoconceito prosocial implícito.

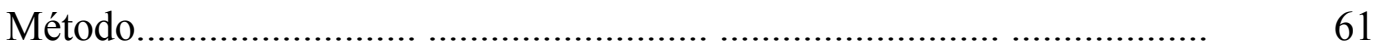

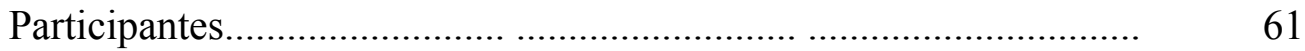

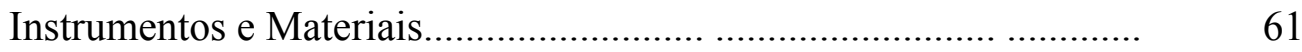

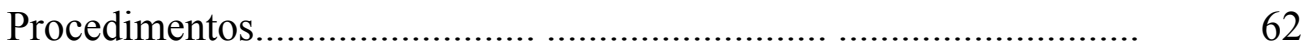

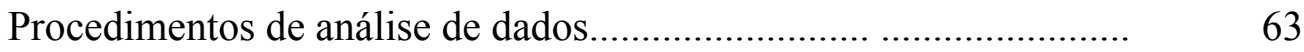

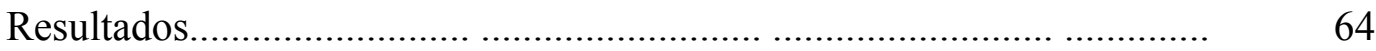

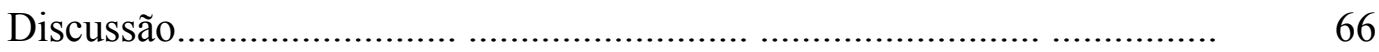

Experimento 4 - Desenvolvimento e pré-teste de um jogo para o estudo do impacto de jogos digitais no comportamento prosocial..................................... $\quad 68$

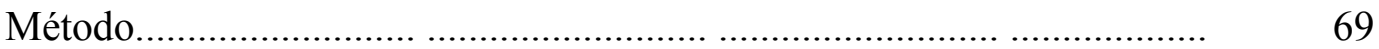

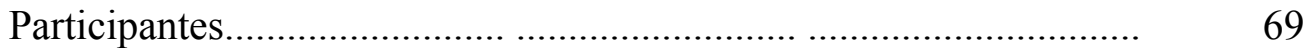

Instrumentos e Materiais............................................................. $\quad 70$

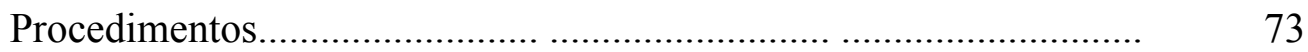

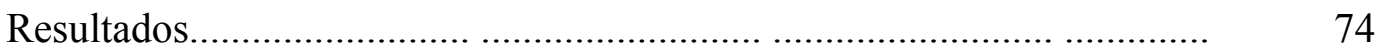

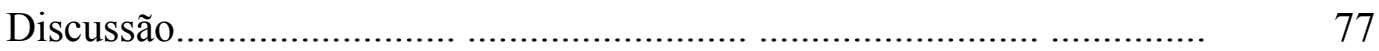

Experimento 5 - Adaptação de um jogo para mensuração do comportamento prosocial........................................................................................ 79

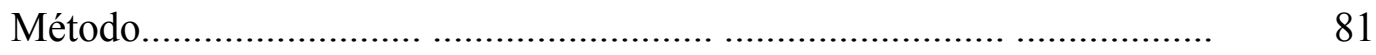

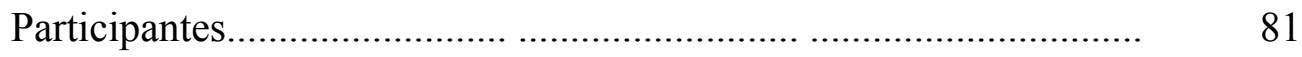

Instrumentos e Materiais........................................................ 81

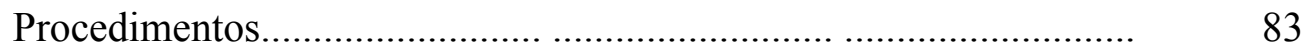

Procedimentos de análise de dados.............................................. $\quad 84$

Resultados....................................................................... 84

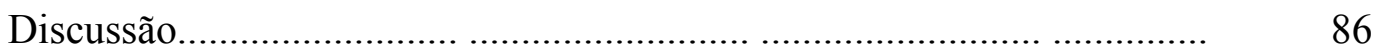

Investigação do efeito da carga cognitiva na relação entre o papel em jogo e o comportamento prosocial.................................................................... 86

Estudo piloto da manipulação de carga cognitiva.................................. $\quad 89$

Método................................................................................. 90 
Participantes ................................................................ 90

Instrumentos e Materiais....................................................... 91

Procedimentos............................................................... 92

Procedimentos de análise de dados......................................... $\quad 93$

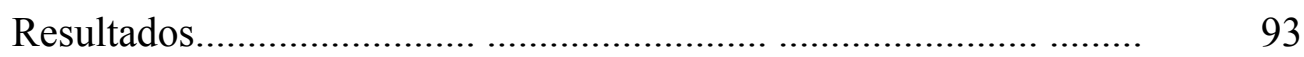

Análises preliminares.................................................... 93

Análises principais........................................................... 94

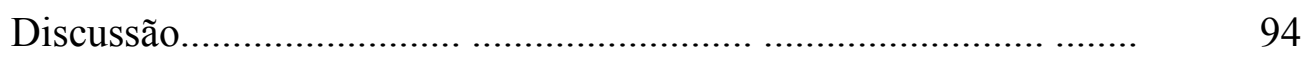

Experimento 6 - Investigação da influência da carga cognitiva no comportamento de ajuda............................................................... 96

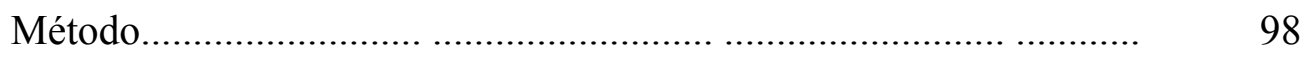

Participantes............................................................... $\quad 98$

Instrumentos e Materiais.................................................. 98

Procedimentos............................................................. $\quad 99$

Procedimentos de análise de dados....................................... 101

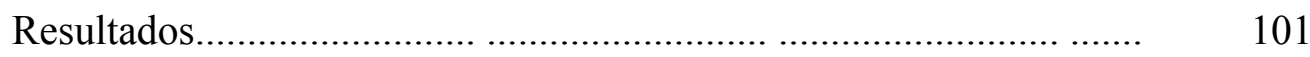

Análises preliminares - checagem de manipulação...................... 101

Análises principais............................................................ 103

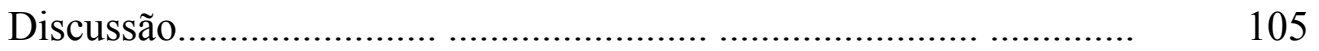

Discussão Geral.................................................................................. $\quad 110$

Considerações finais.............................................................................. 119

Referências........................................................................................... 121

Apêndice A. Questionário contendo questões sobre avaliação do jogo e PANAS.

Apêndice B. Questionário contendo questões demográficas e de hábitos de jogo, BPP e Intenção de ajuda..................................................................... 140

Apêndice C. Lista de estímulos do Teste de Decisão Lexical............................ 142

Apêndice D. Escala de Amabilidade do Big Five (Andrade, 2008)................. 143

Apêndice E. Lista de estímulos utilizada no Teste de Associação Implícita de autoconceito.............................................................................. 144

Apêndice F. Instruções gerais do Zurich Prosocial Game - ZPG.................... 145

Apêndice G. Itens da Interpersonal Reactivity Index (adaptado por Sampaio,
Guimarães, Camino, Formiga \& Menezes, 2011)

Apêndice H. Questionário de avaliação do jogo e de esforço cognitivo............ 150 


\section{Lista de Tabelas}

\section{Página}

Tabela 1. Frequências obtidas e esperadas para a relação entre

comportamento prosocial e a condição experimental

Tabela 2. Coeficientes de regressão para as variáveis preditoras Condição experimental, amabilidade e Condição X Amabilidade.

Tabela 3. Resultados da ANOVA para os efeitos principais e interações

referentes às variáveis reciprocidade, custo e pedido de ajuda no

comportamento de ajuda

Tabela 4. Comparação das avaliações de jogo e da percepção de carga das tarefas em função das condições experimentais $(\mathrm{N}=32)$

Tabela 5. Teste Mann-Whitney para comparação das avaliações de jogo e da percepção de carga das tarefas de acordo com a função jogada - violenta ou prosocial $(\mathrm{N}=38)$

Tabela 6. Teste Mann-Whitney para comparação das avaliações de jogo e da percepção de carga das tarefas de acordo com a condição jogada no ZPG (N $=38)$ 


\section{Lista de Figuras}

Página

Figura 1. General learning model. Adaptado de Buckley e Anderson (2006)

Figura 2. Exemplo da tela do jogo Fat Princess, utilizado como estímulo para as condições experimentais.

Figura 3. Distribuição da frequência de comportamento de ajuda entre as condições violenta $(N=27)$ e prosocial $(N=28)$.

Figura 4. Comparação dos tempos de latência das medidas pré-teste e pósteste do TAI, em função da condição experimental do participante.

Figura 5. Exemplo da tela no modo violento.

Figura 6. Exemplo da tela no modo neutro.

Figura 7. Exemplo da tela no modo prosocial.

Figura 8. Comparação da avaliação do nível de violência em função do modo jogado.

Figura 9. Comparação da avaliação do nível de prosocialidade em função do modo jogado.

Figura 10. Tela do Zurich Prosocial Game.

Figura 11. Médias do comportamento de ajuda por condição $(\mathrm{N}=38)$. As barras de erro representam o Intervalo de Confiança (95\%). 


\section{Resumo}

O efeito de diferentes tipos de mídia sobre o comportamento é um tema que atrai o interesse do público em geral e dos pesquisadores do comportamento humano, e a investigação sobre os efeitos dos jogos digitais tem crescido na literatura. Várias revisões sistemáticas e metaanálises sobre o tema apresentam evidências acerca da existência de uma relação entre a exposição a jogos digitais e comportamentos agressivos e prosociais. No entanto, evidências sobre o papel da cognição, dentro de uma perspectiva processual, ainda são escassas. A presente tese tem como objetivo avaliar o papel dos recursos cognitivos na relação entre a função desempenhada no jogo e o comportamento prosocial. Para isso, uma série de experimentos foram desenvolvidos com o intuito de se analisar a influência dos jogos no comportamento prosocial, na acessibilidade a cognições prosociais (Experimentos 1 e 2) e no autoconceito prosocial implícito (Experimento 3). Além disso, realizou-se o desenvolvimento e pré-teste de um jogo concebido para experimentos considerando diferentes funções (Experimento 4), bem como a adaptação e teste de uma ferramenta informatizada para mensuração do comportamento prosocial (Experimento 5). Com base nos resultados destes experimentos, delineou-se um experimento para investigar o papel dos recursos cognitivos na relação entre tipo de jogo e comportamento prosocial (Experimento 6). Os resultados apontam a carga cognitiva como uma variável relevante para se compreender o efeito dos jogos digitais no comportamento prosocial, além de levantar a necessidade de se discutir o poder explicativo do modelo teórico vigente.

Palavras-chave: jogos digitais; comportamento prosocial; carga cognitiva. 


\begin{abstract}
The effect of different media types on behavior is a subject that attracts the interest of general public and researchers of human behavior, and the investigation concerning the effect of digital games has grown. Several systematic reviews and meta-analysis about this subject present evidence supporting the relation between the exposition to digital games and aggressive and prosocial behaviors. However, evidence about the role of cognition considering a processual perspective is still scarce. The main goal of this dissertation is to evaluate the role of cognitive resources on the relation between the role played on a digital game and prosocial behavior. To test that, a series of experiments was developed to investigate the influence of games on prosocial behavior, accessibility of prosocial cognitions (Experiments 1 and 2) and implicit prosocial self-concept (Experiment 3). Besides that, a game with different roles for experiments was designed (Experiment 4), and a computer measure of prosocial behavior was adapted (Experiment 5). Based on the results of the previous experiments, a last experiment was designed to investigate the role of cognitive resources on the relation between game type and prosocial behavior (Experiment 6). Results shows the relevance of cognitive load on the understanding of the effect of digital games on prosocial behavior, as well as the need to discuss the explanatory power of the theoretical model used.
\end{abstract}

Keywords: digital games; prosocial behavior; cognitive load. 


\section{Introdução}

Imagine-se como um indivíduo cuja função é socorrer os feridos ao seu redor. Imagine que você se encontra em um terreno incerto, muitas vezes hostil, e que deve utilizar de todos os seus recursos para salvar os indivíduos à beira da morte. Envolto em pedidos de ajuda, você deve pensar nas melhores estratégias para auxiliar o máximo possível de pessoas. Concentre-se. Concentre-se em visualizar suas ações enquanto salva os feridos e em como você se sente ao fazer isso.

O breve cenário descrito acima pode ser aplicado a duas situações bastante distintas. A primeira delas é a atuação da organização Médicos Sem Fronteiras (http://www.msf.org.br), que atua em regiões de extrema vulnerabilidade social, muitas vezes envolta em conflitos armados. A outra consiste em atuar como um paramédico ou um curandeiro em jogos multiplayer online. Apesar de uma acontecer em um mundo virtual, muitas vezes fantasioso, e a outra ocorrer no "mundo real", é possível verificar similaridades nas funções que o indivíduo ocupa em cada uma delas. Que outras similaridades elas teriam em comum e, mais importante, quais fatores poderiam explicar o comportamento de ajuda em cada uma delas?

O efeito que diferentes tipos de mídia têm sobre o comportamento é um tema que há muito atrai o interesse do público em geral e dos pesquisadores do comportamento humano. O surgimento de novas mídias traz, inevitavelmente, uma discussão sobre seus efeitos no comportamento, principalmente quando se considera que sistemas de comunicação e entretenimento em massa possuem uma capacidade de atingir um grande número de pessoas, com diversos perfis sociais, como no caso do rádio, do cinema e da televisão. De forma diferente do cenário citado anteriormente, elementos midiáticos têm comumente sido associados a atos de violência, como massacres em escolas (por exemplo, na escola secundária de Columbine, nos Estados Unidos, ou na escola pública de Realengo, no Brasil). 
Nestes casos, é comum que seja feita uma inferência acerca do efeito que mídias agressivas tiveram sobre os perpetradores de tais atos.

Jogos eletrônicos despertam atenção especial sobre este assunto pois, devido à natureza ativa da interação entre o jogo e o jogador, se populariza a noção de que este tipo de mídia pode influenciar ainda mais o comportamento dos indivíduos expostos a ela. Além disso, jogos digitais têm feito parte do cotidiano de pessoas de diversas idades e níveis socioeconômicos, em diferentes formatos (jogos de computador, consoles específicos para este fim, tablets e aparelhos celulares). Cada vez mais, uma quantidade maior de pessoas faz parte de um grupo de consumidores de uma indústria que cresce de maneira vertiginosa diariamente (Mäyrä, 2008; McGonigal, 2011). Caso esta relação venha a ser verdadeira, há um grande potencial nocivo associado à comercialização cada vez mais frequente de jogos que possuem temas associados à violência. No entanto, cada vez mais pesquisadores defendem a ideia de que o contrário também pode ser verdadeiro, e que jogos com características "positivas" podem gerar benefícios em termos de comportamentos. Caso esta premissa seja verdadeira, voltando ao exemplo inicial, o fato do indivíduo exercitar, dentro de um contexto de jogo, ações que beneficiam outros personagens (controlados por outros jogadores ou pela inteligência artificial do jogo), poderia fazer com que atos da mesma natureza ocorressem fora do contexto digital. Os jogos, neste raciocínio, poderiam ser utilizados como ferramentas úteis no treinamento de comportamentos socialmente desejáveis. Pesquisas recentes têm apresentado evidências de que essa relação pode ocorrer, mas o caráter incipiente da linha de investigação ainda deixa uma série de questões em aberto. As revisões sistemáticas e meta-análises sobre o tema apresentam, conforme seus autores, evidências consistentes o bastante para sustentar a existência de uma relação causal entre a exposição a jogos digitais e determinados comportamentos, agressivos ou prosociais (por exemplo, Anderson \& Bushman, 2001; Anderson et al., 2010; Barlett, Anderson, \& Swing, 
2009; Fischer, Greitemeyer, Kastenmüller, Vogrincic, \& Sauer, 2011; Greitemeyer \& Mügge, 2014). Apesar de existirem críticas com relação a aspectos metodológicos e à relevância prática associada a estes estudos (Elson \& Ferguson, 2013; Ferguson, 2007, 2008, 2009a, 2009b; Ferguson \& Dyck, 2012), alguns autores sugerem que pesquisas futuras não deveriam se debruçar sobre a existência ou não do fenômeno, mas sim sobre os elementos processuais associados a ele (Bushman \& Huesmann, 2014). Para estes autores, o importante agora seria investigar como os jogos podem influenciar o comportamento de seus jogadores, e quais variáveis estariam envolvidas nesta relação. Constata-se, no entanto, uma escassez nos estudos que buscam avaliar evidências que sustentem todas as premissas que constituem o modelo teórico utilizado, principalmente no que se refere ao impacto de constituintes dos jogos eletrônicos nos processos (automáticos e controlados) de avaliação dos estímulos recebidos, bem como a influência destes na ocorrência de determinados comportamentos.

Dentro deste contexto de investigação, há um espaço considerável de contribuições de áreas dedicadas ao estudo do comportamento humano, uma vez que a compreensão deste fenômeno pode auxiliar: a) desenvolvedores, à medida em que fornece subsídios para a concepção de jogos que favoreçam (ou evitem) determinados tipos de comportamento; b) agentes governamentais, uma vez que evidências empíricas podem ser utilizadas na elaboração e defesa de políticas públicas associadas à comercialização e incentivo ao desenvolvimento de jogos, c) organizações privadas e não-governamentais, uma vez que os jogos poderiam ser utilizados como ferramentas para, por exemplo, facilitar um processo de melhoria nas relações interpessoais no trabalho ou o treinamento de hábitos voltados para a civilidade, gentileza ou uma gama diversa de comportamentos prosociais, e; d) o público em geral, a partir da conscientização dos possíveis efeitos prejudiciais e benéficos decorrentes da exposição a jogos digitais. 
O presente trabalho possui uma dupla perspectiva de análise: por um lado, foi elaborado com foco nos potenciais efeitos benéficos de jogos digitais no comportamento, visando apresentar um conjunto de evidências que permitam o enriquecimento da área como um todo. Por outro, contempla o interesse em investigar elementos específicos do modelo explicativo mais comumente aceito pelos pesquisadores da área. Neste sentido, tem como objetivo geral avaliar o papel dos recursos cognitivos na relação entre a função desempenhada no jogo e o comportamento prosocial. Como objetivos específicos, busca: a) descrever a influência do tipo de jogo no comportamento prosocial (Experimentos 1 e 2); b) testar a influência dos jogos no autoconceito prosocial implícito (Experimento 3); c) descrever a influência do tipo de jogo na acessibilidade a conteúdos prosociais e no comportamento de ajuda (Experimento 2); d) desenvolver um jogo que permita a manipulação da função no jogo (prosocial, neutro e violento), mantendo-se outras variáveis constantes (Experimento 4); e) testar o papel da carga cognitiva na relação entre a função desempenhada no jogo e o comportamento de ajuda (Experimentos 5 e 6 ).

Para tanto, as informações relevantes são apresentadas de acordo com a seguinte estrutura: inicialmente, o comportamento prosocial é definido e a literatura pertinente revisada. Em seguida, são apresentadas a descrição e as evidências empíricas acerca do general learning model (Buckley \& Anderson, 2006), bem como as principais críticas associadas a ele e modelos explicativos alternativos. Em seguida, são apresentados 6 experimentos realizados, as principais contribuições e limitações de cada um deles. Por fim, são descritas a discussão geral, considerando todos os estudos realizados, e as considerações finais acerca deste trabalho. 


\section{Fundamentação Teórica}

\section{Comportamento Prosocial ${ }^{1}$}

O comportamento prosocial pode ser definido como um conjunto de comportamentos realizados por um indivíduo de forma a beneficiar outros (Mikulincer \& Shaver, 2010; Penner, Dovidio, Piliavin, \& Schroeder, 2005). Tal definição sugere uma ampla categoria que engloba diferentes tipos de comportamentos, bem como perspectivas diversas de análise, e estudos sobre comportamentos prosociais podem englobar fenômenos como ajuda, altruísmo, solidariedade e voluntariado, e envolve aspectos individuais, interpessoais e grupais (Stürmer \& Snyder, 2010). Essa gama de comportamentos se mostra fundamental para a compreensão não só da evolução humana, mas também de outros sistemas biológicos complexos nos quais a cooperação parece ter sido elemento essencial para o seu desenvolvimento (Keltner, Kogan, Piff, \& Saturn, 2014). Dunfield (2014), ao analisar esta temática sob a ótica do desenvolvimento humano, sugere que os comportamentos caracterizados como prosociais estão relacionados a diferentes estágios de desenvolvimento cognitivo requeridos para perceber e interpretar distintos estados negativos de necessidade. Com isso, propõe uma taxonomia que divide os comportamentos que visam a reduzir a necessidade de terceiros em atos de ajuda (helping, atendendo a demandas instrumentais de outros), de compartilhamento (sharing, com vistas a atender a uma necessidade material de outro) e de conforto (conforting, oferecendo suporte verbal ou físico para uma necessidade afetiva).

Na tentativa de estruturar o conjunto de evidências sobre comportamento prosocial, Penner et al. (2005) propõem uma perspectiva multinível de análise dos fatores que influenciam este comportamento: micronível, que envolve o estudo de aspectos biológicos e genéticos, bem como características de desenvolvimento e de personalidade, e sua relação

\footnotetext{
${ }^{1}$ Nesta tese, optou-se por utilizar o termo prosocial ao invés de pró-social, da mesma forma que o sugerido por Pilati, Iglesias, Lima e Simone (2010), de forma a facilitar os processos de busca e indexação, nas diversas bases de dados nacionais e internacionais e buscar o uso homogêneo de uma terminologia técnica mais abrangente na área.
} 
com a ocorrência de comportamentos prosociais; mesonível, que busca analisar os motivos e as condições sociais envolvidas quando um indivíduo auxilia o outro (envolvendo processos de aprendizagem social e avaliação de troca social, por exemplo, bem como os efeitos do processamento não consciente de informações contextuais), e; macronível, que estuda o comportamento prosocial dentro de um contexto organizacional e cultural, e que envolve o estudo de fenômenos como o voluntariado e a cooperação.

Várias teorias foram desenvolvidas com o intuito de explicar as razões pelas quais os indivíduos ajudam os outros em situações de necessidade. McCullough e Tabak (2010) sintetizam diversas delas, como as teorias evolutivas de seleção de parentela, reciprocidade direta e indireta e seleção de grupos, o que é coerente com o descrito no nível micro de análise proposto por Penner et al. (2005). Ainda, todos esses autores apresentam evidências empíricas que relacionam o comportamento prosocial a traços disposicionais como a amabilidade e a empatia, relação que vários outros estudos parecem levar em consideração (por exemplo, Graziano, Habashi, Sheese, \& Tobin, 2007; Hilbig, Glöckner, \& Zettler, 2014).

Propostas recentes de modelização do comportamento prosocial tendem a uma perspectiva multinível semelhante, considerando uma classificação entre níveis intrapsíquico, diádico, grupal e cultural (Keltner et al., 2014). Dentro do nível micro de análise, os autores apresentam estudos que evidenciam a influência de aspectos disposicionais, como amabilidade, abertura a mudanças e empatia, além de sugerir que a ocorrência do comportamento de ajuda está relacionada também às recompensas pessoais decorrentes do ato. Considerando o nível diádico de análise, Keltner et al. sintetizam evidências acerca da importância de processos de percepção e de troca social para a ocorrência do comportamento prosocial. Neste nível de análise, são relevantes os fatores que contribuem para a percepção tanto de características do potencial receptor do comportamento de ajuda quando das chances 
futuras de reciprocidade (o que, mais uma vez, sugeriria a importância dos benefícios para a ocorrência do comportamento de ajuda).

O comportamento prosocial ainda pode ser analisado dentro de uma lógica dual de processamento. Neste sentido, o comportamento prosocial não seria somente definido por um processamento consciente e controlado por parte do indivíduo. Tal noção é sustentada por Perugini, Conner e O’Gorman (2011) que, a partir de evidências empíricas, sugerem que comportamentos relacionados à prosocialidade, como o comportamento espontâneo de ajuda, podem ser influenciados por processos implícitos, além de explícitos, de processamento das informações (pistas) ambientais fornecidas.

Outra evidência que sugere uma perspectiva dual na compreensão do comportamento prosocial está relacionada aos efeitos da escassez de recursos cognitivos na ocorrência destes comportamentos. Considerando que os seres humanos são processadores de informação limitados biologicamente (Jonides \& Irwin, 1981), é natural supor que a alocação de recursos cognitivos seja importante para se compreender a ocorrência de diversos tipos de fenômenos, não só relacionados ao comportamento prosocial, mas também a outros fenômenos como estereótipos (Sherman, Lee, Bessenoff, \& Frost, 1998; Van Boven \& Robinson, 2012) e moralidade (Conway \& Gawronski, 2013; Greene, Morelli, Lowenberg, Nystrom \& Cohen, 2008; Suter \& Hertwig, 2011).

Ao estudar o processo de tomada de perspectiva, fenômeno associado à formação de relações empáticas (e, consequentemente, ao comportamento prosocial), autores sugerem que a manipulação da quantidade de recursos disponíveis pode influenciar a ocorrência de comportamentos de ajuda de forma geral (Epley, Morewedge \& Keysar, 2004; Fennis, 2011). Como princípio explicativo, os autores fizeram uso do modelo dual de processamento, sugerindo que comportamentos egoístas seriam mais automáticos, e que o comportamento prosocial exigiria maior controle e regulação por parte dos indivíduos. 
Dando suporte a este raciocínio, em estudos experimentais que manipulam, por meio de procedimentos de depleção do ego (Dewall, Baumeister, Gailliot, \& Maner, 2008; Fennis, 2011; Xu, Bègue, \& Bushman, 2012), a quantidade de recursos cognitivos disponíveis para a execução de uma tarefa principal, apresentam uma redução no comportamento prosocial, quando comparados grupos que não passam pelo mesmo procedimento. São comuns, em delineamentos como estes, a utilização de tarefas concomitantes de memorização de dígitos como uma maneira de limitar de alguma forma os recursos cognitivos disponíveis para a tarefa principal (Cavallo, Holmes, Fitzsimons, Murray, \& Wood, 2012; Conway \& Gawronski, 2013).

Considerando o exposto, esta tese terá como foco principal o comportamento prosocial relacionado à ajuda instrumental (dentro da perspectiva de Dulfield, 2014). Ainda, enfatizará a análise dentro de uma perspectiva meso/interpessoal (Penner et al., 2005) e diádica (Keltner et al., 2014), considerando principalmente os fatores contextuais relacionados ao comportamento de ajuda os processos de interpretação destes fatores. No entanto, levará em conta também aspectos de nível micro relacionados a traços disposicionais que podem explicar a ocorrência do comportamento de ajuda. Por fim, e levando-se em conta o interesse crescente da literatura no papel de processos não conscientes na influência do comportamento de ajuda (Penner et al., 2005), este trabalho abordará o comportamento prosocial dentro de uma perspectiva dual de processamento.

Ao se considerar o comportamento prosocial no contexto de investigação sobre o efeito de mídias diversas, é fundamental analisar como as pesquisas sobre a temática modelizam os construtos relevantes e suas associações entre eles. A partir desta análise, é factível investigar relações específicas entre variáveis relevantes para a compreensão do comportamento prosocial. Neste sentido, optou-se por iniciar o presente trabalho com uma análise do general learning model, modelo mais comumente utilizado na investigação da 
influência de jogos digitais no comportamento. A seguir, as principais características e pressupostos deste modelo são apresentadas.

\section{Modelo Geral de Aprendizagem (General Learning Model - GLM)}

O GLM é um modelo que apresenta as principais dimensões envolvidas no estudo da influência de diferentes mídias no comportamento, bem como diferentes rotas pelas quais essa influência parece ocorrer (Buckley \& Anderson, 2006). Baseado no general aggression model, de Anderson e Bushman (2002), foi desenvolvido de forma a considerar outros tipos de fenômenos além daqueles relacionados à agressão.

Este modelo propõe, como um dos seus elementos principais, que o impacto de elementos midiáticos ocorre tanto de forma imediata (ou de curto prazo) quanto de longo prazo, em função da exposição repetida a um mesmo estímulo (ou estímulos semelhantes). Neste sentido, algumas características estruturais e processuais dos jogos digitais possibilitam um contexto de aprendizagem que pode gerar mudanças duradouras tanto em disposições quanto em comportamentos (Swing, Gentile, \& Anderson, 2009): a) a capacidade de controlar e ajustar o nível de dificuldade do processo de aprendizagem, possibilitando que a dificuldade se ajuste ao nível de expertise do jogador; b) a aplicação repetida de determinadas habilidades, caracterizando um contexto de treino; c) a existência de um processo ativo de aprendizagem, uma vez que os jogadores devem se engajar intencionalmente na experiência de jogo para cumprir os objetivos propostos; d) a existência de feedbacks imediatos e de recompensas para as ações dos jogadores; e) a possibilidade de generalização de comportamentos específicos a contextos diversos, uma vez que habilidades semelhantes são solicitadas em jogos diferentes (por exemplo, em diferentes jogos de FPS - first person shooters). Tais características muitas vezes são utilizadas para se justificar o efeito 
potencializador que o jogo digital possui em comparação com outras mídias, onde a interatividade e o feedback constantes não são frequentes.

Como bases teóricas, o modelo se fundamenta em diversas teorias sobre a cognição e o aprendizado humano: as teorias de aprendizagem social de Bandura, a teoria neoassociacionista de memória de Berkowitz, de transferência de excitação de Zillmann, de Script de Husmann e de processamento social da informação de Crick e Dodge (Barlett \& Anderson, 2013; Buckley \& Anderson, 2006). Assim, os autores defendem que o GLM parte de uma grande quantidade de estudos que, de uma forma ou de outra, fornecem suporte para essas teorias, o que confere maior robustez teórica ao modelo proposto (Prot \& Anderson, 2013).

No GLM (Figura 1) são descritos dois tipos diferentes de inputs. As variáveis pessoais dizem respeito a atitudes, crenças, objetivos, experiências prévias, estados emocionais anteriores à exposição ao jogo, entre outros. São consideradas variáveis relativamente estáveis no tempo. As variáveis situacionais, por sua vez, envolvem as características da mídia e do contexto, bem como a compreensão que os indivíduos possuem deste contexto específico. Estas variáveis acabam por influenciar o estado interno do indivíduo, composto pelas rotas cognitivas, afetivas e de alerta/excitação (arousal), que interagem para resultar em um processo de avaliação.

De acordo com o modelo, determinadas características da situação podem eliciar conteúdos compatíveis em cada uma das rotas do estado interno e, consequentemente, resultar em comportamentos também similares. Neste sentido, o GLM hipotetiza que um jogo violento, por exemplo, ativará conteúdos relacionados à violência na memória, além de estados afetivos e de excitação (arousal) congruentes ao contexto violento, ocasionando em comportamentos mais agressivos. Além disso, pressupõe efeitos de longo prazo que envolvem o aprendizado fatual e de comportamentos (a partir do treino recorrente, 
reforçamentos e punições), além de mudanças disposicionais (Buckley \& Anderson, 2006). A ocorrência de efeitos de curto e de longo prazo, no entanto, parecem existir em função de processos diferenciados: enquanto os efeitos de curto prazo parecem estar relacionados a efeitos de priming, arousal e de imitação, os efeitos de longo prazo envolvem aprendizagem por observação e ativação e dessensibilização de processos emocionais (Huesmann, 2007).

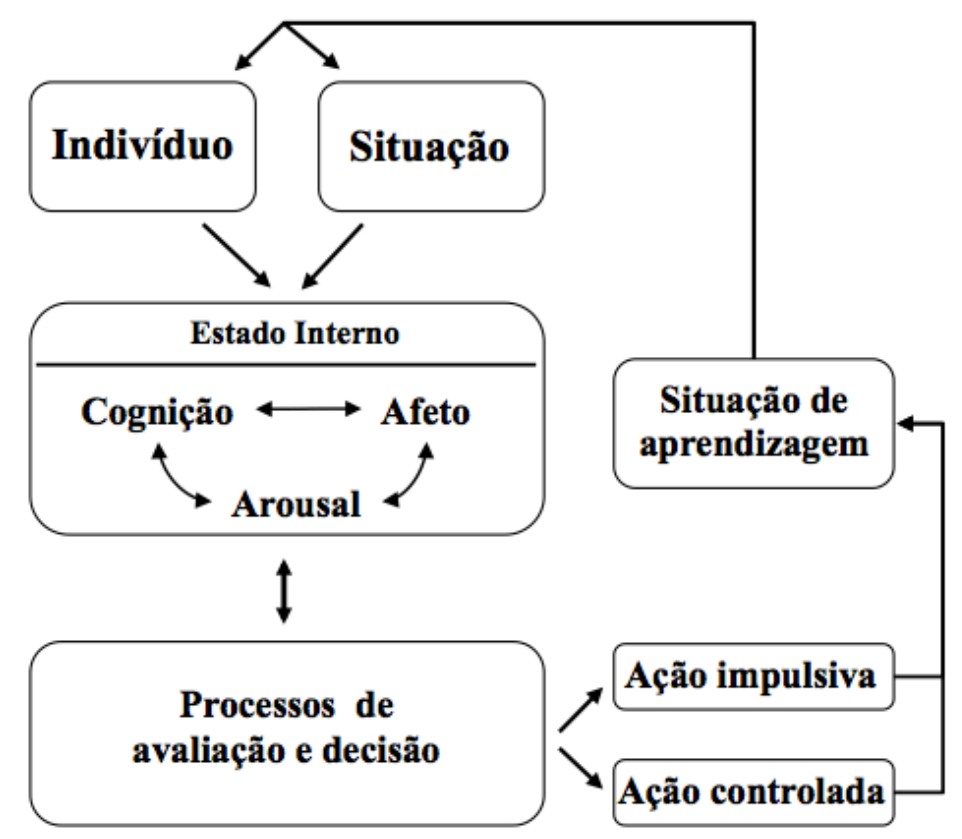

Figura 1. General learning model. Adaptado de Buckley e Anderson (2006).

Em suma, o GLM pressupõe que a interação com os jogos digitais (em função de seu caráter de simulação) possibilita que o conhecimento produzido a partir da experiência de jogo influencie a percepção e interpretação de situações de jogo, podendo envolver estados afetivos, estruturas cognitivas e scripts comportamentais que guiarão o comportamento dos jogadores em situações futuras. A partir do treino recorrente, característico da situação de jogo, a ativação destes padrões pode se tornar mais acessível, alterando a forma como o indivíduo interpreta e lida com as situações externas ao jogo. 
Um ponto importante do GLM diz respeito ao processamento das informações recebidas. Após a exposição ao estímulo, este processo avaliativo ocorre de forma imediata e, a depender da quantidade de recursos atencionais e de quão satisfatório for o resultado desta avaliação, um processo de reavaliação (mais controlado) pode ser ativado (Anderson \& Dill, 2000; Barlett \& Anderson, 2013). A diferença entre processos automáticos ou controlados de avaliação resultam, respectivamente, em ações impulsivas ou controladas, e suscitam uma discussão sobre como as informações recebidas pelo meio, bem como os padrões mnemônicos ativados a partir desta exposição, resultam em determinados padrões comportamentais. Neste sentido, o GLM sugere que a existência de recursos cognitivos, bem como o resultado preliminar da avaliação, pode demandar o uso de estratégias mais controladas de escolha do comportamento a ser manifestado.

Esse aspecto, apesar de ser ainda escasso na literatura sobre jogos digitais, mostra-se relevante para se compreender tanto os resultados empíricos quanto a significância prática de tais achados. Isso porque, caso as proposições do modelo sejam coerentes, o comportamento efetivamente observado não depende somente do tipo de jogo digital consumido (nem de sua natureza, por exemplo, violenta ou prosocial); a influência deste sobre o primeiro seria mediada por uma série de outras variáveis, como a capacidade do indivíduo filtrar suas primeiras avaliações de forma a controlar o tipo de comportamento que considera relevante manifestar.

Vários estudos foram realizados na tentativa de investigar a relação entre as características do jogo e sua influência em diferentes dimensões do GLM. É importante notar que, dado o caráter genérico do modelo e a quantidade de variáveis que o compõe, torna-se inviável testá-lo em sua completude em um mesmo estudo. Em função disso, as evidências produzidas em favor do modelo contemplam relações entre variáveis específicas. A robustez do modelo, de acordo com seus proponentes, se dá justamente em função de uma análise 
conjunta das evidências encontradas relacionando as características da mídia com as principais rotas (cognitiva, afetiva e de excitação) e com o comportamento. A seguir, são apresentadas evidências para cada uma dessas dimensões. É importante ressaltar que, em função da escassez de evidências sobre efeitos no comportamento prosocial, bem como o pressuposto generalista do modelo em função do tipo de consequência da exposição a jogos digitais, optou-se por apresentar evidências relacionadas às principais dimensões do GLM, comportamento, cognição, afeto e arousal, tanto para comportamentos agressivos quanto para prosociais.

\section{Evidências empíricas sobre o GLM}

De forma geral, observa-se que é mais comum o uso de delineamentos experimentais para se verificar a influência dos jogos digitais sobre as diversas dimensões do GLM, em função da necessidade de manipulação e de um maior controle de variáveis (Greitemeyer \& Mügge, 2014). Dentro deste escopo, manipula-se a natureza do jogo a ser utilizado (por meio de jogos prosociais, violentos e neutros, por exemplo) em grupos experimentais diferenciados.

Considerando o comportamento como principal variável dependente, os resultados de vários estudos independentes sugerem que a natureza do jogo pode eliciar comportamentos congruentes com ela. Observa-se, por exemplo, que jogos violentos podem aumentar a ocorrência de comportamentos agressivos medidos pelo competitive reaction time taskCRTT (Anderson \& Dill, 2000; Carnagey \& Anderson, 2005). Nesta tarefa, simula-se uma situação de competição entre jogadores onde é facultado ao vencedor disparar um sinal sonoro de intensidade e duração variáveis e, quanto mais alta é a intensidade (e mais duradoura) escolhida pelo participante, mais agressivo se infere o seu comportamento. Ainda, a exposição a jogos violentos tendem a reduzir o comportamento de doação (Chambers \& 
Ascione, 2001). De forma contrária, jogos prosociais estão associados a uma maior intenção em ajudar terceiros (Greitemeyer \& Osswald, 2010; Jin, 2011; Peng, Lee, \& Heeter, 2010), selecionar quebra-cabeças mais fáceis para outro participante (Gentile et al., 2009; Saleem, Anderson, \& Gentile, 2012b) e ajudar ostensivamente um confederado, coletando lápis que caíram no chão ou auxiliando-o em uma situação simulada de conflito (Greitemeyer \& Osswald, 2010).

De forma semelhante, a exposição a jogos prosociais parece reduzir a ocorrência de comportamentos agressivos (Greitemeyer, Agthe, Turner, \& Gschwendtner, 2011). No entanto, não há consenso na literatura, e alguns estudos apresentam evidências de que o efeito pode não existir (Ferguson, 2007; Sestir \& Bartholow, 2010; Tear \& Nielsen, 2013; Valadez \& Ferguson, 2012). Além disso, alguns autores criticam o uso do CRTT como medida do comportamento agressivo, argumentando a falta de validade ecológica da medida (Elson \& Ferguson, 2013). As críticas ao uso desta medida contemplam tanto a falta de padronização nas instruções, procedimentos e escalas utilizadas, quanto nas estratégias de análise (Elson, Mohseni, Breuer, Scharkow, \& Quandt, 2014), resultando em um conjunto de inconsistências que fragilizam a medida, podendo inclusive resultar em conclusões diferentes a depender das estratégias de tratamento e análise de dados selecionadas pelo pesquisador.

Ao se considerar a dimensão cognitiva, as principais evidências tratam da ativação, a partir da apresentação de um jogo com características específicas, de determinados conteúdos na memória. De forma geral, essa proposta é operacionalizada a partir da medida de acessibilidade de um conteúdo na memória após a exposição a um jogo com conteúdo semelhante. Por exemplo, Anderson e Dill (2000) expuseram participantes a um jogo violento (Mortal Kombat) ou neutro (Myst); após o período de jogo, solicitaram que os participantes realizassem um teste de velocidade de leitura. Os autores encontraram tempos menores de resposta para a leitura de palavras agressivas em participantes expostos ao jogo 
violento, e interpretaram tais evidências como um indicador de que conteúdos violentos estariam mais "acessíveis", resultando em um menor tempo de leitura.

Outra medida utilizada é a tarefa de completamento de palavras (word completion task). Nela, são apresentados aos participantes um conjunto de fragmentos de palavras e é solicitado que os participantes completem cada um deles com a primeira palavra que vier à mente. Evidências empíricas indicam que a exposição a jogos violentos está associada a uma escolha maior por palavras violentas (Carnagey \& Anderson, 2005; Sestir \& Bartholow, 2010). De forma semelhante, a exposição a jogos prosociais tende a reduzir cognições agressivas (Greitemeyer et al., 2011; Greitemeyer \& Osswald, 2009). Outros estudos utilizaram a tarefa de completar histórias ambíguas, sugerindo que jogos prosociais podem aumentar a acessibilidade a cognições prosociais (e.g., Greitemeyer \& Osswald, 2010).

Ainda considerando evidências sobre a rota cognitiva, estudos relacionaram a exposição a jogos violentos com o autoconceito agressivo implícito, por meio do Teste de Associação Implícita (Bluemke, Friedrich, \& Zumbach, 2009; Uhlmann \& Swanson, 2004). Considerando o caráter ativo característico da experiência de interação, uma vez que o indivíduo comanda o que o personagem faz e é recompensado pelo comportamento agressivo dentro do jogo, os resultados encontrados evidenciam que os indivíduos associam mais conceitos agressivos a si do que a outras pessoas, quando em contato com jogos desta natureza. Outros estudos associam a exposição a jogos digitais com sexualidade, estereotipização de gênero (Yao, Mahood, \& Linz, 2010) e percepção de humanidade (Bastian, Jetten, \& Radke, 2012). Ainda, evidências adicionais sobre o papel da cognição têm apontado, por exemplo, que o efeito pode não ser duradouro (Sestir \& Bartholow, 2010), e que um intervalo de 15 minutos entre a fase de jogo e a medida de cognição resultam em um declínio de cognições agressivas. Há, por fim, críticas à forma como as medidas de cognição são operacionalizadas. Bösche (2010), por exemplo, apresenta evidências de que a exposição 
a jogos violentos aumenta a acessibilidade tanto de conteúdos agressivos quanto de prosociais. A partir de um teste de decisão lexical, Bösche sugere que as medidas deveriam considerar tanto cognições positivas quanto negativas ao se medir o efeito dos jogos.

Estudos sobre o impacto dos jogos digitais na dimensão afetiva enfocam, principalmente, a medida de estados afetivos por meio de escalas explícitas, com a Positive and Negative Affect Schedule e a State Hostility Scale, na tentativa de se verificar possíveis alterações destes estados a curto prazo. Sínteses das principais evidências empíricas sobre agressividade (Anderson et al., 2010; Anderson \& Bushman, 2001) e prosocialidade (Greitemeyer \& Mügge, 2014) apontam que a exposição a jogos violentos tendem a aumentar a ocorrência de afetos negativos e reduzir a de afetos positivos, quando comparados a jogos neutros ou prosociais (e uma relação inversa pode ser observada no caso destes últimos). Exemplos de construtos associados a essa dimensão versam sobre, além de estados afetivos, processos de dessensibilização (Huesmann, 2007), cooperação e empatia (Greitemeyer, 2013b), bem como sentimentos agressivos (Jeong, Biocca, \& Bohil, 2012).

No entanto, a relação entre a mudança nos estados afetivos e comportamentos subsequentes parece não estar clara. Por exemplo, em um estudo comparando jogos violentos e neutros, observou-se que, apesar dos grupos expostos ao jogo violento apresentarem índices maiores de afetos negativos, a explicação de comportamentos agressivos parece estar mais associadas à acessibilidade a cognições negativas do que ao afeto (Carnagey \& Anderson, 2005). Resultados similares foram encontrados no estudo da relação entre jogos prosociais (Greitemeyer, 2011). Além disso, alguns estudos não encontraram resultados significativos entre o tipo de jogo e os estados afetivos (por exemplo, Greitemeyer \& Osswald, 2010; Valadez \& Ferguson, 2012), o que sugere que a alteração de estados afetivos poderia ou estar associada a outras características do jogo (que não sua natureza) ou mesmo ao nível de violência ou prosocialidade necessários para que os efeitos ocorram. Em outras palavras, é 
factível supor que, quanto mais violento o jogo for, mais provável é o efeito sobre o afeto ocorrer, e jogos com níveis superficiais de violência possam não ser suficientes para eliciar tal efeito. Problemas com as medidas explícitas de afeto também são apontadas como possíveis explicações para a inconsistência dos achados na literatura (Elson \& Ferguson, 2013; Saleem, Anderson, \& Gentile, 2012a).

A dimensão de excitação (arousal) é a que possui evidências mais contraditórias. Por um lado, estudos que utilizam medidas psicofisiológicas para investigar o impacto de jogos sugerem que o efeito pode existir. Por exemplo, ao estudar o efeito de jogos violentos nos indivíduos, pesquisas evidenciaram mudança significativa na frequência cardíaca, na pressão arterial e no índice de resposta galvânica da pele (Bailey, West, \& Anderson, 2011; Baldaro et al., 2004). Além disso, estudos de revisão sistemática relatam evidências para a relação entre excitação e jogos violentos (Anderson et al., 2010; Anderson \& Bushman, 2001). No caso de jogos prosociais, o único estudo meta-analítico disponível até o momento não encontra resultados significativos (Greitemeyer \& Mügge, 2014). Alguns estudos, no entanto, sugerem que esse efeito pode ocorrer não só em função da natureza do jogo (violento, neutro ou prosocial, por exemplo), mas também em função de elementos gráficos e da imersão que o jogo proporciona ao jogador (Barlett et al., 2009; Jeong et al., 2012).

\section{Impacto dos jogos no funcionamento cognitivo}

Além das evidências apresentadas acima, diversos estudos buscaram evidenciar o impacto de jogos digitais em outras dimensões relacionadas ao comportamento humano. Barllett, et al. (2009), por exemplo, relatam que a prática com jogos digitais pode estar associada à uma melhoria na atenção visual e na percepção de múltiplos estímulos, em habilidades de rotação espacial e na coordenação olho-mão. Além disso, o consumo de jogos pode estar relacionado à problemas de déficit de atenção e piora no controle executivo. 
Outros estudos sugerem que há uma relação positiva entre os jogos digitais e uma melhora geral em diversas habilidade cognitivas (Buelow, Okdie, \& Cooper, 2015; Oei \& Patterson, 2013).

Estudos relacionam jogos digitais com melhor desempenho em tarefas de memória visual independentemente da natureza do jogo (Ferguson, Cruz, \& Rueda, 2007) e tarefas que requerem atenção visual (Vallett, Lamb, \& Annetta, 2013). Ainda sob esta ótica, Murias, Kwok, Castillejo, Liu e Iara ( 2016) apresentaram evidências de que a prática com jogos digitais que exigem habilidades de orientação no mundo virtual está associada a uma melhor performance em tarefas de navegação em meio virtual. Em uma investigação acerca do efeito de jogos em habilidades cognitivas, Dobrowolski, Hanusz, Sobczyk, Skorko e Wiatrow (2015) apresentaram evidências de que a melhoria da performance ocorre em função da mecânica utilizada no jogo; neste sentido, sugere que vários gêneros de jogos sejam estudados para verificar qual habilidade cognitiva ele mais exige para, só depois, verificar seus efeitos nesta habilidade.

Outros estudos buscaram investigar a influência de jogos sobre processos de gestão de recursos cognitivos. A prática com jogos digitais pode, por exemplo, estar associada à uma melhor habilidade em alterar entre tarefas concorrentes (Green, Sugarman, Medford, Klobusicky, \& Bavelier, 2012). Ainda, foram encontradas evidências que sugerem que, considerando uma série de medidas eletrofisiológicas, que a prática com jogos está associada à uma melhor alocação de memória e atenção em outras tarefas: quanto mais o indivíduo praticava por meio dos jogos, melhor ele gerenciava seus recursos ao desempenhar uma segunda tarefa (Maclin et al., 2011).

Por outro lado, Bailey, West e Anderson (2010) verificaram um impacto negativo da prática com jogos digitais no controle cognitivo - definido pelos autores como a capacidade de manter um processamento orientado a objetivo de forma controlada, mesmo frente a 
distrações ou estímulos concorrentes. Em seu estudo, os autores verificaram que esse efeito negativo ocorre somente quando se considera um controle proativo (preparatório, voltado ao futuro), mas não encontraram diferenças entre grupos no que se refere ao controle cognitivo reativo. Engelhardt, Hilgard e Bartholow (2015) encontraram efeito negativo similar considerando jogos digitais e controle cognitivo. No entanto, verificaram que este efeito ocorria em função da dificuldade do jogo, e não em função de outras características. A explicação fornecida pelos autores utiliza o argumento que jogos mais difíceis utilizam mais recursos cognitivos para serem jogados; nessas circunstâncias, o indivíduo possuiria menos recursos cognitivos para a performance em uma nova tarefa (geralmente a medida de controle cognitivo). Os autores sugerem, inclusive, que os efeitos encontrados em outros estudos acerca da relação entre jogos violentos e queda no desempenho em tarefas que exigem controle cognitivo podem ter a dificuldade do jogo como variável interferente.

Apesar das evidências favoráveis, alguns estudos sugerem que decisões inadequadas, tanto do ponto de vista metodológico quanto analítico, levaram a se estabelecer uma relação que na verdade não existe. Unsworth et al. (2015), por exemplo, analisaram os dados de dois experimentos e verificaram que, ao se considerar somente os casos mais extremos, o efeito tende a existir. No entanto, ao se analisar os dados de forma mais abrangente, os efeitos relacionados à memória de trabalho e atenção tendem a zero.

As evidências apresentadas até o momento elucidam, por um lado, alguns questionamentos sobre a influência dos jogos digitais no comportamento humano e, por outro, apresentam novas questões de pesquisa buscando melhor compreender este fenômeno. Estas novas questões necessitam ser exploradas buscando-se identificar e avaliar os efeitos de outras variáveis que podem exercer efeitos de moderação e mediação entre as variáveis preconizadas no GLM. A próxima seção aborda este aspecto necessário no estado atual da produção teórica e empírica no tema. 


\section{Estudos sobre variáveis mediadoras}

Considerando a diversidade de variáveis previstas no GLM, faz-se necessário compreender quais outras variáveis podem intermediar a relação entre jogos e comportamento, o que pode inclusive esclarecer os diferentes resultados encontrados na literatura. Para se atingir este objetivo, uma estratégia natural de pesquisa é explorar relações de mediação entre variáveis. Pesquisadores que estudam tanto o comportamento agressivo (Barlett \& Anderson, 2013) quanto prosocial (Greitemeyer \& Osswald, 2009) tem sugerido que se considerar variáveis mediadoras é um dos caminhos mais profícuos para o desenvolvimento teórico e metodológico da área.

Conforme ressaltado anteriormente, uma das primeiras evidências empíricas de mediação está relacionada à dimensão cognitiva, ao se considerar como variável dependente tanto o comportamento agressivo quanto prosocial (Anderson \& Dill, 2000; Carnagey \& Anderson, 2005; Greitemeyer et al., 2011; Greitemeyer \& Osswald, 2010). Isso sugere um papel central da cognição como elemento processual: os conceitos, scripts e esquemas ativados pela exposição ao jogo, bem como a forma como as informações são interpretadas, parecem ser fundamentais para a manifestação de comportamentos coerentes (ou destoantes) do conteúdo exposto. Coerente com este argumento, outros mediadores relacionados à cognição acabam por ter suporte empírico.

No caso de jogos violentos, um mediador é o viés de expectativa hostil (que envolve a tendência de perceber, como o nome sugere, uma intenção hostil no comportamento de terceiros). Por exemplo, estudos investigaram o efeito da natureza do jogo (violento ou não violento) no comportamento agressivo, e mensuraram o viés de expectativa hostil por meio da tarefa de completar histórias ambíguas. Nesta tarefa, era solicitado aos participantes que listassem o que o protagonista estava pensando, sentindo e fazendo no decorrer da história (Hasan, Bègue, \& Bushman, 2012; Hasan, Bègue, Scharkow, \& Bushman, 2013). As análises 
sugeriram que a exposição ao jogo violento impactou em interpretações mais hostis das histórias, e que quanto mais hostil era a interpretação, maior era a ocorrência de comportamentos violentos (medidos por meio do competitive reaction time task). Outra variável mediadora encontrada relacionada à forma como os indivíduos interpretam a situação é a percepção de agressividade (Greitemeyer, 2014). Nesse caso, participantes expostos continuamente a jogos violentos tenderam a perceber seus comportamentos como menos violentos e, quanto maior era este efeito, mais frequente era o comportamento agressivo em uma situação posterior.

Ainda sobre jogos violentos, outro mediador relevante é a presença, ou seja, a capacidade de imersão que o jogo pode proporcionar ao jogador (Jeong et al., 2012). Neste estudo, investigou-se a influência do nível de realismo do jogo nos estados agressivos dos jogadores, e observou-se que o nível de realismo do jogo exerce influência sobre o estado dos jogadores, mas somente quando há uma imersão significativa do jogador. É importante considerar que este efeito ocorre independente de outras características do jogo, como a perspectiva (primeira ou terceira pessoa) ou a excitação.

No caso de comportamentos prosociais, uma das principais variáveis mediadoras encontradas é a empatia, cujas evidências empíricas foram encontradas inclusive em estudos longitudinais e transculturais (por exemplo, Prot et al., 2013). Mais especificamente, quanto mais o jogo elicia sentimentos de preocupação com o outro, mais frequentes podem ser os comportamentos de ajuda, mesmo em outros contextos. Algumas características de jogos, como a necessidade de cooperação entre jogadores (ou personagens controlados pelo computador) podem aumentar a chance de tal relação empática ocorrer (Greitemeyer, 2013a).

As evidências apresentadas, bem como as críticas associadas a elas, levantam diversos questionamentos que devem ser respondidos, caso se busque uma melhor compreensão deste 
fenômeno. Neste sentido, alguns pontos de reflexão são apresentados a seguir e que resultaram nos estudos propostos nesta tese.

\section{Aprofundando o estudo de jogos: investigação de processos psicológicos e desenvolvimento de ferramentas de pesquisa}

Conforme abordado no início deste trabalho, há um número considerável de evidências que dão suporte à hipótese de que a exposição a jogo digital de uma determinada natureza influencia a forma como os indivíduos interpretam diferentes situações dentro e fora do jogo, bem como a forma como se comportam em outros contextos. Ao longo do texto, foram apresentados resultados de algumas pesquisas experimentais que dão suporte e que criticam tal afirmação, com o propósito de ilustrar o estado atual da pesquisa nessa temática. No entanto, várias lacunas ainda merecem atenção com vistas a esclarecer pontos ainda não resolvidos, como a dificuldade na replicação de efeitos relevantes, da importância de outras variáveis (como variáveis processuais e disposicionais) para a compreensão do fenômeno, problemas relacionados à validade externa e à pequena magnitude dos efeitos encontrados, além da fragilidade das medidas utilizadas (Elson \& Ferguson, 2013; Ferguson, 2009a, 2009b; Ferguson \& Kilburn, 2010). O aprofundamento da compreensão do fenômeno, neste sentido, é fundamental para que se possa verificar o nível de adequação do GLM, dado o seu caráter genérico, como modelo explicativo.

Com o intuito de contribuir para o esclarecimento de tais pontos, são apresentadas sugestões para o refinamento de pesquisas experimentais sobre a temática considerando duas vertentes: um critério maior para a seleção (ou desenvolvimento) de jogos a serem utilizados em delineamentos experimentais e a investigação da influência de processos automáticos e controlados na avaliação, julgamento e comportamento do jogador. 


\section{Considerações sobre a seleção dos jogos digitais}

A decisão sobre quais jogos utilizar em delineamentos experimentais deve levar em conta diferentes elementos. Um deles, mais aparente, diz respeito à natureza (ou conteúdo) do jogo. Neste sentido, analisa-se quais conteúdos se deseja eliciar a partir da exposição do participante ao jogo, e quais são as variáveis dependentes de interesse. A seleção de jogos caracterizados como violentos, neutros ou prosociais é um exemplo. No entanto, os jogos possuem diversas características além de seu conteúdo, como mecânica de jogo, narrativa, elementos gráficos e sonoros, periféricos de entrada e comandos e complexidade, vários deles influenciando as principais variáveis do GLM (Barlett et al., 2009, para uma síntese).

Considerando a necessidade de controle para a realização de delineamentos experimentais, bem como o fato de que as características do jogo são elementos situacionais que, de acordo com o GLM, podem influenciar os estados internos dos indivíduos, duas opções podem ser utilizadas: selecionar jogos comerciais (jogos produzidos por empresas, comercializado para o público comum) ou investir no desenvolvimento de jogos especialmente planejados para a pesquisa (McMahan, Ragan, Leal, Beaton, \& Bowman, 2011).

A utilização de jogos comerciais possui, como principais vantagens: disponibilidade imediata e maior validade ecológica. No entanto, os pesquisadores devem garantir, seja por procedimentos de pré-teste ou checagem de manipulação, que o jogo possui as características relevantes para a manipulação da variável independente dentro das condições experimentais e que outras variáveis não comprometem a análise dos resultados. Comumente, a estratégia de inserir questões que versem sobre a percepção de dificuldade, excitação, agradabilidade, satisfação, entre outros, é utilizada em procedimentos de análise post facto. No entanto, alguns autores colocam em dúvida se essa estratégia é suficientemente robusta para excluir as variáveis intervenientes como possíveis explicações para os resultados obtidos (Elson \& Ferguson, 2013). 
Por outro lado, o desenvolvimento de jogos digitais específicos, especialmente ao se considerar o fenômeno de interesse deste trabalho, é uma estratégia pouco utilizada pela literatura e mais afinada com as atuais necessidades metodológicas para o desenvolvimento teórico do campo. Jogos personalizados possuem a vantagem de poderem ser detalhadamente construídos para que o controle e a manipulação das variáveis de interesse sejam feitos de forma rigorosa, aumentando a qualidade das evidências encontradas. O processo de desenvolvimento de um jogo semelhante aos jogos comercializados requer o envolvimento de profissionais especializados, demandando recursos nem sempre disponíveis pelos grupos de pesquisa, sem ignorar que geralmente é um processo que requer tempo (McMahan et al., 2011). Com isso, tentativas neste sentido podem resultar em produtos que se distanciam muito do que os participantes veriam como um jogo "de verdade". Apesar desta característica, entende-se que o desenvolvimento de jogos específicos traz contribuições mais eficientes para a produção de delineamentos metodológicos mais robustos e consequente compreensão mais refinada dos processos cognitivos, afetivos e comportamentais consequentes ao envolvimento com o jogo eletrônico. Desta feita considera-se que é fundamental o investimento no desenvolvimento de jogos dedicados ao teste de hipóteses específicas sobre os processos envolvidos, de forma a suprir esta lacuna que impede o desenvolvimento adequado da teoria robusta que permita uma melhor compreensão dos efeitos relatados na área de investigação.

\section{Investigação de processos automáticos e controlados}

As evidências empíricas apresentadas neste trabalho acerca da dimensão cognitiva reforçam sua relevância para a compreensão da influência de jogos digitais no comportamento. No GLM, os autores pressupõem a existência de processos diferenciados de avaliação e reavaliação, ativados em função da existência de recursos cognitivos suficientes e de resultados satisfatórios, ocasionando em ações ora impulsiva, ora controladas. No entanto, 
não apresentam evidências empíricas suficientes para justificar a inclusão de tais elementos no modelo, nem para compreender como os outros elementos do modelo (principalmente, as características do jogo e os elementos contextuais durante a experiência de jogo) interagem com tais processos. Esta é uma lacuna basilar na pesquisa, que coloca em cheque várias das pressuposições do próprio GLM.

A visão de um sistema duplo de processamento de informações não é exclusiva da área de estudo de jogos digitais. A ideia de que existem processos, não acessíveis à consciência, que influenciam a forma como os indivíduos percebem, interpretam e agem sobre o mundo vem sendo objeto de discussão em várias áreas do conhecimento (Hassin, Uleman, \& Bargh, 2005) e pode-se considerar como a modelagem teórica predominante, atualmente, para a compreensão da cognição humana. Tal modelo tem sido utilizado no estudo de processos associados a raciocínio, julgamento e tomada de decisões, percepção social, estereótipos, mudança de atitude, entre outros (Evans, 2008), e é embasado por um conjunto de evidências que sugere que o comportamento humano é regido por uma série de processos que não necessariamente ocorrem em um nível explícito de consciência (Dijksterhuis \& Aarts, 2010).

A discussão sobre processamento implícito - o conjunto de processamento de informações que ocorre sem a atenção e/ou controle do indivíduo - é uma questão que vem, há muitos anos, ganhando campo na área de cognição social em função, principalmente, das evidências encontradas em favor do modelo de processamento dual de informação (Fiske \& Taylor, 2008b; Kahneman, 2011). De acordo com este modelo, o processamento cognitivo possui gradações, desde um processamento puramente automático da informação, sem a consciência da presença do estímulo e sem controle do processamento, até um processamento controlado e consciente. Neste sentido, o processamento implícito de informações recebidas 
do ambiente influenciam de forma sistemática processos decisórios em diversos contextos (Bargh, Schwader, Hailey, Dyer, \& Boothby, 2012).

Dentro desta perspectiva, são escassos os estudos que busquem verificar, empiricamente, o efeito de tais processos na compreensão da influência de jogos no comportamento. As evidências encontradas dizem respeito a influência do conteúdo do jogo no autoconceito agressivo implícito (Bluemke et al., 2009; Uhlmann \& Swanson, 2004). No entanto, outros questionamentos podem ser feitos: é coerente supor que, na ausência de recursos cognitivos, as vias automáticas de processamento de informações tenham um papel mais influente, uma vez que é mais difícil para o indivíduo exercer o controle sobre cada etapa de interpretação e julgamento das informações. Nestes casos, quais seriam os resultados esperados a partir da exposição a tipos diferentes de jogos, e o papel de variáveis individuais e situacionais? Uma hipótese factível, por exemplo, seria a de que características disposicionais (como agressividade, empatia e prosocialidade) possam ser mais relevantes para predizer a ocorrência do comportamento do que o tipo de jogo, em situação de escassez de recursos. Essa, e outras possíveis hipóteses, requerem uma linha de pesquisa que parece ter sido ignorada pela área até o momento. Neste sentido, sugere-se que novas perspectivas de pesquisa venham a contemplar, por meio de delineamentos experimentais, o efeito da escassez de recursos, de interferência, bem como de abordagens que considerem o modelo duplo de processamento, na relação entre jogos digitais e comportamento, considerando a dimensão cognitiva não somente como uma variável dependente do modelo, mas também como uma variável independente ou mediadora.

Exemplos de tais manipulações geralmente envolvem uma tarefa simultânea de memorização de dígitos, como os trabalhos de Cavallo et al. (2012) e Conway e Gawronski (2013), ou uma tarefa de depleção do ego (Fennis, 2011; Xu, Bègue, \& Bushman, 2012). Por meio da manipulação da disponibilidade de recursos cognitivos, seria possível avaliar o papel 
dos processos controlados, bem como o efeito das características disposicionais dos jogadores, na ocorrência do comportamento de ajuda fora do jogo.

Com o intuito de abordar as lacunas apontadas, uma série de estudos foi desenvolvida. Os Experimentos 1, 2 e 3 foram concebidos com o intuito de avaliar efeitos já conhecidos relacionando o efeito de tipos de jogo nas rotas de comportamento, cognição e afetos. Com base nos resultados encontrados, os Experimentos 4 e 5 apresentam evidências da adequação de jogos digitais para a manipulação da principal variável de estudo e para a medida de comportamento prosocial, respectivamente. Por fim, o Experimento 6 (e seu piloto) foi desenvolvido com a finalidade de avaliar o papel da carga cognitiva na relação entre a prosocialidade do jogo e o comportamento prosocial.

\section{Experimento 1 - Influência da função desempenhada em jogo no comportamento prosocial}

A concepção do Experimento 1 partiu da análise das diversas evidências empíricas que sustentam a existência de uma relação entre a natureza do jogo digital e o comportamento (Anderson et al., 2010; Anderson \& Bushman, 2001; Bailey et al., 2011; Barlett \& Anderson, 2013; Barlett et al., 2009; Swing et al., 2009). Mais especificamente, diversos estudos apontam que jogos de natureza prosocial (em que o jogador é solicitado a auxiliar, direta ou indiretamente, outros personagens controlados ou não por outros jogadores) tendem a aumentar a frequência de comportamentos de ajuda e doação, bem como de relatos de intenção de ajuda (Greitemeyer \& Mügge, 2014; Greitemeyer \& Osswald, 2010; Jin, 2011; Prot et al., 2013). Além disso, jogos prosociais estão associados a um relato maior de afetos positivos e de cognições congruentes com a natureza prosocial (Greitemeyer \& Osswald, 2009, 2011; Saleem et al., 2012b). No caso de jogos de natureza violenta, em que o papel dos indivíduos consiste em causar danos a outros personagens, espera-se o efeito inverso na 
manifestação do comportamento prosocial. Por fim, estudos que fazem uso de jogos neutros (como jogos de raciocínio) não estariam associados a nenhuma variação nas diferentes dimensões associadas à prosocialidade - comportamentos, acessibilidade a cognições e afetos.

No entanto, questionou-se o fato de que quase a totalidade dos estudos revisados utilizam jogos diferentes para caracterizar a natureza violenta, neutra ou prosocial. $\mathrm{Na}$ tentativa de reduzir a chance de outras variáveis (como mecânica, elementos gráficos, sonoros e narrativa), buscou-se investigar se somente um aspecto da experiência de jogo (a função desempenhada pelo jogador) seria suficiente para culminar em tendências similares às dos estudos anteriores. Neste estudo, a função desempenhada no jogo foi definida como o conjunto de ações que, em conjunto, refletem a finalidade do personagem controlado pelo jogador. Além disso, envolve um conjunto de feedbacks do jogo acerca do quanto essa função está sendo fielmente desempenhada pelo jogador (por meio da pontuação, por exemplo). Uma função prosocial, portanto, envolve um conjunto de ações que tem como finalidade salvar, proteger ou beneficiar outros personagens, controlados por outros jogadores ou por inteligência artificial. A função violenta segue lógica semelhante, porém considera ações cuja finalidade é prejudicar, ferir ou destruir outros personagens.

Assim, este estudo tem por objetivo avaliar a influência da função desempenhada em jogo no comportamento prosocial, mantendo-se o mesmo jogo para as diferentes condições experimentais. Buscou-se testar a hipótese de que a função desempenhada influenciaria a ocorrência do comportamento prosocial, assim como da intenção de ajuda. Mais especificamente, esperava-se que jogadores solicitados a desempenhar uma função prosocial apresentariam mais comportamento prosocial e intenção de ajuda do que aqueles que desempenharam uma função violenta. 


\section{Método}

\section{Participantes}

Sessenta e um estudantes universitários participaram do experimento. Contudo, seis deles suspeitaram da manipulação utilizada e, portanto, foram excluídos da amostra final. Os 55 participantes restantes (31 homens) tinham uma média de 20,4 anos $(D P=1,90)$ e, apesar de não ser um critério de seleção da amostra a experiência com jogos digitais, vinte e nove deles declararam jogar regularmente algum tipo de jogo (em artefatos variados, como computadores, consoles de videogame, tablets e aparelhos celulares).

\section{Instrumentos e materiais}

Jogo utilizado. Na tentativa de manter constantes o máximo possível de atributos do jogo, somente alterando-se a função desempenhada, foi utilizado o jogo Fat Princess (Titan Studios), para Playstation 3 em ambas as condições experimentais. Este jogo consiste em uma competição entre integrantes de dois reinos (Figura 2). O objetivo geral do jogo é manter a princesa do time adversário capturada e a do seu time, a salvo. Para isso, o jogador pode assumir vários personagens, cada qual com uma função específica, variando entre causar dano ao adversário, curar unidades amigas e buscar materiais para aprimorar equipamentos e estruturas. Para este estudo, optou-se pela seguinte configuração do jogo: partida off-line e single player, trinta e um personagens de cada lado (todos, com exceção do personagem controlado pelo participante, são controlados pela inteligência artificial do jogo) e com presença de sangue, utilizando o mapa padrão do jogo. Para a execução do jogo, foi utilizado um videogame Playstation 3, ligado a um monitor LCD de 21 polegadas. 


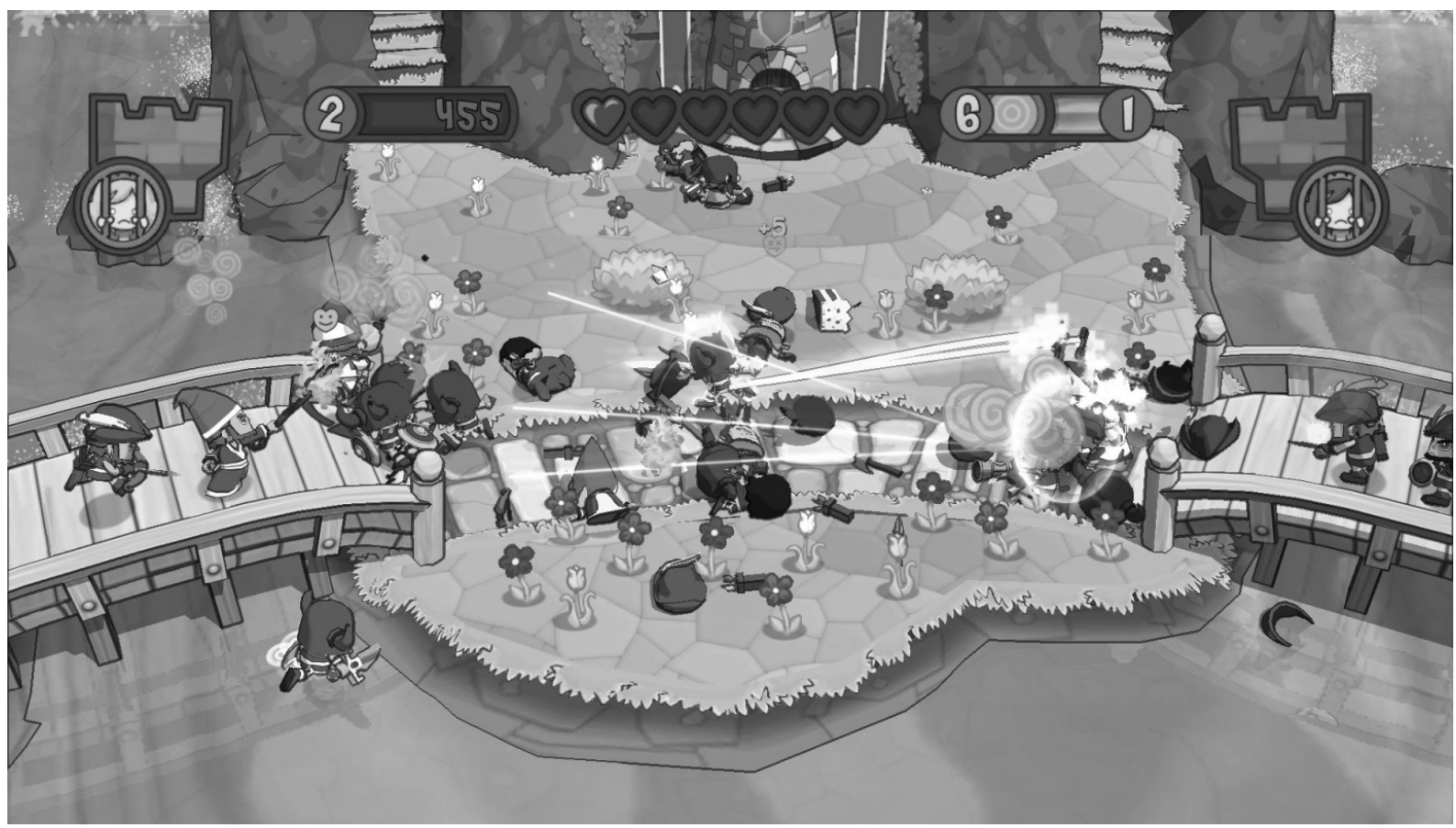

Figura 2. Exemplo da tela do jogo Fat Princess, utilizado como estímulo para as condições experimentais.

Questionário de avaliação do jogo. Consiste em um conjunto de itens, respondidos a partir de uma escala de 7 pontos, em que os participantes avaliaram quão difícil, frustrante, excitante, violento e divertido foi o jogo (Apêndice A).

Escala de Afetos Positivos e Negativos - PANAS. Esta escala, adaptada para o português por (Galinha \& Pais-Ribeiro, 2005), consiste em 20 adjetivos que relatam afetos positivos (10 itens, $\alpha=0,87)$ ou negativos ( 10 itens, $\alpha=0,82)$ A partir de uma escala Likert de 5 pontos (de Nada a Extremamente), os participantes eram solicitados a avaliar o quanto cada adjetivo representava o que ele sentiu após o período de jogo (Apêndice A).

Questionário demográfico. Este instrumento consistiu em questões relacionadas a características pessoais e de hábitos de jogo (frequência semanal, horários mais comuns de jogo, artefatos e jogos mais utilizados - Apêndice B). 
Bateria de Personalidade Prosocial (Penner, Fritzsche, Craiger, \& Freifeld, 1995). Foi utilizada a versão adaptada para o português (Rabelo \& Pilati, 2013), totalizando 8 itens. Os participantes responderam às dimensões de desconforto pessoal (três itens, $\alpha=0,44$ ) e altruísmo autorreladado (cinco itens, $\alpha=0,45$ ) com base em uma escala Likert de 5 pontos. Nos estudos de adaptação realizado por Rabelo e Pilati (2013), tanto a análise de componentes principais quanto a análise fatorial confirmatória apresentaram estrutura e índices compatíveis com os do estudo original de Penner et al. (1995). Para às dimensões de desconforto pessoal e altruísmo autorrelatado, foram encontrados medidas de confiabilidade similares às do estudo original ( $\alpha=0,75$ e $\alpha=0,74$, respectivamente). São exemplos dos itens: "Eu permiti que alguém passasse na minha frente em uma fila (ex. supermercado, fotocopiadora, etc.)." e "Tenho tendência a perder o controle durante emergências." (Apêndice B).

Medida de intenção de ajuda. Consistiu em uma pergunta dicotômica acerca do interesse em participar de pesquisas futuras, bem como de uma questão aberta em que o participante indicava a quantidade de horas semanais que poderia dedicar a tal participação (Apêndice B).

\section{Procedimentos}

Trata-se de um delineamento experimental. Os participantes foram convidados sob o argumento de se tratar de um estudo sobre a influência das novas tecnologias no cotidiano, e foram informados de que participariam de um estudo sobre coordenação motora usando um jogo. A coleta de dados foi feita individualmente e cada participante foi designado aleatoriamente para uma das duas condições: (a) a condição violenta, na qual era solicitado que ele controlasse o personagem do guerreiro e cumprisse o objetivo de causar dano ao maior número possível de adversários ou (b) a condição prosocial, na qual o participante jogava com o personagem do trabalhador e cujo objetivo era coletar matéria-prima e aprimorar estruturas do seu castelo, bem como habilidades e equipamentos dos seus 
companheiros de time. Tais funções foram escolhidas por se considerar que eram a mais próxima e a mais distante, respectivamente, da situação de violência, mas ainda mantendo elementos visuais e sonoros semelhantes entre as condições.

Após o sorteio da função a ser desempenhada no jogo, o pesquisador fornecia informações gerais sobre o jogo e os comandos mais importantes e dava ao participante até 1 minuto para se familiarizar com os controles. Dentre as informações fornecidas, em nenhum momento se esclarecia o objetivo real do jogo, para que o participante não interpretasse a função violenta como um tipo de função prosocial (salvar a princesa). Após o participante declarar que se sentia pronto para iniciar o estudo (ou após o término do período de 1 minuto, o que ocorresse primeiro), era solicitado que jogasse por 10 minutos. Caso o personagem controlado pelo participante morresse, depois de 3 segundos o personagem renascia e o participante podia retomar o jogo. É importante ressaltar que sua performance foi gravada em vídeo (com autorização do participante), para cumprir duas finalidades: a primeira, para servir como registro da ocorrência do comportamento prosocial, e a segunda para tornar a história encobridora mais convincente.

Depois da fase de jogo, o pesquisador informava que seria necessário que o participante preenchesse alguns questionários e que ele iria buscá-los na sala ao lado. Neste momento, um confederado abria a porta e pedia licença ao pesquisador para buscar documentos que estavam em cima de uma mesa. Após a autorização do pesquisador e a saída deste, o confederado recolhia os materiais (que consistam em caixas de arquivo de documentos) e se dirigia à porta. Neste momento, o confederado aparentava ter dificuldade em abrir a porta e, sem solicitar ajuda e ainda com as caixas em mãos, tentava abri-la por 5 segundos. A medida de comportamento de ajuda, portanto, consistia em verificar se o participante auxiliava ou não o confederado a abrir a porta. Após o retorno do pesquisador, o participante preenchia o questionário de avaliação do jogo, a PANAS, o questionário 
demográfico e a BPP. Por fim, era realizado um debriefing do participante, os reais objetivos da pesquisa eram esclarecidos e o pesquisador agradecia pela sua participação.

Cinco esclarecimentos sobre este procedimento são necessários: em primeiro lugar, a saída do pesquisador da sala foi planejada de forma a minimizar a sua influência no comportamento do participante, assim como na do confederado, por se entender que a sua presença poderia eliciar o participante a se comportar de acordo com normas sociais (criando um possível efeito de desejabilidade social). Em segundo lugar, o confederado evitou estabelecer qualquer tipo de contato visual ou verbal com o participante ao tentar abrir a porta, para que esses comportamentos não fossem entendidos pelo participante como um pedido de ajuda. Em terceiro lugar, caso o participante não auxiliasse o confederado em 5 segundos, o confederado colocava as caixas no chão, abria a porta, pegava novamente as caixas e saía. Neste sentido, qualquer tentativa de assistência depois deste momento não foi classificada como comportamento de ajuda. Em quarto lugar, buscou-se compatibilizar o sexo do participante com o do confederado com o intuito de evitar possíveis efeitos de gentileza em função da diferença de sexo entre os dois indivíduos. Por fim, o confederado era ingênuo com relação à condição experimental à qual o participante estava vinculado, para que potenciais efeitos de demanda fossem minimizados.

\section{Procedimentos de análise de dados}

As análises principais consistiram em análises de qui-quadrado e Análises de Variância. Os pressupostos foram testados antes da execução destas análises e, no caso do qui-quadrado, todas as condições foram satisfeitas. No caso das ANOVAs, o pressuposto de normalidade não foi atendido para todas as variáveis contínuas. No entanto, a ANOVA tende a ser robusta a violações de normalidade em condição de grupos de tamanho semelhante. Por precaução, foram realizados testes não paramétricos de Mann-Whitney e chegou-se a resultados similares. Em função disso, decidiu-se por relatar a ANOVA. 


\section{Resultados}

Para uma melhor compreensão dos resultados, estes foram divididos em três diferentes sessões. Inicialmente são apresentados os resultados referentes à avaliação do participante sobre o jogo em si. Em seguida, são analisados os efeitos principais relacionados ao comportamento e à intenção de ajuda, variáveis diretamente relacionadas às hipóteses de estudo. Por fim, são descritos resultados complementares com o intuito de investigar elementos adicionais.

\section{Avaliação do jogo}

ANOVAs de uma via foram conduzidas para os níveis de violência, dificuldade, excitação, frustração e diversão. Tais análises foram realizadas com o intuito de verificar se as diferentes condições foram percebidas, dentro das dimensões descritas, pelos participantes em diferentes condições. Resultados significativos foram encontrados somente para: a) dificuldade, na qual jogadores perceberam a função violenta como mais difícil $(M=3,93, D P$ $=1,27,95 \% I C[3,42,4,43])$ que a prosocial $(M=2,79, D P=0,92,95 \% I C[2,43,3,14]), F$ $(1,53)=14,67, p<0,001, r=0,49,95 \% I C[0,24,0,67]$; e b) frustração, no qual participantes consideraram o jogo mais frustrante na função violento $(M=3,85, D P=1,70$, $95 \% \operatorname{IC}[3,18,4,53])$ que a prosocial $(M=2,14, D P=1,27,95 \% \operatorname{IC}[1,65,2,63]), F(1,53)=$ $17,91, p<0,001, r=0,49,95 \%$ IC $[0,25,0,68]$. A análise do efeito da condição experimental em afetos positivos e negativos não apresentou resultados significativos, $F(1,53)=0,18, p=$ $0,723, r=-0,05,95 \%$ IC $[-0,30,0,21]$ e $F(1,53)=0,01, p=0,906, r=-0,02,95 \%$ IC $[-0,27$, $0,24]$, respectivamente.

\section{Análises acerca do comportamento prosocial e da intenção de ajuda}

Para avaliar a existência de relação entre as condições experimentais e a ocorrência do comportamento prosocial, testes de Qui-quadrado foram executados. Como a Figura 3 sugere, houve uma diferença significativa entre as condições, $\chi^{2}(1)=5,35, p=.021, r=0,31$, 
$95 \%$ IC $[0,05,0,53]$. No entanto, esta diferença não se manifestou no sentido esperado: jogadores que jogaram com a função violenta ajudaram mais os confederados (15 casos observados) do que aqueles que jogaram a prosocial (7 casos).

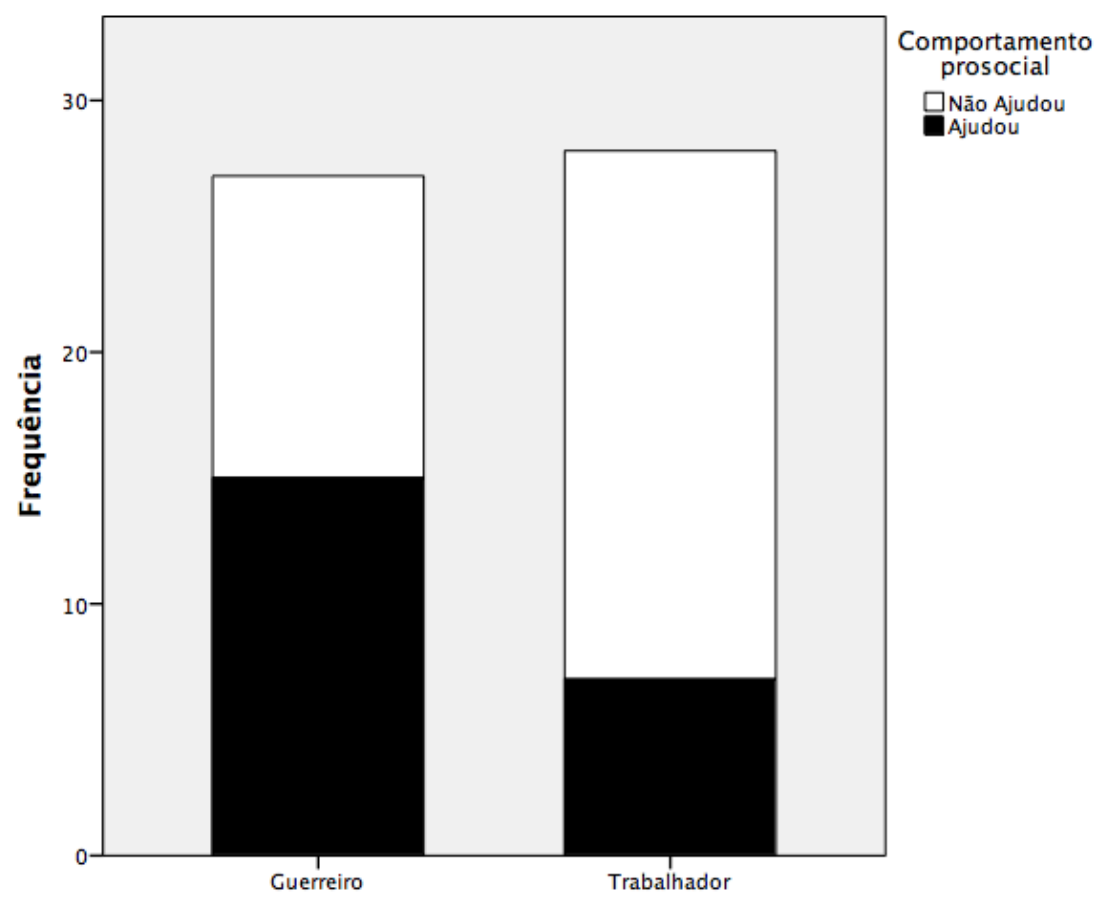

Figura 3. Distribuição da frequência de comportamento de ajuda entre as condições violenta $(N=27)$ e prosocial $(N=28)$.

Quando comparada a intenção de ajuda entre os grupos, a análise de Qui-quadrado não apresentou diferenças significativas entre eles, $\chi^{2}(1)=0,46, p=0,50, r=0,09,95 \%$ IC [$0,17,0,34]$. Ambos os grupos tenderam a declarar interesse em participar de outras pesquisas no futuro. Considerando as situações em que os participantes declararam a intenção de ajudar (e considerando uma declaração negativa como um valor de zero horas), a Análise de variância não mostrou resultados significativos, $F(1,53)=0,83, p=0,366, d=0,25,95 \% C I$ $[-0,28,0,77]$. 


\section{Análises adicionais}

Por fim, análises de moderação foram conduzidas para checar se variáveis antecedentes ao experimento poderiam influenciar os resultados encontrados. O tempo que participantes usualmente gastam jogando jogos digitais poderia, por exemplo, influenciar como a exposição a uma função violenta ou prosocial afetaria seu comportamento após a exposição. Além disso, uma disposição à prosocialidade também poderia ser relevante, e participantes com um traço mais prosocial poderiam ser mais afetados pelo conteúdo do videogame. No entanto, análises de regressão não apresentaram resultados de interação significativos considerando tais variáveis. Da mesma forma, não foi encontrado efeito relacionado ao sexo na intenção ou comportamento de ajuda.

\section{Discussão}

Os resultados obtidos neste experimento não dão suporte nem à predição inicial de que a função prosocial no jogo estaria relacionada a uma maior ocorrência de comportamento prosocial, nem à relação esperada entre a função prosocial e a intenção de ajuda. Estes resultados contradizem evidências prévias relativas à influência de jogos digitais no comportamento e no afeto (Anderson \& Bushman, 2001; Ferguson \& Kilburn, 2010; Gentile \& Anderson, 2006; Gentile et al., 2009; Greitemeyer et al., 2011; Greitemeyer \& Mügge, 2014; Greitemeyer \& Osswald, 2009, 2010; Swing et al., 2009). Com base nisso, é possível tecer as seguintes explicações alternativas.

Uma explicação possível diz respeito ao impacto da função violenta na auto-avaliação do participante. Neste sentido, o comportamento prosocial poderia ser eliciado como uma reação ao comportamento violento manifesto no jogo, como uma tentativa de equilibrar seu autoconceito (Gollwitzer \& Melzer, 2012; Jin, 2011) e compensar o eventual estado negativo associado ao comportamento violento dentro do jogo. Ainda, as diferenças encontradas relacionadas à avaliação de dificuldade e frustração também poderia influenciar 
negativamente no autoconceito, e o comportamento de ajuda manifesto na situação pós-jogo poderia ser entendido como uma tentativa de recuperar uma perspectiva negativa de si. Se esta explicação é coerente, é factível esperar que traços disposicionais associados com a preocupação com o bem-estar dos outros e como os outros julgam seu comportamento poderia ser relevante para compreender o impacto do conteúdo dos jogos digitais no comportamento.

Outro ponto que merece reflexão está relacionado à ausência de diferenças de avaliação do nível de violência entre as condições experimentais. Estudos anteriores utilizam esta medida como checagem de manipulação (por exemplo, o trabalho de Greitemeyer \& Osswald, 2010), mas o fazem dentro do contexto de uso de jogos diferenciados para cada situação experimental. No presente experimento, no entanto, como os participantes estão expostos a estímulos violentos da mesma maneira entre as duas condições (a única diferença está na função e nas ações do próprio participante), compreende-se que a avaliação do nível de violência do jogo não deveria diferir.

Por fim, suspeitou-se que o personagem escolhido para a função prosocial pode não ter sido adequado. Apesar da possibilidade do trabalhador ser entendido como tendo uma função prosocial, suas ações não afetam diretamente a condição dos outros personagens. O ato de aprimorar as defesas e estruturas do castelo pode ter sido visto como uma função simplesmente auxiliar, e não prosocial. Ademais, o trabalhador pode ter colocado o participante tão alheio à "ação real" do jogo, criando mais uma função neutra do que uma prosocial. Se este for o caso, os personagens utilizados neste experimento podem não ter ativado as cognições, afetos e excitação consistentes com uma função prosocial (e condizente com as evidências da literatura), afetando as chances de auxiliar o confederado. 
Com base nas informações obtidas no Experimento 1, decidiu-se complementá-lo com um novo estudo, mantendo alguns de seus elementos e alterando outros. A descrição de suas características é feita a seguir.

\section{Experimento 2 - Influência do papel desempenhado em jogo no comportamento prosocial e na acessibilidade cognitiva}

O Experimento 2 foi concebido, principalmente, em função de algumas limitações observadas no estudo anterior. A primeira delas diz respeito ao personagem utilizado para representar a função prosocial. Com base nos argumentos apresentados anteriormente, e com o intuito de resolver esta questão, foi selecionado um personagem cuja função pode ser entendida como mais diretamente prosocial neste experimento, na qual participantes deveriam manter vivos os companheiros de seu time durante a batalha.

Outra modificação foi o acréscimo de um teste de decisão lexical, como uma tentativa de mensurar o impacto do papel jogado na dimensão cognitiva (conforme predito pelo GLM). A dimensão cognitiva foi entendida como um importante mediador entre o conteúdo do jogo e o comportamento prosocial (Greitemeyer \& Mügge, 2014; Greitemeyer \& Osswald, 2010). No presente estudo, além de se manter as hipóteses do Experimento 1, esperou-se que a função prosocial ativaria mais cognições prosociais que a função violenta.

Neste sentido, continuou-se a investigar o impacto das funções violenta e prosocial no comportamento prosocial e na intenção de ajuda. O delineamento do experimento foi similar ao do Experimento anterior. No entanto, acrescentou-se a acessibilidade a cognições prosociais como variável dependente, consistente com pesquisas anteriores que relacionaram a influência de jogos digitais na acessibilidade cognitiva. Em suma, hipotetizou-se que: 1) quando jogando um personagem com uma função prosocial, participantes apresentariam mais comportamento prosocial do que os que jogaram com um personagem violento; 2) a função 
prosocial levará a uma maior intenção de ajuda que a violenta; 3 ) participantes na condição prosocial apresentarão uma maior acessibilidade a cognições prosociais que aqueles na condição violenta.

\section{Método}

\section{Participantes}

Setenta e sete estudantes universitários foram convidados a participar deste experimento. Em função de problemas de funcionamento dos equipamentos utilizados durante o experimento, cinco casos foram excluídos, resultando em uma amostra final de 72 casos. A amostra consistiu de 40 homens, com idades variando de 17 a 30 anos, com uma média de 20,35 $(D P=3,50)$. Considerando a experiência anterior com jogos, cinquenta e oito deles $(80,6 \%)$ declararam jogar regularmente algum tipo de jogo em diferentes artefatos.

\section{Instrumentos e materiais}

Este experimento utilizou os mesmos estímulos do Experimento 1, mudando apenas o personagem relacionado à função prosocial que o jogador poderia desempenhar. Agora, a função prosocial era o de um clérigo, cuja função consistia em usar seus poderes de cura para manter vivos os outros integrantes de sua equipe. As medidas para comportamento prosocial, prosocialidade, afetos positivos e negativos, avaliação do jogo e questões demográficas e de hábitos de jogo foram as mesmas do Experimento 1. Com relação à medida de intenção de ajuda, utilizou-se uma escala de 7 pontos (de "totalmente indisposto" a "totalmente disposto"). Além disso, foram adicionadas as seguintes medidas:

Acessibilidade cognitiva. Medida por meio de um teste de decisão lexical, no qual participantes deveriam julgar, o mais rápido possível, se cada estímulo apresentado era ou não uma palavra. Vinte e quatro estímulos (Apêndice C) foram divididos em três categorias: palavras-alvo (palavras prosociais), palavras neutras (nomes de equipamentos de escritório e de uso comum) e pseudopalavras (conjuntos de letras que, apesar de construídas de acordo 
com regras ortográficas do português, não eram palavras de fato). As palavras-alvo foram selecionadas a partir da busca de termos relacionados a comportamentos prosociais em textos de revisão e em instrumentos sobre comportamento prosocial, além da análise de dicionários em busca de termos relacionados à temática. Respostas foram registradas por meio de um software específico (Inquisit, versão 3.0). Antes das análises principais, foram excluídos os erros, além de casos extremos (o que resultou na exclusão de respostas além de 2,5 desviospadrão da média). A precisão dos participantes também foi checada, e nenhum caso foi excluído, considerando que todos os participantes apresentaram uma taxa de precisão acima de $80 \%$. Por fim, os dados foram transformados utilizando a inversão (1/Tempo de Resposta) com o intuito de eliminar a assimetria positiva e possibilitar um melhor ajustes dos dados a um padrão normal de distribuição (Bösche, 2010).

Escala de amabilidade do Big Five (Apêndice D). Utilizou-se a dimensão de amabilidade do Inventário dos Cinco Fatores de Personalidade adaptado para o português (Andrade, 2008). Participantes respondiam o quanto cada afirmação se assemelhava a eles utilizando uma escala Likert de 5 pontos ( 5 itens, $\alpha=0,62)$. A dimensão de amabilidade está relacionada à percepção de um indivíduo sobre os outros e à preocupação com o bem-estar deles, e é frequentemente associado à empatia, cooperação e diversos tipos de comportamento prosocial.

\section{Procedimentos}

Participantes foram convidados a contribuir em um experimento sobre o uso de diferentes tecnologias no cotidiano. Após ler e fornecer seu consentimento informado, os participantes foram solicitados a jogar. De forma similar ao Experimento 1, foram designados aleatoriamente a uma das duas condições experimentais. Na condição violenta, os participantes jogaram no papel de um guerreiro e tinham a tarefa de matar o maior número possível de inimigos. Na condição prosocial, foram solicitados a jogar como o clérigo e curar 
aliados, mantendo-os vivos. Após o período de jogo, foram convidados a avaliar o jogo, e a medida de comportamento prosocial foi coletada. Após a avaliação do jogo, os participantes foram informados que eles jogariam outro jogo, um jogo de tempo de reação, no computador. Após os preparativos do equipamento, foi apresentado o conjunto de instruções e aplicado o teste de decisão lexical. Por fim, os participantes preencheram as outras medidas, responderam oralmente ao debriefing e foram dispensados após os agradecimentos.

\section{Resultados}

\section{Análises preliminares}

Inicialmente, a realização de ANOVAs de uma via não apresentou diferenças significativas nas características dos participantes anteriores à execução do delineamento, uma vez que não houve diferenças significativas entre os grupos no que se refere às medidas de Prosocialidade e amabilidade. Além disso, não foram encontradas diferenças relevantes no que tange à idade, sexo e hábitos de jogo. Portanto, é possível supor que as condições experimentais apresentaram grupos similares levando-se em conta os traços disposicionais de interesse.

Além disso, não foram encontradas diferenças estatisticamente significativas na percepção dos participantes acerca do jogo, considerando as dimensões de dificuldade, diversão, frustração, excitação ou nível de violência do jogo, $\left(p_{s}>0,05\right)$. Neste sentido, supõe-se os participantes avaliaram o jogo de forma semelhante, à despeito da diferença de funções desempenhadas pelos grupos experimentais distintos. A análise do debriefing indicou não ter havido suspeita sobre o desenho do experimento, a relação entre suas principais variáveis e a associação do confederado com a pesquisa. 
Análise do efeito sobre o comportamento prosocial, intenção de ajuda, afetos positivos e negativos e acessibilidade a cognições prosociais

De forma distinta do Experimento 1, a função jogada não parece estar relacionada com a frequência do comportamento de ajuda (Tabela 1$), \chi^{2}(1)=0,00, p=0,984$. As análises referentes à intenção de ajuda também não apresentaram diferenças significativas entre os grupos, nem para a intenção propriamente dita, $t(69)=-1,58, p=0,120, r=-0,19$, $95 \%$ IC $[-0,04,0,05]$, nem para a quantidade de tempo dedicado à participação, $t(69)=0,43$, $p=0,666, r=-0,05,95 \%$ IC $[-0,28,0,18]$. Para a análise da dimensão afetiva, os resultados das ANOVAs não apresentaram diferenças estatisticamente significativas entre as condições experimentais considerando afetos positivos ou negativos, $F(1,70)=2,13, p=0,149, r=$ $0,17,95 \%$ IC $[-0,38,0,06]$ e $F(1,71)=0,21, p=0,650, r=-0,06,95 \%$ IC $[-0,28,0,17]$, respectivamente.

Para as análises relativas à acessibilidade cognitiva, foram executadas Análises de Variância para medidas repetidas, considerando as latências para palavras prosocial, neutras e pseudopalavras como fator intra-sujeito, e o papel desempenhado no jogo como fator entresujeitos. Considerando a comparação das latências entre categorias de palavras, os resultados sugerem uma diferença significativa entre elas, $F(2,140)=312,04, p<0,001, r=0,83$, nas quais as palavras (neutras e prosociais) são classificadas mais rapidamente que as pseudopalavras. Contudo, a análise conjunta com efeitos entre-sujeitos não apresentou resultados significativos, $F(1,70)=0,2, p=0,656, r=0,005$. 
Tabela 1. Frequências obtidas e esperadas para a relação entre comportamento prosocial e a condição experimental.

\begin{tabular}{|c|c|c|c|c|c|}
\hline & & & \multicolumn{2}{|c|}{ Comportamento prosocial } & \multirow[b]{2}{*}{ Total } \\
\hline & & & Não ajudou & Ajudou & \\
\hline \multirow{10}{*}{$\begin{array}{l}\text { Condição experimental } \\
\text { - violenta ou prosocial }\end{array}$} & \multirow[t]{5}{*}{ Violenta } & Frequência & 20 & 17 & 37 \\
\hline & & Frequência esperada & 20,0 & 17,0 & 37,0 \\
\hline & & $\begin{array}{l}\text { \% dentro de Condição } \\
\text { experimental }\end{array}$ & $54,1 \%$ & $45,9 \%$ & $100,0 \%$ \\
\hline & & $\begin{array}{l}\text { \% dentro de } \\
\text { Comportamento } \\
\text { prosocial }\end{array}$ & $51,3 \%$ & $51,5 \%$ & $51,4 \%$ \\
\hline & & $\%$ do total & $27,8 \%$ & $23,6 \%$ & $51,4 \%$ \\
\hline & \multirow[t]{5}{*}{ Prosocial } & Frequência & 19 & 16 & 35 \\
\hline & & Frequência esperada & 19,0 & 16,0 & 35,0 \\
\hline & & $\begin{array}{l}\text { \% dentro de Condição } \\
\text { experimental }\end{array}$ & $54,3 \%$ & $45,7 \%$ & $100,0 \%$ \\
\hline & & $\begin{array}{l}\text { \% dentro de } \\
\text { Comportamento } \\
\text { prosocial }\end{array}$ & $48,7 \%$ & $48,5 \%$ & $48,6 \%$ \\
\hline & & $\%$ do total & $26,4 \%$ & $22,2 \%$ & $48,6 \%$ \\
\hline \multirow[t]{5}{*}{ Total } & & Frequência & 39 & 33 & 72 \\
\hline & & Frequência esperada & 39,0 & 33,0 & 72,0 \\
\hline & & $\begin{array}{l}\text { \% dentro de Condição } \\
\text { experimental }\end{array}$ & $54,2 \%$ & $45,8 \%$ & $100,0 \%$ \\
\hline & & $\begin{array}{l}\text { \% dentro de } \\
\text { Comportamento } \\
\text { prosocial }\end{array}$ & $100,0 \%$ & $100,0 \%$ & $100,0 \%$ \\
\hline & & $\%$ do total & $54,2 \%$ & $45,8 \%$ & $100,0 \%$ \\
\hline
\end{tabular}

\section{Análises adicionais}

Com relação às medidas de Prosocialidade e amabilidade, foram conduzidas análises de moderação para a relação entre a função desempenhada e o comportamento prosocial. Para cada traço, as variáveis relevantes (função no jogo, traço e comportamento prosocial) foram inseridas na primeira etapa da regressão, e a interação entre o traço (Prosocialidade ou amabilidade) e a condição experimental foi adicionada na segunda etapa.

Ao se analisar o potencial efeito moderador da Prosocialidade, os resultados da regressão logística não apresentaram resultados significativos, nem para os efeitos principais nem para a interação $\left(p_{s}>0,005\right)$. No caso da amabilidade, no entanto, as análises sugeriram um potencial efeito de moderação deste traço disposicional. Quando considerada somente a condição experimental e amabilidade como preditoras, o modelo não se mostrou 
significativo, $\chi^{2}(2)=0,34, p=0,844$. Com a inserção da moderação, o modelo mostrou melhora considerável, apesar de ainda não ter atingido a significância estatística, $\chi^{2}(3)=7,14$, $p=0,068$ (Tabela 2).

Tabela 2. Coeficientes de regressão para as variáveis preditoras Condição experimental, amabilidade e Condição X Amabilidade.

\begin{tabular}{lccccccccc}
\hline \hline & B & E.P & Wald & gl & Sig. & Exp(B) & \multicolumn{2}{c}{$\begin{array}{c}95 \% \text { I.C. } \\
\text { EXP(B) }\end{array}$} \\
\hline $\begin{array}{l}\text { Condição } \\
\text { experimental }\end{array}$ & $-11,193$ & 4,801 & 5,434 & 1 & 0,020 & 0,000 & 0,000 & 0,168 \\
\hline $\begin{array}{l}\text { Amabilidade } \\
\text { CondiçãoX }\end{array}$ & $-2,346$ & 1,084 & 4,689 & 1 & 0,030 & 0,096 & 0,011 & 0,800 \\
$\begin{array}{l}\text { Amabilidade } \\
\text { Constante }\end{array}$ & 2,874 & 1,225 & 5,509 & 1 & 0,019 & 17,713 & 1,607 & 195,274 \\
\hline \hline
\end{tabular}

a. Nagelkerke R square: 0,128

Os resultados sugerem que a função jogada teve um efeito diferenciado no comportamento prosocial a depender do escore de amabilidade: na violenta o comportamento prosocial foi mais frequente quando o escore de amabilidade foi mais elevado; na condição prosocial, o comportamento prosocial foi mais associado com escores mais baixos de amabilidade.

\section{Discussão}

Os resultados do Experimento 2 apresentaram um padrão diferenciado quando comparados tanto com o Experimento 1 quanto com o apontado na literatura. Não foram encontrados resultados significativos da função desempenhada no comportamento prosocial, na intenção de ajuda, nos índices de afetos positivos e negativos ou na acessibilidade a cognições prosociais. De fato, as evidências encontradas mostram resultados quase idênticos entre as condições experimentais. Quando são levados em consideração o traço de 
prosocialidade e as avaliações do jogo, não foram encontradas evidências que sugerissem uma explicação alternativa. Ainda, uma análise cuidadosa do delineamento não apresentou evidências de problemas relacionados à medida das variáveis dependentes.

Foi encontrada, no entanto, evidências referentes a um possível efeito moderador da amabilidade, sugerindo que a tendência a se preocupar com o bem-estar dos outros pode ter um papel importante na compreensão da influência dos jogos digitais no comportamento prosocial. Evidências anteriores da literatura sugerem que a empatia (um construto relacionado tanto ao comportamento prosocial quanto à amabilidade) pode ser um importante moderador deste fenômeno (Greitemeyer, 2013a; Prot et al., 2013). O fato de que escores altos em amabilidade estarem positivamente relacionados ao comportamento prosocial somente na condição violenta tende a dar suporte à relação entre as ações dentro do jogo e ameaças ao autoconceito (Gollwitzer \& Melzer, 2012; Jin, 2011): quando o comportamento dentro do jogo tende a prejudicar outro personagem, participantes com um índice maior de amabilidade tendem a "compensar" o ato em ações subsequentes.

Há uma gama de variáveis que pode ser responsável pelos efeitos dos jogos digitais no comportamento. De acordo com o GLM, o principal modelo utilizado para explicar os efeitos desta e de outros tipos de mídia, tanto variáveis individuais quanto situacionais podem influenciar, pelas dimensões de cognição, afeto e arousal, a interpretação e o julgamento das situações experimentadas, resultando em comportamentos específicos manifestados pelos participantes (Buckley \& Anderson, 2006). De forma geral, os estudos até o momento investigaram a influência de fatores individuais (idade, sexo, hábitos de jogo, Prosocialidade e amabilidade) e situacionais (papel violento ou prosocial) nas dimensões afetivas, cognitivas e comportamentais, e resultaram em evidências contraditórias. Considerando os fatores individuais, não houve diferença entre os grupos experimentais, o que - por um lado - pode ser interpretado como uma consequência positiva dos procedimentos de designação 
randômica dos participantes nas condições experimentais. Por outro, traz dúvida sobre a importância de tais variáveis na compreensão do efeito de jogos digitais. Quando analisados os efeitos no comportamento, afeto e acessibilidade cognitiva, as análises não sugerem influência relevante, a não ser no caso de um possível efeito de moderação da amabilidade na relação entre a função desempenhada no jogo e o comportamento prosocial. Tal efeito de moderação, contudo, é coerente com evidências da importância de construtos relacionados à empatia na compreensão deste fenômeno (Greitemeyer, Osswald, \& Brauer, 2010; Greitemeyer, 2013a; Prot et al., 2013), e mais estudos são necessários com o intuito de melhor testar esta hipótese.

Considerando o efeito referente à função desempenhada do jogo, os Experimentos $1 \mathrm{e}$ 2 apresentaram evidências distintas relacionadas ao comportamento prosocial. No primeiro, desempenhar uma função violenta levou a uma maior ocorrência do comportamento prosocial quando comparado a uma função prosocial de suporte. Apesar do efeito encontrado ocorrer em um sentido contrário ao das evidências apresentadas na literatura, o tamanho do efeito é longe de ser trivial, especialmente quando se consideram os parâmetros em meta-análises tendo em conta estudos experimentais sobre comportamento prosocial (Greitemeyer \& Mügge, 2014). No Experimento 2, o comportamento prosocial não foi associado diretamente a nenhuma das funções desempenhadas. Uma das possíveis explicações é a de que o efeito encontrado no Experimento 1 não foi decorrente da função violenta, mas sim em função do personagem escolhido para a função prosocial. Ao se comparar todas as condições experimentais de ambos os estudos, observa-se uma tendência comum entre as condições violentas e a condição prosocial do segundo experimento, mas não do primeiro. Neste sentido, é factível supor que o personagem do trabalhador, por não estar relacionado a aspectos centrais do jogo, tenha gerado um efeito inibidor, reduzindo a chance do 
comportamento prosocial ocorrer. No entanto, são escassas as evidências que permitam aprofundar esta reflexão.

Com base nas evidências encontradas até o presente momento, optou-se pela realização de um novo experimento, desta vez com o intuito de investigar como o papel desempenhado no jogo pode influenciar no autoconceito prosocial implícito.

\section{Experimento 3 - Influência da função em jogo no autoconceito prosocial implícito}

Nos estudos dedicados à compreensão da prosocialidade como variável dependente, resultados de diversas investigações sustentam a hipótese de que jogos prosociais tendem a estar relacionados à manifestação de comportamentos e cognições prosociais, mais do que jogos neutros e violentos (Anderson et al., 2010; Anderson \& Bushman, 2001; Barlett \& Anderson, 2013; Barlett et al., 2009; Gentile et al., 2009; Gentile \& Anderson, 2006; Greitemeyer et al., 2011; Greitemeyer \& Osswald, 2009, 2010, 2011).

Dentre os vários estudos citados, a estratégia mais comum é investigar os efeitos dos jogos por meio de medidas explícitas, como a manifestação do comportamento e o preenchimento de escalas (principalmente no que se refere a medidas relacionadas a atitudes). No entanto, um grande conjunto de evidências sugere vantagens na adoção de medidas implícitas, não sujeitas a problemas associados à desejabilidade social por parte do respondente. O uso de medidas como o Teste de Associação Implícita - TAI (Greenwald, McGhee, \& Schwartz, 1998; Greenwald, Nosek, \& Banaji, 2003; Nosek, Greenwald, \& Banaji, 2005), por exemplo, poderia auxiliar os pesquisadores na compreensão dos processos envolvidos neste fenômeno. No entanto, o uso de medidas implícitas ainda é incipiente na literatura relacionada a jogos digitais.

Um dos estudos encontrados, por exemplo, avaliou o impacto de jogos violentos (Doom) e neutros (Majjong) no autoconceito implícito agressivo (Uhlmann \& Swanson, 
2004). Participantes foram solicitados a jogar um dos dois jogos e, após este procedimento, a responder ao TAI específico. Os resultados deste estudo evidenciaram que os jogadores expostos ao jogo violento tenderam a apresentar um autoconceito mais voltado para a agressividade do que os participantes que jogaram o jogo neutro. Além disso, evidenciaram uma relação entre os resultados do TAI e medidas anteriores de exposição ao jogo, sugerindo que fatores disposicionais podem, de alguma forma, moderar a relação encontrada.

Em outro estudo, os pesquisadores compararam grupos que jogaram jogos violentos, pacíficos ou neutros com relação à medida de autoconceito agressivo, também por meio de um TAI (Bluemke et al., 2009). Esse estudo complexificou os procedimentos de avaliação, inserindo 2 medidas do TAI antes e depois da exposição ao jogo, com o intuito de observar de forma mais refinada a possível influência entre o jogo e eventuais mudanças no autoconceito implícito. As evidências encontradas sugerem que, a partir da análise de um indicador composto pela diferença entre os escores de pré e pós-teste, há uma influência do tipo de jogo na medida do TAI. No entanto, os tamanhos de efeito são considerados bastante pequenos $\left(\eta_{p}^{2}=0,09\right)$.

O presente estudo busca dar continuidade a essa linha de investigação, e busca testar as seguintes hipóteses: 1) Quando solicitado a jogar um jogo cumprindo uma função prosocial, os participantes tenderão a exibir um autoconceito mais prosocial do que antissocial; 2) Quando solicitado a jogar um jogo cumprindo uma função violenta, os participantes tenderão a exibir menos autoconceito prosocial e mais antissocial; 3) Quando solicitado a jogar um jogo neutro, não haverá diferença no autoconceito prosocial implícito entre participantes.

Com a intenção de enriquecer a investigação, optou-se por manter as condições experimentais do Experimento 2 e acrescentar uma condição neutra, em que o participante joga um jogo de raciocínio, sem conteúdo violento ou prosocial. A lógica por trás desta 
decisão é fornecer dados sobre uma condição onde há a experiência de jogo, mas sem que o participante seja solicitado a desempenhar funções violentas ou prosociais. Infelizmente, não foi encontrado um jogo com o qual as três condições experimentais pretendidas pudessem ocorrer. O delineamento da pesquisa é detalhado a seguir.

\section{Método}

\section{Participantes}

Foram selecionados, por conveniência, 103 estudantes universitários para participar da pesquisa em diversos locais de ampla circulação dentro da universidade. Após uma análise preliminar dos dados, optou-se pela exclusão de 7 casos em função de um alto índice de erros no TAI (6 casos) e da existência de um caso extremo multivariado. Por fim, considerou-se uma amostra de 96 participantes (50 homens, $M_{\text {idade }}=19,85$ anos, $D P_{\text {idade }}=2,35$ anos). Apesar da familiaridade com o consumo de jogos eletrônicos não ter sido requerida, 80 dos participantes $(83,3 \%)$ declararam jogar regularmente algum tipo de jogo eletrônico.

\section{Instrumentos e Materiais}

Jogos utilizados como estímulos. Como estímulo nas condições violenta e prosocial, foi utilizado o jogo Fat Princess, da empresa Titan Studios, para Playstation 3, seguindo a mesma lógica do Experimento 2. Para a condição neutra, utilizou-se o jogo Bejewled (PopCap Games), no qual o participante deveria organizar as pedras coloridas em grupos de três ou mais pedras da mesma cor para marcar pontos.

Medidas disposicionais e de avaliação do jogo. De forma similar ao Experimento 1, foram utilizadas as dimensões de desconforto pessoal (Três itens, $\alpha=0,42$ ) e altruísmo autorrelatado (Cinco itens, $\alpha=0,78$ ) da Bateria de Personalidade Prosocial de Penner, Fritzsche, Craiger e Freifeld (1995), adaptada para o Brasil por Rabelo e Pilati (2013), e a Positive and Negative Affect Schedule - PANAS com as dimensões de afetos positivos $(\alpha=$ 0,88) e negativos $(\alpha=0,81)$, adaptada para o português (Galinha \& Paes-Ribeiro, 2005), para 
medir traços disposicionais relacionados à prosocialidade e a reação emocional decorrente do jogo, respectivamente. Além delas, foi utilizada a escala reduzida do fator de amabilidade, composta por 5 itens $(\alpha=0,60)$, um questionário para avaliação do jogo, contendo perguntas fechadas sobre Agradabilidade, diversão, dificuldade, excitabilidade e nível de violência do jogo (utilizando uma escala Likert de 5 pontos) e o questionário demográfico e de hábitos de jogo, e de intenção de ajuda.

Teste de Associação Implícita. Além das medidas coletadas acima, utilizou-se (como principal medida da variável dependente) um Teste de Associação Implícita de Autoconceito Prosocial. Este TAI era composto das categorias-alvo Prosocial (8 palavras) X Antissocial (8 palavras) e das categorias-atributo Eu (7 palavras) X Outros (7 palavras), e possuíam os mesmos estímulos (Apêndice E) nas versões de pré $(\alpha=0,46)$ e pós-teste $(\alpha=0,57)$. O TAI foi aplicado por meio do software Inquisit 3.0, via computador. A seleção de estímulos se deu de forma semelhante ao Experimento 2. Para facilitar o manuseio do TAI, ele foi configurado para que o participante o respondesse utilizando o mesmo controle utilizado no Playstation 3. Além disso, o programa automaticamente executou o contrabalanceamento das categorias do TAI, uma vez que a ordem de apresentação das categorias pode ser um fator de influência na resposta da medida.

\section{Procedimentos}

Trata-se de um delineamento experimental. Os participantes foram convidados sob o argumento de se tratar de um estudo sobre a influência das novas tecnologias no cotidiano dos indivíduos, e foram informados de que participariam de um estudo sobre coordenação motora e tempo de reação. A coleta de dados foi feita individualmente e, ao chegar ao laboratório, o participante respondia o TAI. Após a resposta do TAI, cada participante foi designado aleatoriamente para uma das três condições: (a) a condição violenta, na qual era solicitado que ele controlasse o personagem do guerreiro e cumprisse o objetivo de causar 
dano ao maior número possível de adversários, (b) a condição prosocial, na qual o participante jogava com o personagem do clérigo e cumprisse o objetivo de curar e manter vivos os seus companheiros de equipe ou c) a condição neutra, onde os participantes foram solicitados a jogar um jogo de raciocínio que envolvia organizar pedras coloridas de acordo com um determinado conjunto de regras. Tais funções foram escolhidas por se considerar que eram os mais condizentes com as condições planejadas a priori.

Após o sorteio da função a ser desempenhada no jogo, o pesquisador fornecia informações gerais sobre o jogo e os comandos mais importantes e dava ao participante até 1 minuto para se familiarizar com os controles. Após o participante declarar que se sentia pronto para iniciar o estudo (ou após o término do período de 1 minuto, o que ocorresse primeiro), era solicitado que jogasse por 10 minutos.

Depois da fase de jogo, o participante preenchia o questionário de avaliação do jogo, a PANAS, respondia o pós-teste do TAI, o questionário demográfico e a BPP. Por fim, era realizado um debriefing do participante e o pesquisador agradecia pela sua participação.

\section{Procedimentos de análise de dados}

Para a análise das hipóteses principais, inicialmente foram executados os testes para verificação dos pressupostos relacionados à casos omissos e casos extremos, normalidade e linearidade. Computou-se, de acordo com a recomendação da literatura (Greenwald et al., 2003), o escore $d$, índice utilizado como medida interpretativa da força da associação implícita. No caso do TAI aplicado neste experimento, quanto mais o escore se aproxima de zero, maior seria o valor no autoconceito prosocial implícito.

Após o tratamento da base de dados, foram realizadas análises de correlação, Análises de variância univariadas e Análises de variância para medidas repetidas, tendo como fatores intra-sujeito os resultados dos TAIs pré e pós, e como variáveis entre-sujeitos a condição experimental dos participantes. 


\section{Resultados}

Inicialmente, foi executado um conjunto de análises com o intuito de verificar a qualidade da medida do TAI utilizado. Após o cálculo da medida de confiabilidade para as medidas pré-teste e pós-teste ( $\alpha=0,46$ e $\alpha=0,57$, respectivamente), computou-se a correlação entre elas. Esperava-se, com isso, encontrar uma elevada correlação significativa entre as medidas, uma vez que se trata da aplicação do mesmo teste em momentos distintos. A correlação encontrada mostrou-se significativa, porém mediana, $r=0,56, p<0,01$.

Com base nisso, optou-se por realizar uma Análise de Variância para cada categoria de estímulos do TAI, considerando cada estímulo como uma variável de grupo. O raciocínio com tal procedimento é verificar o quanto cada estímulo se diferenciaria dos outros, em termos do tempo médio de latência, de uma mesma categoria (prosocial, antissocial, eu e outros). Apesar deste procedimento não detalhar a razão de tal dissimilitude (se existir), auxilia o pesquisador a verificar se existem estímulos muito discrepantes, o que pode auxiliálo na interpretação dos resultados principais do estudo. Os resultados das ANOVAs apontaram diferença significativa para o tempo de latência entre os estímulos para as categorias: prosocial, $F(7,5592)=2,54, p<0,013$; antissocial, $F(7,5592)=3,64, p=$ 0,001; Eu, $F(6,4473)=49,80, p<0,001$; e outros, $F(6,4473)=46,98, p<0,001$. As análises post hoc sugerem que as inconsistências se devem principalmente seguintes estímulos: indelicado (antissocial), cooperativo (prosocial), próprio e comigo (Eu), alheio e consigo (Outros). Por esta razão, optou-se por realizar os procedimentos de construção do escore $d$ sem a inserção destes estímulos (o que resultou em alfas para as medidas de pré e pós teste de 0,53 e 0,59 , respectivamente).

Ao se analisar, de forma independente, possíveis diferenças entre os grupos experimentais nas medidas do TAI nas situações de pré-teste e pós-teste, evidenciou-se a ausência de diferenças significativas entre os grupos para o pré-teste, $\mathrm{F}(2,93)=0,58, \mathrm{p}=$ 
0,654. No caso do pós-teste, observou-se resultados marginalmente significativos, $\mathrm{F}(2,93)=$ $2,51, \mathrm{p}=0,087, \eta_{p}{ }^{2}=0,05$. Análises post hoc permitiram observar uma diferença somente entre as condições prosocial e violenta, sendo que o autoconceito prosocial implícito foi maior $(M=0,41, D P=0,32)$ na condição prosocial do que na violenta $(M=0,59, D P=0,41)$.

Ao se considerar ambas as medidas em uma análise de variância para medidas repetidas, no entanto, não foi possível encontrar diferenças significativas entre os grupos experimentais, $V=0,15, F(2,93)=0,70, p=0,50, \eta_{p}{ }^{2}=0,03$, apesar da inspeção visual dos gráficos sugerir uma tendência coerente com a esperada no caso da condição prosocial (Figura 4).

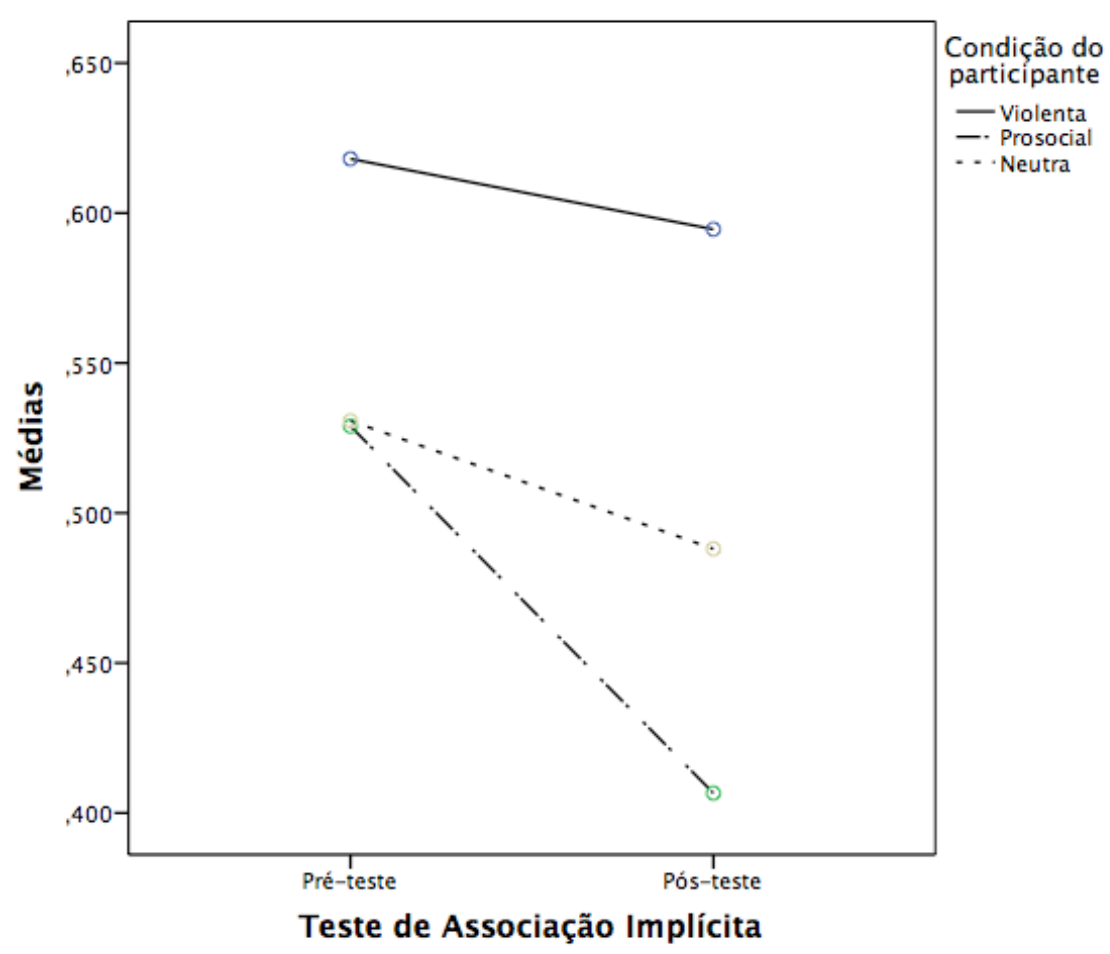

Figura 4. Comparação dos tempos de latência das medidas pré-teste e pós-teste do TAI, em função da condição experimental do participante. 
Por fim, ao se analisar as possíveis influências de idade, sexo, experiência anterior, prosocialidade, afetos positivos e negativos e amabilidade, não foram encontrados resultados significativos $\left(p_{s}>0,10\right)$.

\section{Discussão}

Com base nos resultados apresentados, não foi possível observar evidências consistentes acerca da influência da função violenta, neutra ou prosocial no autoconceito prosocial implícito no pré-teste. Observou-se, no entanto, um resultado próximo da significância para a aplicação pós-teste do TAI no sentido esperado, e a análise para medidas repetidas apresentou uma tendência coerente com o sugerido na literatura. Contudo, tanto os índices de significância quanto os tamanhos de efeito encontrados limitam o potencial explicativo de tais resultados. Além disso, não foram observados os efeitos esperados com relação aos afetos positivos e negativos, indo de encontro às evidências apresentadas por estudos anteriores sobre o tema (Anderson \& Bushman, 2001; Anderson et al., 2010; Bluemke et al., 2009; Gentile et al., 2009; Gentile \& Anderson, 2006; Greitemeyer et al., 2011; Greitemeyer \& Osswald, 2009, 2010; Uhlmann \& Swanson, 2004). Na tentativa de compreender quais elementos podem ter contribuído para a obtenção dos resultados apresentados, algumas reflexões são necessárias.

Ao se analisar o modelo GLM (Buckley \& Anderson, 2006), observa-se que tanto características individuais como situacionais podem influenciar, por meio das três rotas (cognição, excitação e afeto), os processos de interpretação e de tomada de decisão o que, por fim, acabaria por influenciar as diferentes dimensões e suas manifestações por parte dos indivíduos.

Com relação às características situacionais, é possível que os estímulos apresentados tenham sido insuficientes para ativar padrões, mnemônicos e afetivos, discriminados o bastante para ocasionar diferenças mais intensas no autoconceito implícito e afetos positivos 
e negativos. Um dos argumentos a favor desta interpretação consiste na evidência de que os estudos que utilizaram jogos diferentes em vários aspectos, e não só em termos de conteúdo e contexto de jogo, encontraram o efeito hipotetizado. Ao utilizar jogos muito discrepantes, a interação entre diversas características distintas pode amplificar a chance do efeito ocorrer (e.g., por meio de uma trilha sonora mais estimulante e gráficos mais realistas). Sugere-se, neste sentido, um estudo mais aprofundado sobre as características mais relevantes dos jogos eletrônicos para que um participante de fato diferencie um jogo violento de um jogo neutro ou prosocial.

Outra reflexão relevante diz respeito à ausência de correlação entre as variáveis dependentes do estudo. Neste sentido, questiona-se se o resultado de uma medida implícita e os resultados da medida de afeto positivo (de natureza explícita) são de fato influenciados de forma diferenciada pela estimulação do jogo. É possível que as medidas implícitas e explícitas utilizem rotas diferentes de processamento de informação (Fiske \& Taylor, 2008a). Neste sentido, seria factível supor uma não relação entre as variáveis selecionadas para este estudo. Neste sentido, sugere-se a realização de análises mais aprofundadas correlacionando medidas implícitas e explícitas.

Por fim, o estudo de como as características dos jogos podem estar associadas à ativação de padrões específicos de processamento de informação deve ser intensificado. Já existem várias características levantadas como possíveis fatores de influência em comportamentos como agressão e prosocialidade (Barlett et al., 2009). No entanto, somente a comparação sistemática destas características pode permitir uma compreensão mais apurada sobre o fenômeno, bem como do papel de cada dimensão relacionada à experiência de jogo. 


\section{Experimento 4 - Desenvolvimento e pré-teste de um jogo para o estudo do impacto de jogos digitais no comportamento prosocial.}

A execução dos experimentos anteriores resultou em um conjunto de informações relevantes para a compreensão da influência de jogos digitais no comportamento; mais do que isso, levantou uma série de questionamentos sobre os elementos que poderiam estar associados aos resultados comumente evidenciados na literatura. Um dos principais pontos a serem resolvidos para o presente trabalho diz respeito à escolha do jogo a ser utilizado como estímulo. As decisões metodológicas até o presente momento trouxeram, neste sentido e na opinião deste autor, um diferencial e um desafio.

Com relação ao diferencial associado ao uso do jogo Fat Princess, este estudo se junta a um escasso número de estudos que se propõe a, na medida do possível, alterar o mínimo possível as características do jogo entre as condições experimentais, à exceção da característica principal de interesse, a saber, o conteúdo/papel violento no jogo. Neste sentido, há o potencial de se avaliar com maior precisão o papel desta variável na compreensão do fenômeno em questão.

No entanto, tal decisão traz um desafio associado às escolhas dos personagens e funções a serem jogados. Mais importante, os resultados não significativos encontrados nos Experimentos 2 e 3 levantam dúvidas se as personagens tinham características distintas o bastante para que operassem como estímulos adequados. Conforme mencionado na discussão dos referidos experimentos, não há como assumir que a ausência de efeito se deu em função da sua inexistência ou da inadequação dos estímulos. Os elementos frequentemente utilizados para se excluir a hipótese de inadequação dos estímulos geralmente consistem em uma checagem de manipulação na qual se pede que os participantes avaliem o nível de violência do jogo. Com isso, é possível inferir que, caso os jogos sejam classificados corretamente, que os estímulos são adequados para o experimento (por exemplo, Greitemeyer \& Osswald, 2009, 
2010, 2011). Contudo, tal procedimento não gerou resultados nos experimentos relatados aqui, provavelmente em função do nível de violência ter sido considerado semelhante entre as condições experimentais (e geralmente com escores baixos). Em uma situação ideal, é factível supor que as diferentes funções utilizadas no jogo diferissem somente na dimensão de violência, mas não das outras avaliadas (dificuldade, agradabilidade, diversão, frustração e excitação).

Uma investigação voltada para a seleção de estímulos para pesquisas sobre jogos digitais poderia contribuir para a compreensão das críticas comumente associadas a esta temática (Elson \& Ferguson, 2013), bem como a existência de estudos em que não houve sucesso em encontrar evidências coerentes com a concepção mais adotada pela literatura (Chambers \& Ascione, 2001; Gunter \& Daly, 2012; Tear \& Nielsen, 2013, 2014).

Neste sentido, o presente experimento foi proposto com o intuito de cumprir dois objetivos centrais: a) desenvolver um jogo digital que pudesse ser utilizado em estudos experimentais; b) testar se as funções desempenhadas no jogo (violento, prosocial e neutro) são corretamente classificados pelos participantes. As informações referentes a estes dois objetivos serão apresentadas a seguir.

\section{Método}

\section{Participantes}

Para a avaliação do jogo, participaram da pesquisa 101 respondentes, selecionados por conveniência a partir da divulgação da pesquisa em diversas redes sociais. Destes, 72,3\% relataram o hábito de jogar regularmente algum tipo de jogo. Os participantes foram aleatoriamente designados a jogar uma condição específica, dentro das combinações possíveis entre os três modos (violento, neutro e prosocial) e três níveis diferentes de dificuldade (fácil, médio e difícil). 


\section{Instrumentos e Materiais}

Desenvolveu-se um jogo em terceira pessoa com o uso da ferramenta Unity em um projeto de cooperação com alunos do Departamento de Ciências da Computação da Universidade de Brasília. O jogo, doravante denominado Field of Valor - FoV, foi concebido de forma a possuir as seguintes características:

Diferentes modos - O jogo possui três modos definidos a priori em função do tipo de papel solicitado ao jogador. No modo violento (Figura 5), o jogador tem a missão de matar o maior número possível de oponentes. Inicialmente, o jogador possui um fuzil e um conjunto limitado de granadas, com a possibilidade de adquirir novos armamentos durante o jogo. Neste modo, há a presença de sangue e explosões decorrentes das ações do jogador.

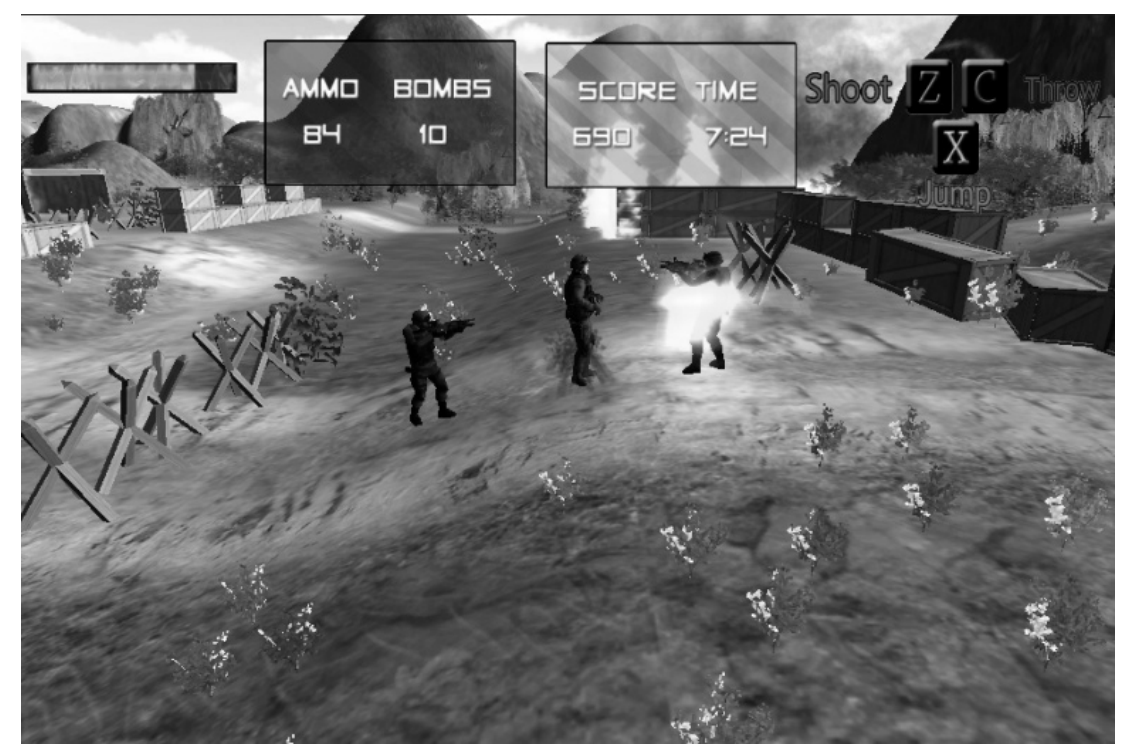

Figura 5. Exemplo da tela no modo violento.

No modo neutro (Figura 6), o jogador tem como objetivo principal coletar o máximo possível de moedas no cenário, com a possibilidade de abrir baús de tesouro por meio da execução de uma sequência de etapas. Não há a presença de efeitos visuais como sangue, fogo ou explosões. 


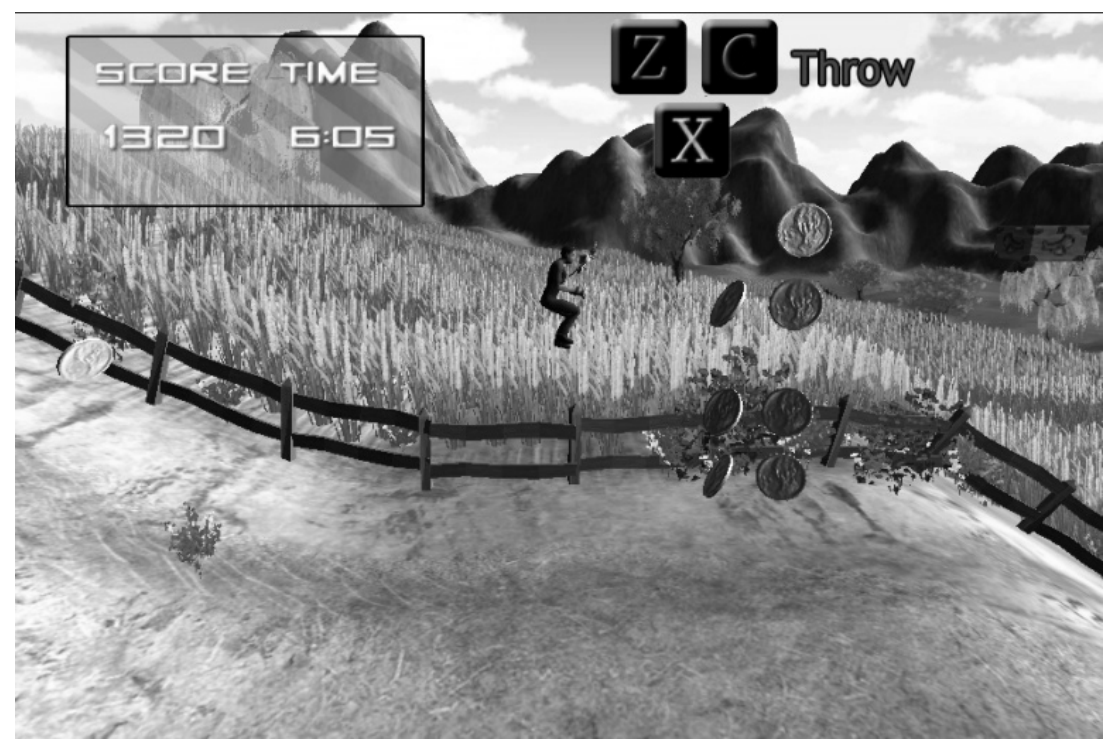

Figura 6. Exemplo da tela no modo neutro.

Por fim, o modo prosocial (Figura 7) é caracterizado pela tarefa de curar personagens (Non-player characters - personagens controlados pelo computador) feridos no mapa. A depender da gravidade do ferimento, o jogador deve curar o personagem no local ou solicitar apoio de um helicóptero de resgate. Não há a presença de efeitos visuais como sangue, fogo ou explosões.

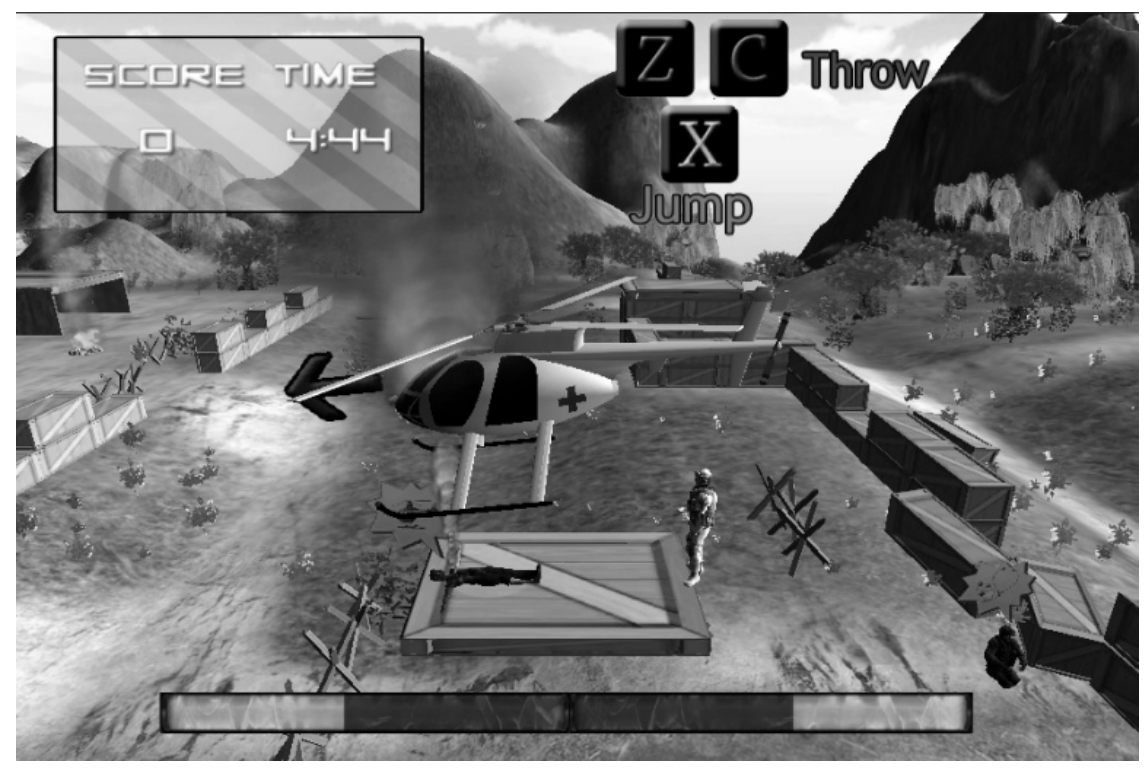

Figura 7. Exemplo da tela no modo prosocial. 
Além dos modos apresentados, o jogo foi desenvolvido de forma a que fosse possível definir, a partir de um menu de acesso restrito, se estímulos como explosões, fogo ou sangue estariam presentes. Desta forma, é possível controlar elementos específicos do cenário e, ainda, criar condições experimentais adicionais (como por exemplo, um personagem prosocial dentro de um contexto com estímulos mais associados à violência). Além disso, é possível definir o nível de dificuldade no qual o participante irá jogar. São três níveis diferentes, fácil, médio e difícil, e um sistema de balanceamento dinâmico foi criado para os níveis fácil e difícil, permitindo que a quantidade e dificuldade de obstáculos e inimigos (no caso do modo violento) fossem definidos de acordo com o desempenho do próprio jogador.

Ainda, o jogo possui uma ferramenta de designação aleatória do modo a ser jogado, de forma a auxiliar o pesquisador na execução dos delineamentos de pesquisa e um sistema de registro que coleta informações em tempo real sobre o desempenho dos participantes, como quantidade de vezes que morre, quais botões aperta e com qual frequência, o número total de pontos alcançado, entre outras informações. Por fim, o jogo foi concebido de forma a permitir que um arquivo de áudio fosse ativado aleatoriamente em um determinado número de vezes no jogo, de forma a gerar uma tarefa interferente enquanto ocorre a experiência de jogo (para estudos futuros relacionados à carga cognitiva).

Com relação às demais características constituintes do jogo, buscou-se manter a uniformidade entre os diferentes modos; elementos como cenário, gráficos e mecânica eram semelhantes (na medida do possível, já que objetivos diferenciados demandaram alterações que afetam, de uma forma ou de outra, a mecânica do jogo). Este aspecto foi essencial no desenvolvimento do jogo, uma vez que a possibilidade de manipular determinados elementos, mantendo o restante o mais constante possível, possibilita o controle necessário para a execução de estudos experimentais sobre a influência de jogos. No caso da interface, as 
únicas diferenças entre os modos dizem respeito ao modo violento, uma vez que informações adicionais precisavam ser apresentadas aos jogadores (como quantidade de vida e munições). Além do jogo eletrônico, foi utilizado um instrumento de avaliação, composto por itens que versavam sobre determinadas características do jogo a serem avaliadas. Os participantes foram solicitados a julgar, de acordo com a sua experiência com o jogo, o nível de dificuldade, violência, prosocialidade, agradabilidade, excitação e frustração. Todos os itens eram respondidos com o uso de uma escala tipo Likert de 11 pontos. Ao final, o instrumento continha questões relacionadas a características demográficas e de hábitos de jogo do respondente. $\mathrm{O}$ instrumento foi adaptado para aplicação online, por meio do sistema EFS Survey que permitiu, entre outros aspectos, a participação anônima dos respondentes e o registro, em um banco de dados pré-definido, das respostas de cada participante.

\section{Procedimentos}

O desenvolvimento do jogo foi baseado nas seguintes etapas: inicialmente, foram realizadas diversas reuniões com o grupo de pesquisa em psicologia social, que possui a experiência e interesse em realizar delineamentos experimentais com jogos. Nessas reuniões, foram levantados os requisitos necessários para a concepção do jogo. Além disso, foram consultados artigos empíricos sobre o tema, com o intuito de verificar o conjunto de variáveis mais utilizadas (por exemplo, Barlett \& Anderson, 2013, e Barlett et al., 2009). Por fim, foram desenvolvidas versões preliminares para se definir as características gráficas, sonoras e de mecânica de jogo.

Após a finalização da versão de teste, os instrumentos foram configurados no sistema de coleta e os participantes foram convidados por meio de redes sociais. Ao acessar o sistema, o participante tinha acesso às instruções gerais do estudo e, caso concordasse em participar, era alocado aleatoriamente em uma das condições de estudo. Neste sentido, é importante ressaltar que os participantes não tinham conhecimento de qual era o modo 
selecionado para eles (e nem que existiam modos alternativos), já que essa informação poderia influenciar a forma como eles avaliariam o jogo. Após 8 minutos de jogo, este se encerrava e o participante era encaminhado para o instrumento de avaliação do jogo e de caracterização da amostra.

A pesquisa foi aplicada durante o período de duas semanas. Após o tratamento dos dados válidos (aqueles em que o respondente completava todas as etapas da pesquisa), foram realizadas análises descritivas e análises de variância (ANOVAs), com o intuito de verificar se a avaliação dos respondentes sobre o jogo seria condizente com o modo e o nível de dificuldade experimentado por ele. Em outras palavras, verificou-se se haveria consistência entre o modo concebido pelos desenvolvedores e a percepção do mesmo atributo por parte dos respondentes.

\section{Resultados}

Inicialmente, buscou-se verificar se os modos de jogo (violento, neutro e prosocial) seriam percebidos de forma análoga pelos participantes. Para isso, foram realizadas ANOVAs comparando as avaliações dos níveis de violência e prosocialidade feitas pelos participantes de cada grupo. Observou-se uma diferença significativa entre os grupos que jogaram o modo violento, prosocial ou neutro na avaliação do nível de violência do jogo, $F(2,91)=29,14, p<0,001, \omega^{2}=0,38$ (Figura 8). Análises post hoc identificaram que a diferença na avaliação dos participantes segue o esperado, com o modo violento avaliado como mais violento $(M=5,53, D P=3,49)$ que os modos neutro $(M=1,07, D P=0,26)$ e prosocial $(M=2,24, D P=2,05)$, sem diferença significativa entre estes. 


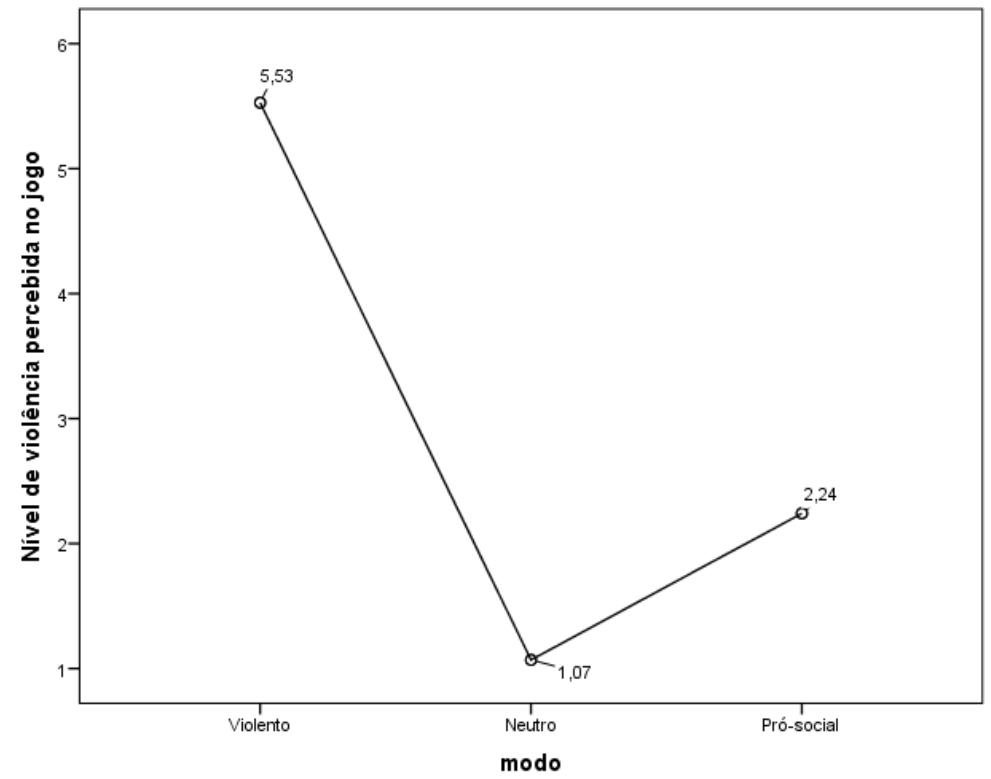

Figura 8. Comparação da avaliação do nível de violência em função do modo jogado.

A mesma análise foi realizada considerando a percepção do caráter prosocial e os resultados sugerem que há uma diferença significativa entre os grupos, $F(2,91)=83,50, p<$ $0,001, \omega^{2}=0,64$. A Figura 9 apresenta a diferença entre as médias de avaliação para cada grupo, e os testes post hoc sustentam a análise visual de que o grupo exposto ao modo prosocial avaliou o jogo como mais prosocial $(M=8,14, D P=2,75)$ do que os modos neutro $(M=1,72, D P=2,07)$ e violento $(M=2,06, D P=1,64)$, e sem diferença significativa entre estes. 


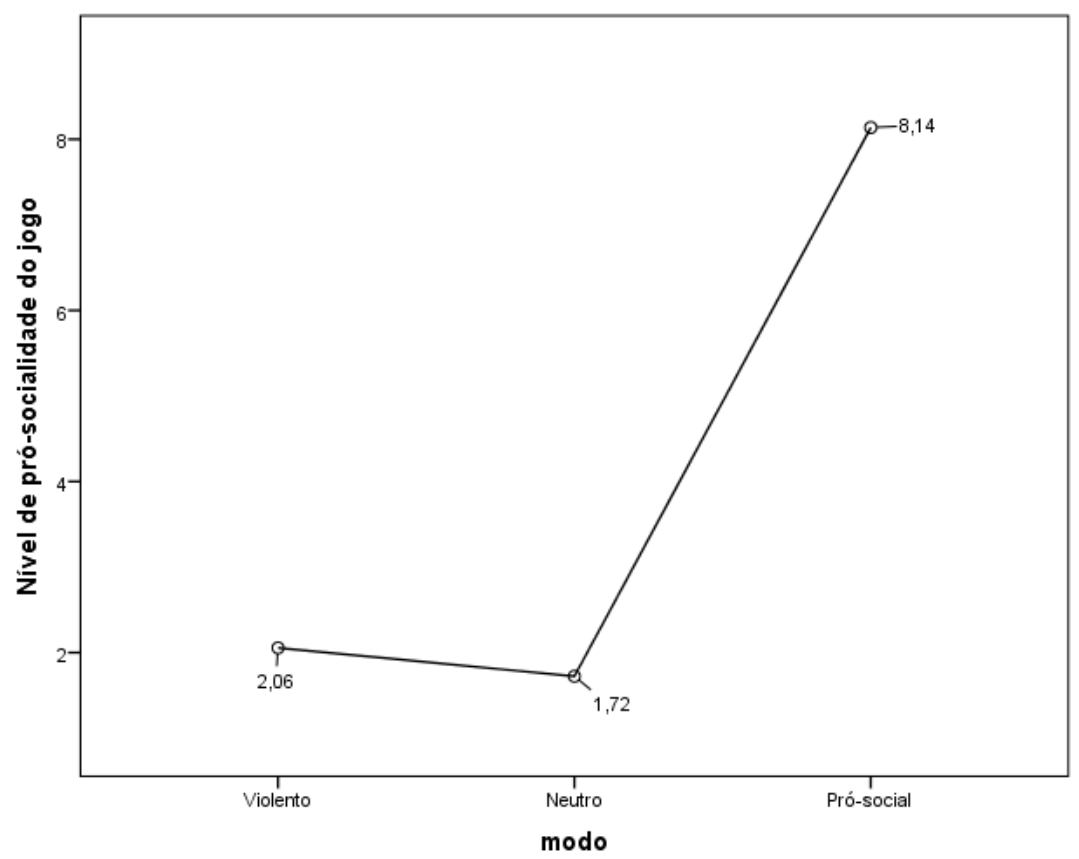

Figura 9. Comparação da avaliação do nível de prosocialidade em função do modo jogado.

Ainda considerando os modos pré-estabelecidos do jogo, verificou-se se os participantes percebiam de forma diferente os níveis de agradabilidade, excitação, dificuldade e frustração em função da experiência de jogo. Tal análise é importante uma vez que se esperava que os modos não diferissem em outros atributos além daqueles intencionalmente manipulados. As ANOVAs específicas comparando o modo de jogo com cada uma dessas variáveis não indicou diferenças significativas $\left(p_{\mathrm{s}}>0,05\right)$.

Com relação ao nível de dificuldade, a ANOVA apresentou resultados significativos, indicando que os participantes perceberam a dificuldade de forma diferente ao se considerar o modo de dificuldade (fácil, médio e difícil), $F(2,91)=7,46, p=0,001, \omega^{2}=0,12$. Ao se analisar as diferenças específicas entre cada grupo, observou-se os participantes julgaram o modo prosocial como mais fácil $(M=2,42, D P=1,82)$ que o modo neutro $(M=4,54, D P=$ $2,78)$ e o violento $(M=5,03, D P=2,09)$, não havendo diferença significativa na percepção de dificuldade por parte dos respondentes que foram expostos ao jogo médio e difícil. 


\section{Discussão}

O desenvolvimento de aplicações voltadas para processos de investigação científica traz consigo diversos desafios. O processo de desenvolvimento e avaliação do jogo em questão permitiu levantar considerações interessantes sobre este processo. De forma geral, considera-se que o objetivo deste trabalho foi alcançado, uma vez que os participantes avaliaram os modos dos jogos de forma congruente com as especificações utilizadas no desenvolvimento de cenários violentos, neutros e prosociais. No entanto, algumas reflexões se fazem necessárias.

Com relação ao nível de dificuldade, é necessário ajustar o balanceamento dos níveis médio e difícil, para que essa diferença possa ser percebida de forma mais explícita. Os resultados apresentados sugerem que o sistema de balanceamento do nível difícil deve ser revisto para que ele seja melhor diferenciado. Ainda assim, os resultados encontrados sugerem um caminho promissor de trabalho, reforçando a lógica de que os jogos podem ser utilizados como ferramentas de pesquisa e trabalho, mais do que somente fonte de entretenimento.

O processo de desenvolvimento do jogo apresentou uma série de desafios concretos a serem alcançados, porém de difícil operacionalização. Desenvolver os diferentes modos do jogo, garantindo o máximo possível de uniformidade, exigiu a criação de diversos modelos alternativos que foram minimamente implementados até ser possível contar com uma versão suficientemente estável para a fase de testes.

O processo de desenvolvimento de ferramentas como esta e, mais importante, de avaliação das decisões de concepção, permitirão que estudos voltados para a investigação do efeito de jogos pode fornecer um nível maior de precisão nas pesquisas desta natureza, e resultados muitas vezes contraditórios encontrados na literatura poderão ser esclarecidos a 
partir do momento que variáveis intervenientes associados a diferentes características e dimensões dos jogos atualmente utilizados sejam adequadamente controladas (Gentile, 2011). Todos os experimentos anteriores permitiram ao pesquisador abordar alguns pontos específicos relacionados ao estudo dos efeitos de jogos digitais no comportamento, apresentados ao final do referencial teórico deste trabalho. Aspectos como a definição/seleção de jogos a serem utilizados como estímulos experimentais, bem como o controle de variáveis relacionadas a gráficos, efeitos visuais, narrativa e mecânica, permitiram o desenvolvimento de vários testes que culminaram com a proposta de um jogo específico para os próximos estudos. Além disso, reflexões acerca das possíveis variáveis de influência, além do conteúdo do jogo propriamente dito, resultaram em um conjunto de reflexões para os próximos estudos.

Um ponto ainda não abordado neste trabalho, no entanto, diz respeito ao papel de processos automáticos e controlados para a compreensão deste fenômeno. Este aspecto, presente conceitualmente no próprio GLM (Buckley \& Anderson, 2006), ainda carece de evidências empíricas específicas para o contexto de jogos digitais, principalmente com relação ao impacto esperado do processamento em cada uma dessas vias.

Com o intuito de contribuir para a compreensão dos elementos acima, propõem-se as seguintes etapas. Primeiramente, uma nova medida da variável dependente comportamento prosocial é empregada, buscando não somente aumentar a viabilidade e a economia na execução dos experimentos, bem como uma maior semelhança entre os contextos de exposição ao estímulo e de manifestação do comportamento. Em seguida, descreve-se um experimento para analisar o papel da carga cognitiva na relação entre a função prosocial do jogo e o comportamento de ajuda. 


\section{Experimento 5 - Adaptação de um jogo para mensuração do comportamento prosocial}

Este experimento teve como objetivo adaptar o Zurich Prosocial Game (ZPG) para uso em contexto brasileiro. O ZPG é um jogo digital, desenvolvido em Java, com a finalidade de mensurar a frequência de comportamentos prosociais em diversas situações (Leiberg, Klimecki, \& Singer, 2011). Originalmente, foi desenvolvido para um estudo sobre treinamento de compaixão, e foi utilizado como medida da eficácia de tal treinamento. Uma das principais vantagens do ZPG é a possibilidade de medir o comportamento prosocial repetidas vezes, uma vez que ele é composto por rodadas individuais. Este aspecto pode ser considerado como uma vantagem em relação a outras medidas comuns para medir o comportamento prosocial que podem ser aplicados uma única vez para cada participante, como procedimentos de deixar canetas caírem no chão, solicitar ajuda no preenchimento de questionários ou solicitar doações (Leiberg et al., 2011).

O jogo consiste em uma série de rodadas (quatro de treino e onze de teste) em que o participante é convidado a jogar um jogo de corrida ao tesouro. Em cada rodada, o participante joga com outro jogador, conectado via internet (na verdade, trata-se de uma inteligência artificial controlada pelo computador), e sua tarefa é percorrer um caminho para se chegar ao tesouro. Durante o percurso, há a possibilidade de portões azuis ou vermelhos surgirem no caminho. Cada jogador possui um conjunto limitado de chaves azuis e vermelhas, e devem utilizá-las para abrir os portões (caso não abra o portão a tempo, o jogador perde a partida). Os jogadores podem utilizar as chaves que possuem para abrir tanto os portões que surgem em seu caminho quanto no caminho do outro jogador, e o comportamento prosocial é mensurado em função da quantidade de vezes em que o participante utiliza de suas chaves para abrir o portão do outro jogador (Figura 10) 


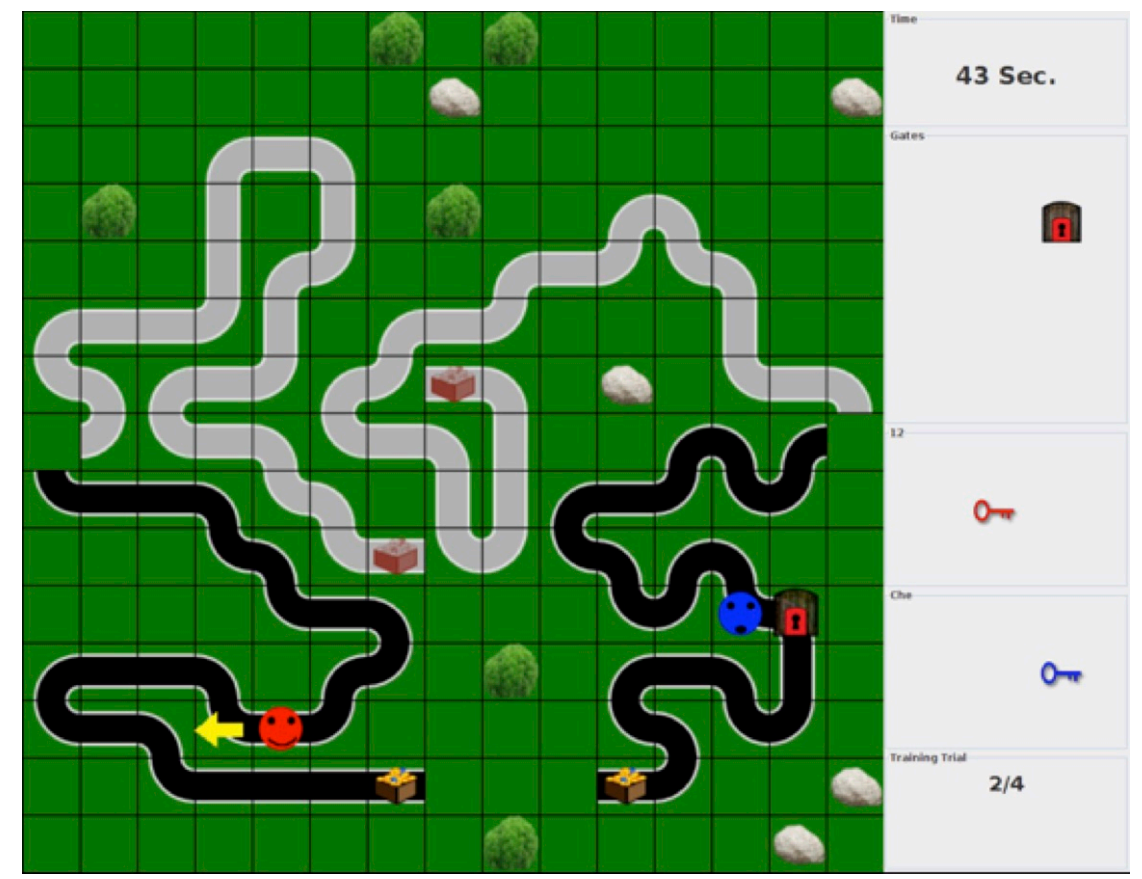

Figura 10. Tela do Zurich Prosocial Game

Para garantir uma variedade de situações nas quais a ajuda se faria necessária, em cada partida do jogo podem ser manipuladas as seguintes variáveis: a) custo (alto ou baixo), relacionado ao impacto da ajuda para o sucesso do participante naquela rodada. Em situação de baixo custo, o uso de uma chave para auxiliar o outro jogador não ameaça a chance do participante de alcançar o tesouro. No contexto de alto custo, a ajuda pode resultar na perda da partida (por não possuir a chave certa para abrir seu próprio portão); b) reciprocidade (com ou sem), em que se manipula se o jogador controlado pelo computador ajuda o participante ou não. Na situação de reciprocidade, o jogador utiliza uma de suas chaves para ajudar o participante antes que o inverso seja solicitado. Na situação sem reciprocidade, não há ajuda prévia; c) pedido de ajuda (distress), em que se define se o personagem controlado pela inteligência artificial do jogo emitirá ou não estímulos visuais (o ícone do personagem muda para um rosto chorando) e auditivos (emite-se um som de choro) relacionados a necessidade de ajuda. O jogo, a depender das configurações feitas pelo pesquisador, cria diversas rodadas que considerem a combinação destas variáveis. 
No estudo original de Leiberg et al. (2011), o ZPG foi aplicado a 68 participantes do sexo feminino considerando um delineamento intra-sujeito $2 \mathrm{X} 2 \mathrm{X} 2$ no qual as variáveis custo, reciprocidade e pedido de ajuda foram manipuladas. Além disso, os participantes foram solicitados a jogar o jogo do ditador e responder questionários relacionados à risco e engajamento, bem como responderam um teste de memória (como medida de validade discriminante). Os resultados deste estudo mostraram, a partir de uma ANOVA para medidas repetidas, que as manipulações de reciprocidade, custo e distress resultaram em variações no comportamento de ajuda. Além disso, as análises relacionadas à propensão ao risco não apresentaram influência significativa na ocorrência de comportamentos de ajuda, e a correlação com o resultado do jogo do ditador apresentou um índice significativo $(\rho(65)=$ $0,3595 \%$ IC $[0,133,0,551], p=0,004)$ que, na opinião das autoras, indica que o ZPG pode ser um instrumento adequado para mensurar o comportamento prosocial.

Para este experimento, será mantido o delineamento 2(reciprocidade: com reciprocidade, sem reciprocidade) x 2 (custo: baixo custo, alto custo) x 2 (pedido de ajuda: com pedido, sem pedido) original, bem como o jogo do ditador como medida de validade convergente. No entanto, considerando os experimentos anteriores, foram aplicadas escalas associadas à empatia e amabilidade.

\section{Método}

\section{Participantes}

Foram selecionados, por conveniência, 107 estudantes universitários, sendo 52 mulheres $(53,6 \%)$, com idade variando de 17 a 29 anos $(M=20,26, D P=2,82)$.

\section{Instrumentos e Materiais}

Zurich Prosocial Game. Foi utilizado o ZPG, descrito anteriormente, executado em um computador com acesso à internet. 
Instruções do ZPG. Este documento possui uma dupla finalidade. A primeira parte consistiu em um conjunto de instruções sobre os objetivos, as regras e o funcionamento geral do jogo. Em um segundo momento, apresentam-se um conjunto de cinco perguntas sobre situações do jogo, com o intuito de checar se o participante compreendeu as regras do ZPG (Apêndice F). As questões versavam sobre situações hipotéticas no jogo e questionavam o jogador sobre a possibilidade de abrir os portões a partir do uso das chaves existentes.

Interpersonal Reactivity Index (Apêndice G). Trata-se de uma escala para mensurar a empatia, construto associado ao comportamento prosocial. A escala foi adaptada para o português (Sampaio, Guimarães, Camino, Formiga, \& Menezes, 2011), e manteve os seus fatores originais: Fantasia (7 itens), Tomada de perspectiva (6 itens), Consideração empática (7 itens) e Angústia pessoal (6 itens). O processo de adaptação para o Brasil obteve alfas maiores que 0,72 para todos os fatores, o que pode ser considerado adequado para utilização. A escala é respondida por meio de uma escala Likert de 5 pontos, e será apresentada ao participante por meio do software EFS Survey. Neste estudo, a IRI obteve índices de confiabilidade de 0,69 para Fantasia, 0,90 para Consideração Empática, 0,73 para Angústia Pessoal e 0,64 para Tomada de Perspectiva.

Fator de amabilidade. De forma semelhante aos experimentos anteriores, este estudo utilizou a escala de amabilidade adaptada por Andrade (2008). Para este estudo, a escala atingiu um índice aceitável de confiabilidade $(\alpha=0,66)$.

Jogo do ditador. O jogo do ditador foi aplicado via EFS Survey, e foi utilizado como uma medida de validade convergente. Neste jogo, o participante foi informado que ele e o outro jogador do ZPG possuíam 10 números para participar de um sorteio e, em função de seu desempenho, o participante poderia definir quantos números ficariam com cada um dos participantes. A medida de comportamento prosocial para o jogo do ditador consiste na quantidade de números que o participante define para o suposto outro jogador. 
Questionários de dados demográficos e de avaliação do jogo. Foi utilizado o mesmo instrumento dos experimentos anteriores.

\section{Procedimentos}

Inicialmente, os textos da instrução e do instrumento de checagem de compreensão, bem como dos elementos textuais da interface do ZPG foram objetos de um processo de tradução feito por um tradutor com proficiência em tradução inglês-português. Após serem definidos os textos para o jogo, procedeu-se o processo de configuração propriamente dito, no qual todos os elementos textuais da interface foram modificados no código do jogo para o idioma português. Em seguida, foram configuradas as rodadas a serem utilizadas no jogo, e ele foi testado no computador de coleta de dados com o intuito de verificar possíveis erros de execução. Somente quando todos os erros foram eliminados o processo de coleta teve início.

Após este processo de configuração, os participantes foram convidados a participar da avaliação de um jogo digital, e foi informado que sua participação dava direito à concorrer em um sorteio de um gift card de uma livraria. Após a apresentação das informações gerais sobre o estudo e o consentimento do participante, foi solicitado que ele(ela) lesse as instruções do ZPG e respondesse às perguntas de checagem de compreensão.

Após esta etapa, os participantes foram convidados a jogar o ZPG. Não há duração definida de tempo, mas os participantes levaram aproximadamente 15 minutos para jogar todas as 14 etapas ( 4 rodadas de treino e 10 rodadas de teste). Após finalizar o jogo, o participante respondeu o questionário de avaliação do jogo. Em seguida, foi informado que o participante, em função de sua pontuação no jogo, deveria definir, de um total de dez chances no sorteio, quantas seriam alocadas para ele e para o outro jogador. O participante era informado que o outro participante não teria conhecimento de como as chances foram divididas, nem teria como alterar esta divisão. É importante ressaltar que todo este procedimento era feito por meio do formulário eletrônico, via $E F S$, e que o pesquisador não 
tinha acesso às informações digitadas durante o processo de coleta. Optou-se por este procedimento para que o participante não se sentisse inibido pela presença ou conhecimento do pesquisador acerca de sua resposta.

Após a resposta do participante, eram preenchidos os instrumentos de amabilidade, IRI e dados demográficos. Por fim, os participantes respondiam ao debriefing, e recebiam os esclarecimentos sobre a pesquisa.

\section{Procedimentos de análise de dados}

Inicialmente, o banco de dados foi analisado em busca de casos omissos ou extremos que possam comprometer as análises. Após a checagem dos pressupostos relevantes, foram realizadas Análises de Variâncias para medidas repetidas e análises de correlação. Para se verificar a correlação entre o comportamento de ajuda nos dois jogos (ZPG e ditador) fez-se uso da correlação de Spearman, uma vez que os dados do jogo do ditador não apresentaram uma distribuição normal.

\section{Resultados}

Inicialmente, verificou-se se os participantes apontaram, no debriefing, terem desconfiado de algo relacionado ao delineamento da pesquisa. De todos os participantes, apenas 10 deles $(9,4 \%)$ apontaram acreditar ter algo de estranho ou incomum na pesquisa. No entanto, uma análise pormenorizada das respostas indicou que indicou que 7 deles suspeitaram do comportamento do outro jogador (perceberam que estavam jogando contra o computador), e os outro 3 relataram corretamente os reais objetivos da pesquisa. Optou-se, considerando uma abordagem mais conservadora, por retirá-los do banco de dados final, resultando em uma amostra de 97 participantes.

Para avaliar o efeito das manipulações de reciprocidade, custo e pedido de ajuda no comportamento prosocial, realizou-se uma ANOVA para medidas repetidas intra-sujeitos, considerando o delineamento $2 \times 2 \times 2$ descrito anteriormente. Esta análise apresentou 
resultados significativos apenas para a variável reciprocidade, no qual a existência da condição de reciprocidade aumentou a frequência do comportamento de ajuda; as demais variáveis, bem como os efeitos de interação, não apresentaram resultados significativos $\left(p_{s}>\right.$ 0,05). A Tabela 3 detalha os resultados encontrados.

Tabela 3. Resultados da ANOVA para os efeitos principais e interações referentes às variáveis reciprocidade, custo e pedido de ajuda no comportamento de ajuda.

\begin{tabular}{lcccc}
\hline \hline \multicolumn{1}{c}{ Variável } & $d f$ & $F$ & $\eta^{2}$ parcial & $p$ \\
\hline Reciprocidade & $(1,96)$ & 78,96 & 0,45 & $<0,001$ \\
\hline Custo & $(1,96)$ & 3,06 & 0,03 & 0,083 \\
\hline Pedido de Ajuda & $(1,96)$ & 2,40 & 0,02 & 0,124 \\
\hline Reciprocidade X Custo & $(1,96)$ & 0,11 & 0,00 & 0,737 \\
\hline Reciprocidade X Pedido de Ajuda & $(1,96)$ & 1,98 & 0,02 & 0,163 \\
\hline Custo X Pedido de Ajuda & $(1,96)$ & 0,47 & 0,00 & 0,829 \\
\hline $\begin{array}{l}\text { Reciprocidade X Custo X Pedido de } \\
\text { Ajuda }\end{array}$ & $(1,96)$ & 0,00 & 0,00 & 1,000 \\
\hline \hline
\end{tabular}

Ao se analisar os dados de frequência do jogo do ditador, constata-se que a maior parte atribuiu entre $5(47,4 \%)$ e $4(11,3 \%)$ para o outro jogador. Somente 12 participantes doaram mais de 5 chances para o outro jogador (12,5\%), o que representaria um benefício maior para o outro do que para o participante. Em 28 casos $(28,9 \%)$, os participantes forneceram menos de quatro chances para o outro jogador, o que representaria um comportamento mais egoísta do participante.

De forma semelhante ao estudo original de Leiberg et al. (2011), esperava-se que houvesse uma correlação entre os resultados do jogo do ditador e do comportamento de ajuda no ZPG. Encontrou-se uma correlação positiva significativa, $\rho=0,297,95 \%$ IC [0,104, 0,468], $p=0,008$, indicando que quanto maior foi o comportamento de ajuda no ZPG, mais chances os participantes doaram para o outro jogador. 
Ao se analisar a influência do sexo no comportamento de ajuda tanto no ZPG quanto no jogo do ditador, não foram observados resultados significativos. Da mesma forma, a análise dos fatores de amabilidade e da Interpersonal Reactivity Index não apresentaram influência significativa.

\section{Discussão}

De forma geral, o processo de adaptação do Zurich Prosocial Game apresentou pontos positivos e negativos. O principal ponto negativo foi que, ao contrário dos resultados encontrados por Leiberg et al. (2011), o presente experimento não encontrou os efeitos esperados com relação às variáveis de custo e pedido de ajuda, uma vez que somente a manipulação da reciprocidade influenciou significativamente a ocorrência do comportamento de ajuda dentro do jogo. $\mathrm{O}$ fato do tamanho da amostra neste estudo ter sido superior ao do estudo original conta em favor das evidências encontradas; no entanto, mais estudos sobre o uso desta medida, ainda recente, devem ser realizados com o intuito de verificar o poder explicativo de cada uma das varíaveis passíveis de manipulação dentro do jogo.

Outro ponto relevante a ser apontado diz respeito à similaridade encontrada com relação à correlação entre o comportamento de ajuda e o jogo do ditador. Apesar da magnitude encontrada no presente experimento ter sido menor do que no estudo original, considera-se que o ZPG apresentou um índice de convergência suficientemente adequado para utilização como medida de comportamento prosocial no próximo experimento.

\section{Investigação do efeito da carga cognitiva na relação entre o papel em jogo e o comportamento prosocial.}

Apesar da existência de diversas evidências sobre o efeito dos jogos na cognição, são escassos os estudos que consideram a cognição como uma variável antecedente ou moderadora. Os relatos apresentados consideram, pela sua forma de mensuração, a cognição 
como uma variável dependente, afetada pelas características dos jogos. Em outras palavras, considera-se como o conteúdo e a natureza de determinados jogos podem afetar a cognição e o comportamento. No entanto, é necessário verificar se, de acordo com as relações propostas pelo GLM, a cognição pode ser entendida como um moderador entre o tipo de jogo e o comportamento humano. Mais do que isso, é necessário considerar, dentro da lógica proposta pelas abordagens mais contemporâneas de cognição social, quais são os subsistemas de processamento de informação envolvidos.

A lógica de um modelo dual de processamento, por exemplo, levanta questionamentos sobre quais são os processos mais relevantes para o estudo da influência de jogos eletrônicos, a saber, processos automáticos e/ou controlados (Kahneman, 2011). Algumas perspectivas teóricas descrevem como o modelo duplo de processamento vem sendo aplicado no estudo de diversos fenômenos como, por exemplo, processos decisórios, mudança de atitude, preconceito, discriminação e formação de impressão, o que sugere a relevância do modelo dual no processamento de uma variedade de construtos associados ao julgamento e comportamento humanos (Gawronski \& Creighton, 2006). Tais perspectivas teóricas partem do princípio que os seres humanos são processadores limitados de informação, o que demanda um processamento seletivo de estímulos e um gerenciamento dos recursos cognitivos de forma a propiciar o processamento de informações sem a necessidade do controle consciente (Jonides \& Irwin, 1981). É factível supor que o processamento de informações relacionadas aos jogos eletrônicos também contemple esses dois sistemas. No entanto, não há evidências sólidas sobre esta hipótese. Ademais, há evidências de que o comportamento prosocial pode ser afetado pela carga cognitiva e que traços disposicionais (como a empatia) podem ser mais influentes para o comportamento na ausência de recursos cognitivos para controlar o comportamento (Cappelletti, Güth, \& Ploner, 2011). 
Neste sentido, torna-se imprescindível a execução de estudos que manipulem diretamente variáveis relacionadas à cognição, com o intuito de verificar sua relevância na relação entre jogos e o comportamento. Exemplos de tais manipulações podem ser encontrados em estudos sobre outros construtos de interesse da psicologia social (Bargh et al., 2012), e os procedimentos geralmente envolvem uma tarefa simultânea de memorização de dígitos (Cavallo et al., 2012; Conway \& Gawronski, 2013; Sherman et al., 1998; Van Boven \& Robinson, 2012). No entanto, considera-se necessário garantir, considerando a natureza complexa e a forma de exposição aos jogos eletrônicos, que o indivíduo não utilize uma estratégia que permita que ele alterne seu foco de atenção, ou que a tarefa de carga cognitiva seja mais leve para um respondente do que outro (por exemplo, por meio de uma estratégia de memorização mais eficiente dos dígitos recebidos).

Outras estratégias utilizadas como manipulação de carga cognitiva estão relacionadas ao ritmo da tarefa principal. A realização de tarefas em situação de pressão temporal, por exemplo, pode ser entendida como uma medida de carga cognitiva, uma vez que reduz a possibilidade de ocorrência de processos deliberativos e insere uma tarefa de gestão de tempo (Cappelletti et al., 2011; Cornelissen, Dewitte, \& Warlop, 2011; Suter \& Hertwig, 2011). Outros delineamentos consideram a complexidade da tarefa como uma forma de manipular a carga cognitiva (Van Gog, Kester, \& Paas, 2011).

O presente estudo faz uso de tarefas concorrentes que demandem do participante monitoramento constante da tarefa concorrente. Exemplos de tarefas desta natureza consistem no monitoramento visual da tela em busca de estímulos específicos, como números ou formas geométricas, solicitando uma resposta do indivíduo a cada vez que tal estímulo estivesse presente (Greene eet al., 2008; Mattys \& Wiget, 2011). Desta forma, há a possibilidade de se inferir, por meio da quantidade de acertos do participante, se houve comprometimento com a tarefa concorrente. 
Dando continuidade ao processo de investigação proposto nesta tese, o próximo experimento teve como finalidade principal investigar o efeito da carga cognitiva na relação entre a função em jogo e o comportamento prosocial. Ainda, buscou investigar o papel da empatia nesta relação.

Para alcançar os objetivos propostos, o experimento consistiu em duas etapas distintas. Inicialmente, realizou-se um estudo piloto para testar a eficácia da manipulação de carga cognitiva proposta dentro do jogo por meio de uma tarefa concorrente de monitoramento auditivo. Após este procedimento, realizou-se o experimento principal. Para facilitar a compreensão das duas etapas, elas são apresentadas separadamente.

\section{Estudo piloto da manipulação de carga cognitiva}

A manipulação da carga cognitiva não é uma novidade dentro do campo da psicologia social (Baumeister, Bratslavsky, Muraven, \& Tice, 1998). Vários estudos que enfocam o processamento duplo de informações parte do pressuposto que a escassez de recursos cognitivos tem impacto em tarefas que necessitam de processamento controlado de informações (Kahneman, 2011). O impacto na carga cognitiva é estudado em processos relacionados a estereótipos, preconceitos e comportamentos de diferentes naturezas, como o comportamento prosocial (Cappelletti et al., 2011; DeWall et al., 2008; Fennis, 2011; Green, Sugarman, Medford, Klobusicky, \& Bavelier, 2012; Xu et al., 2012).

Um dos problemas em se utilizar este tipo de procedimento consiste em garantir não só o impacto na variável de interesse, mas também que o participante de fato está utilizando recursos atencionais para lidar com ele. É preciso minimizar a chance, por exemplo, que o participante utilize estratégias que permitam uma alternância eficiente de recursos atencionais entre as tarefas, ou que inibam a necessidade de manter a atenção na tarefa concorrente. Como exemplo, estudos fazem uso do procedimento de memorização de dígitos como tarefa 
concorrente (Cappelletti et al., 2011; Cavallo et al., 2012; Conway \& Gawronski, 2013). É fornecido ao participante um conjunto de dígitos que ele deve recuperar corretamente ao final do estudo. No entanto, o fato do participante relatar com sucesso os dígitos não significa necessariamente que ele, durante o período de execução da tarefa principal, utilizou recursos atencionais para, por exemplo, ensaiar repetidas vezes os estímulos.

Assim, este estudo piloto tem como finalidade verificar se o procedimento proposto de manipulação de carga cognitiva demanda do participante a alocação de recursos e, consequentemente, um maior esforço cognitivo para sua execução. Para isso, é utilizado um pareamento entre a tarefa principal (jogar o ZPG) e uma tarefa concorrente de monitoramento auditivo. Espera-se que a presença da tarefa concorrente a) esteja relacionada a uma menor ocorrência de comportamento prosocial dentro do ZPG e b) resulte em uma avaliação, por parte do participante, tanto de maior exigência cognitiva quanto de uma piora em seu desempenho, quando comparado a jogar o ZPG isoladamente.

\section{Método}

Utilizou-se um delineamento intra-sujeitos para testar a manipulação de carga cognitiva e seu impacto no comportamento de ajuda dentro do ZPG. Optou-se por esse delineamento uma vez que ele permite uma análise mais refinada da medida, uma vez que o participante é sua própria referência com relação ao efeito da variável independente na variável dependente (reduzindo o potencial efeito interveniente de variáveis individuais), além de tornar a pesquisa mais eficiente do ponto de vista do tamanho amostral necessário para garantir suficiente poder estatístico.

\section{Participantes}

Participaram do estudo piloto 32 estudantes universitários selecionados por conveniência, com idades variando de 18 a 32 anos $(M=20,26, D P=3,15), 26$ do sexo 
masculino e 31 cursando algum curso superior. Destes, 26 declararam jogar habitualmente algum tipo de jogo eletrônico.

\section{Instrumentos e materiais}

Zurich Prosocial Game. Foi utilizado o ZPG, bem como seu formulário de instruções, descritos anteriormente, executado em um computador com acesso à internet.

Ferramenta de manipulação da carga cognitiva. Foi desenvolvida uma ferramenta auxiliar ao ZPG para manipular a carga cognitiva dentro do jogo. Tal ferramenta consistiu em um banco de estímulos auditivos que, durante as rodadas do jogo, apresentava os estímulos aleatoriamente por meio de uma tarefa concorrente de monitoramento auditivo. Foram selecionados 13 numerais, recitados pelo programa Google Voice, na tentativa de garantir que sua natureza não competisse de alguma forma com os conteúdos do jogo. O programa permitia a definição de estímulos-alvo que, quando apresentados, eram associados a uma tecla específica no teclado. A ferramenta registrava automaticamente quando o participante pressionava a tecla, bem como o tempo de resposta do participante. Neste estudo, foram definidos 3 estímulos-alvo. Além disso, a ferramenta apresentava os estímulos em intervalos randomicamente variados, para evitar que o participante pudesse prever, com base no ritmo, quando o estímulo apareceria, gerando estratégias para alternar seu foco de atenção.

Questionários de avaliação do jogo. Foram utilizados dois questionários para avaliação do jogo nas diferentes etapas da pesquisa (condição sem manipulação de carga e com manipulação de carga). Ambos possuíam questões que solicitavam que o participante indicasse, por meio de uma escala de 7 pontos, sua percepção do quanto o jogo era difícil, agradável, frustrante e excitante. Além disso, os questionários possuíam questões para que o participante julgasse, naquela etapa de jogo, a) o quanto ele teve que se concentrar para cumprir as tarefas, b) o grau de dificuldade das tarefas solicitadas, c) o quão bem ele acreditava ter sido seu desempenho e d) o quão cansado ele se sentiu ao final da etapa 
(Apêndice H). A única diferença entre os questionários residia em um teste de recuperação livre dos estímulos-alvo (na condição de manipulação de carga), o que foi utilizado como medida de engajamento na tarefa concorrente.

Questionário demográfico e de hábitos de jogo. Este questionário foi o mesmo utilizado nas etapas anteriores.

\section{Procedimentos}

Inicialmente, os participantes eram convidados a ocupar o computador utilizado para visualização do jogo e preenchimento dos questionários. O objetivo da pesquisa relatado aos participantes neste momento era o de investigar o desempenho dos indivíduos em diversos jogos de computador. Após uma explicação geral da pesquisa, os participantes liam as instruções do ZPG e respondiam às questões de compreensão das regras do jogo. Após este procedimento, o participante era alocado randomicamente pelo programa a uma de duas ordens de aplicação, tendo ou a condição sem manipulação de carga ou a com manipulação de carga como primeira (para verificar, a posteriori, se havia um efeito de ordem na resposta dos participantes).

Os participantes então, jogavam a primeira etapa do ZPG, que consistiu em 3 etapas de treino e 10 etapas de teste, nas quais a variável reciprocidade era manipulada (5 rodadas para cada nível da variável). Após este procedimento, o participante era solicitado a preencher o instrumento de avaliação do jogo/etapa. Após finalizar o preenchimento, a segunda etapa de aplicação do ZPG tinha início, seguida da segunda aplicação do instrumento de avaliação. Por fim, os participantes respondiam ao questionário demográfico e de hábitos de jogo, respondiam ao debriefing e eram esclarecidos acerca dos reais objetivos do estudo. 


\section{Procedimento de análise de dados}

Inicialmente, realizou-se a análise das variáveis de avaliação de jogo, percepção de carga, comportamento de ajuda e tempo de ajuda om relação às medidas de tendência central e de dispersão, em busca de indícios de normalidade. Considerando que as variáveis em questão não apresentavam distribuição similar à normal, optou-se por utilizar testes nãoparamétricos para medidas repetidas

\section{Resultados}

\section{Análises preliminares}

Inicialmente, verificou-se o índice de acertos da tarefa de recuperação dos estímulosalvo como teste do quanto os participantes estavam engajados e concentrados na tarefa concorrente. Índices muito baixos de acerto poderiam significar que os participantes ignoraram a tarefa, o que poderia influenciar de forma significativa a eficácia da manipulação da variável de carga cognitiva. Observou-se que 90,9\% dos participantes recuperaram corretamente os três estímulos-alvo (30 casos), e 9,1\% deles recuperou corretamente pelo menos dois deles (3 casos).

Com o intuito de testar se a ordem de apresentação das etapas resultou em efeitos indesejados na pesquisa, realizou-se uma série de testes não-paramétricos de comparação de grupos. Com relação ao comportamento de ajuda no ZPG, observou-se uma ocorrência similar para a condição em que havia a tarefa concorrente de manipulação de carga, $U=144$, $z=0,693, p=0,512, r=0,12$, independente dela ter ocorrido como primeira $(M d n=5,00)$ ou segunda $(M d n=3,50)$ etapa. $O$ mesmo resultado foi encontrado para a condição sem a tarefa concorrente de manipulação de carga como primeira $(M d n=7,0)$ ou segunda etapa $(M d n=$ $8,00), U=154, z=1,079, p=0,301, r=0,19$. 


\section{Análises principais}

Em seguida, procedeu-se a análise do efeito das variáveis de Carga Cognitiva e Reciprocidade no comportamento de ajuda dentro do ZPG. Análises de Wilcoxon não pontaram diferenças significativas para a manipulação de reciprocidade, $z=-0,26, p=0,979$, $r=0,05$; no entanto, foram encontradas diferenças significativas para a manipulação da carga cognitiva, $z=3,77, p<0,001, r=0,67$, no sentido de que o comportamento de ajuda foi maior quando a tarefa concorrente de manipulação da carga cognitiva não estava presente $(M d n=8,0)$ do que quando ela estava $(M d n=4,5)$.

Ao se comparar a avaliação do jogo e a percepção de carga das tarefas em cada etapa, as análises de Wilcoxon apontaram diferenças significativas com relação à dificuldade, à agradabilidade do jogo e à frustração, bem como à exigência de concentração, dificuldade de execução das tarefas e percepção de desempenho (Tabela 4).

Tabela 4. Comparação das avaliações de jogo e da percepção de carga das tarefas em função das condições experimentais $(\mathrm{N}=32)$.

\begin{tabular}{lccccc}
\hline \multirow{2}{c}{ Variável } & $z$ & $p$ & $r$ & \multicolumn{2}{c}{ Medianas } \\
\cline { 5 - 6 } & & & & Com carga & Sem carga \\
\hline Dificuldade do jogo & 4,58 & $<0,001$ & 0,81 & 3,00 & 1,00 \\
\hline Agradabilidade do jogo & 2,43 & 0,015 & 0,43 & 5,00 & 6,00 \\
\hline Frustração com o jogo & 2,94 & 0,003 & 0,52 & 2,00 & 1,00 \\
\hline Excitação com o jogo & 0,79 & 0,427 & 0,14 & 5,00 & 4,00 \\
\hline $\begin{array}{l}\text { Necessidade de } \\
\text { concentração }\end{array}$ & 3,93 & $<0,001$ & 0,69 & 5,00 & 2,00 \\
\hline Dificuldade das tarefas & 3,66 & $<0,001$ & 0,65 & 3,00 & 1,00 \\
\hline Desempenho nas tarefas & 3,17 & 0,002 & 0,56 & 4,00 & 4,00 \\
\hline Cansaço após tarefas & 1,68 & 0,093 & 0,30 & 2,00 & 1,00 \\
\hline \hline
\end{tabular}

\section{Discussão}

O objetivo deste piloto foi verificar o grau de adequação da tarefa concorrente de monitoramento como manipulação da variável Carga Cognitiva. Esperava-se que a tarefa, da 
forma como foi desenhada, resultasse em uma redução na ocorrência de comportamentos prosociais (em função da necessidade de alocar recursos atencionais para a tarefa concorrente em detrimento da tarefa principal). Além disso, esperava-se que os participantes relatassem uma percepção maior de esforço cognitivo envolvido na realização das tarefas simultaneamente, bem como uma percepção de uma piora em seu desempenho. Por fim, esperava-se que os participantes relatassem uma avaliação diferenciada do jogo em função da presença ou não da tarefa concorrente.

Com relação ao impacto no comportamento de ajuda, observou-se o efeito esperado, uma vez que a presença da tarefa concorrente reduziu a frequência do comportamento prosocial. Este resultado é condizente com estudos que sugerem, por exemplo, que o comportamento prosocial exige a execução de um processamento controlado da informação e que, em situações de escassez de recursos cognitivos, a frequência de comportamentos desta natureza tende a diminuir (DeWall et al., 2008).

Com relação à percepção de exigência cognitiva, os resultados mais uma vez dão suporte para as hipóteses postuladas, uma vez que os participantes percebem que a existência da tarefa concorrente torna a tarefa principal mais difícil, demanda maior concentração e tem um impacto negativo em seu desempenho. Contudo, não se observou diferença com relação à percepção de cansaço, talvez por considerar que as tarefas propostas, de forma geral, não são exigentes em demasia (mesmo com a existência da tarefa concorrente). Da mesma forma, os participantes tenderão a perceber o jogo como mais difícil, menos agradável e mais frustrante quando a tarefa concorrente estava presente. Tal avaliação faz sentido se considerarmos que a inserção de mais uma tarefa traz dificuldades adicionais para o cumprimento da tarefa principal.

Por fim, considera-se que a manipulação da carga cognitiva atingiu os objetivos propostos para este teste piloto. A utilização deste procedimento traz benefícios quando 
comparados aos procedimentos tradicionais (como, por exemplo, de memorização de dígitos) de manipulação de carga, uma vez que exige tanto o processo de memorização dos estímulosalvo como o monitoramento ativo do canal auditivo em busca de tais estímulos. A seguir, será apresentado o experimento em que esta medida será utilizada.

\section{Experimento 6 - Investigação da influência da carga cognitiva no comportamento de ajuda}

Neste experimento, pretendeu-se investigar o impacto da manipulação de carga cognitiva na relação entre a função jogada (prosocial ou violenta) no comportamento prosocial e na avaliação do jogo e de exigência cognitiva. Ainda, buscou-se analisar o papel de traços de empatia e amabilidade nesta relação.

Assim como nos experimentos anteriores, este estudo se fundamenta nas evidências da literatura acerca de um efeito positivo de jogos prosociais em cognições e comportamentos prosociais (Gentile et al., 2009; Greitemeyer \& Mügge, 2014; Greitemeyer \& Mügge, 2015; Greitemeyer \& Osswald, 2010; Peng et al., 2010; Saleem et al., 2012a). De acordo com essa premissa, espera-se que o jogo ative, de acordo com a lógica apresentada pelo GLM, conteúdos coerentes com a sua natureza - no caso, prosocial - e que tal ativação gere um impacto nas dimensões afetivas, cognitivas e comportamentais. Além disso, espera-se que a existência de recursos cognitivos esteja relacionada ao resultado deste processamento, resultando em ações impulsivas ou controladas (Barlett \& Anderson, 2013; Buckley \& Anderson, 2006; Huesmann, 2007; Prot et al., 2013).

Conforme apontado anteriormente, são escassos os estudos que buscam avaliar as consequências da escassez de recursos na relação entre o tipo de jogo e o comportamento prosocial, principalmente ao se considerar as evidências existentes entre o comportamento prosocial em si e as demandas em termos de recursos cognitivos. Caso o comportamento 
prosocial seja entendido como uma atividade que demanda processos ativos de autoregulação, é factível supor que a frequência de comportamentos desta natureza venha a diminuir caso o indivíduo se encontre em situações de escassez de recursos (DeWall et al., 2008; Gailliot, 2010). Além disso, há evidências que a escassez de recursos esteja associada à uma redução de processos empáticos e de tomada de perspectiva, o que também poderia reduzir a ocorrência de comportamentos prosociais (Fennis, 2011). Considerando que a empatia também está relacionada como um dos fatores de explicação na relação entre jogos prosociais e comportamento (Greitemeyer, 2013a; Greitemeyer et al., 2010; Prot et al., 2013), faz-se necessário investigar de forma mais aprofundada a relação entre o tipo de jogo, a carga cognitiva, as medidas de empatia e o comportamento prosocial propriamente dito. Com relação ao comportamento prosocial, considera-se fundamental aprofundar a discussão sobre como o GLM considera o impacto da disponibilidade de recursos cognitivos, uma vez que o modelo sugere que ela somente influenciaria no tipo de manifestação do comportamento, impulsivo ou controlado (Buckley \& Anderson, 2006), mas não sua natureza (agressiva ou prosocial, por exemplo). De acordo com o modelo, a influência da mídia ocorreria sempre da forma prevista, mudando somente a forma como ele se manifestaria, o que vai de encontro aos efeitos apontados pela literatura acerca da relação entre recursos cognitivos e comportamento prosocial.

Em função disso, foi executado um experimento com delineamento 2 (Função em jogo: prosocial, violento) X 2 (Carga cognitiva: alta ou baixa) para se testar as seguintes hipóteses: 1) Indivíduos expostos ao personagem com uma função prosocial apresentarão maior comportamento prosocial quando comparados ao personagem com função violenta; 2) A situação de alta carga cognitiva resultará em menor ocorrência de comportamento prosocial; 3) Haverá uma interação entre a função desempenhada em jogo e a carga cognitiva na ocorrência de comportamentos prosociais; 4) A empatia atuará como moderadora entre a 
função desempenhada e o comportamento prosocial; 5) A amabilidade atuará como moderadora entre a função desempenhada e o comportamento prosocial. Por fim, utilizou-se a reciprocidade no ZPG como variável intra-sujeitos para verificar uma possível influência da reciprocidade na relação entre comportamento de ajuda e função jogada.

\section{Método}

\section{Participantes}

Participaram da pesquisa 38 estudantes universitários com idades variando de 19 a 40 anos $(M=23,29, D P=1,17)$, sendo 24 do sexo feminino $(63,2 \%), 33$ com curso superior incompleto $(86,8 \%)$ e sem histórico de crises epiléticas ou patologias igualmente sensíveis aos estímulos gerados pelo videogame. De todos os participantes, apenas 20 deles $(52,6 \%)$ relataram jogar regularmente, com uma média de 8,11 horas semanais $(D P=11,97)$.

Os participantes foram selecionados por conveniência nas disciplinas da universidade, e receberam pontuação em disciplinas como remuneração pela participação na pesquisa. A designação dos participantes foi aleatória para cada condição experimental.

\section{Instrumentos e Materiais}

Para a apresentação do jogo, foi necessário um computador e monitor compatíveis com as especificações do jogo, bem como de um joystick dualshock ligado ao computador. Este equipamento foi alocado em uma mesa que permitia a visualização do monitor em um ângulo reto, sem focos de ofuscamento na tela. Além disso, o procedimento foi aplicado em uma sala individual e sem interrupções externas. Foram utilizados os seguintes instrumentos: Jogo para manipulação da função no Jogo - Field of Valor(FoV). Utilizou-se o jogo digital desenvolvido no Experimento 4. Ele foi configurado para que fossem utilizadas duas funções, prosocial e violenta, mas não houve manipulação do nível de dificuldade (em ambos os casos, foi mantido um nível médio de dificuldade) ou dos elementos constantes na cena 
(como explosões e presença de sangue. Neste sentido, foram utilizados elementos coerentes com as funções específicas).

Medidas disposicionais. Como medidas disposicionais, foram utilizadas a adaptação brasileira da Interpersonal Reactivity Index (Sampaio et al., 2011), por entender-se que o comportamento de ajuda pode ser intensificado em função da capacidade do indivíduo de se colocar no lugar daquele que necessita de ajuda, bem como a medida da dimensão de amabilidade dos 5 grandes fatores de Personalidade (Andrade, 2008), adaptada para o português e já utilizada nos Experimentos 2 e 3. Estas escalas foram aplicadas eletronicamente nos participantes. Neste experimento, os fatores obtiveram os seguintes índices de confiabilidade: amabilidade $(\alpha=0,60)$, IRI-Fantasia $(\alpha=0,63)$, IRI-Consideração Empática $(\alpha=0,78)$, IRI-Angústia Pessoal $(\alpha=0,87)$ e IRI-Tomada de Perspectiva $(\alpha=$ $0,69)$.

ZPG com manipulação da carga cognitiva. Foram utilizadas as mesmas ferramentas computacionais do teste piloto, com as mesmas configurações. O ZPG foi utilizado tanto como medida do comportamento prosocial quanto como ferramenta de manipulação da variável reciprocidade. Além disso, utilizou-se o formulário de instruções do ZPG. Questionários de avaliação de jogo, PANAS, dados demográficos e hábitos de uso. Foram utilizados os mesmos instrumentos utilizados nos Experimentos 1, 2 e 3. Todos os questionários foram aplicados eletronicamente aos participantes.

\section{Procedimentos}

Os participantes foram informados que se tratava de uma pesquisa sobre atenção dividida (na condição de alta carga cognitiva) ou sobre a avaliação da qualidade do jogo (na condição de baixa carga cognitiva). Em seguida, o jogador recebeu instruções básicas acerca do primeiro jogo (FoV), incluindo o objetivo geral do jogo (a depender da função sorteada (prosocial ou violenta) e os comandos básicos de movimentação do personagem. No caso da 
condição prosocial, o participante foi informado que seu objetivo era curar o máximo possível de pessoas feridas na tela, utilizando todos os recursos à sua disposição, e que sua pontuação refletiria a quantidade de pessoas que ele salvou. No caso da condição violenta, a orientação fornecida foi a de que o participante faria mais pontos em função da quantidade de inimigos que ele destruísse durante o tempo de jogo. Em seguida, o participante foi instruído a jogar uma fase de treino para que se familiarizasse com o jogo. Esta fase se consistiu em um tutorial em que o participante exercitava os comandos básicos de seu personagem a partir de instruções apresentadas pelo próprio jogo. Após o período de treino, foi solicitado que ele jogasse o jogo FoV por 10 minutos.

Depois da fase de jogo, o participante foi solicitado a avaliar o jogo e a percepção de exigência cognitiva. Em seguida, foi convidado a jogar o ZPG (de acordo com os mesmos procedimentos do Experimento 5). Da mesma forma, o ZPG contou com 4 rodadas de treino para que o participante se familiarizasse com a mecânica do jogo.

Na condição de alta carga cognitiva, foi esclarecido que o participante deveria, enquanto joga buscando o melhor desempenho possível, executar outra tarefa. Esta tarefa consistiu em monitorar um conjunto de sons por um fone de ouvido, e o participante foi solicitado a pressionar uma tecla específica no teclado (não utilizada na mecânica do jogo) a cada momento em que um som específico for ouvido. É importante ressaltar que o participante foi informado que identificações bem-sucedidas dos estímulos-alvo acarretariam em uma maior pontuação geral no jogo (como forma de incentivar o engajamento tanto na tarefa principal quanto na concorrente). Na condição de baixa carga cognitiva, foram utilizadas as instruções normais do ZPG. Os participantes levavam aproximadamente 15 minutos para jogar o ZPG.

Após o período de jogo, os participantes foram solicitados a responder novamente o instrumento de avaliação do jogo e de exigência cognitiva e proceder a recuperação livre dos 
estímulos-alvo (no caso da condição de alta carga cognitiva), além de preencher o questionário demográfico e de hábitos de jogo e as escalas de amabilidade e de empatia. Por fim, realizou-se um debriefing do participante e os reais objetivos da pesquisa foram esclarecidos.

\section{Procedimentos de análise de dados}

Inicialmente, investigou-se o conjunto de dados obtidos com o intuito de verificar se os pressupostos para as análises paramétricas foram respeitados. Considerando que grande parte dos dados apresentou uma distribuição que violava os pressupostos de normalidade, e considerando também o tamanho da amostra obtida, optou-se por utilizar análises nãoparamétricas comparação de grupos e para análise de medidas repetidas. Análises paramétricas de Regressão foram utilizadas para a análise de moderação.

\section{Resultados}

\section{Análises preliminares - checagem de manipulação}

Inicialmente, buscou-se verificar se os participantes percebiam o Jogo FoV de forma condizente com as condições experimentais pré-estabelecidas. Esperava-se que os participantes julgassem o jogo de forma distinta somente para o critério de violência do jogo, uma vez que esta é a dimensão que diferencia as funções jogadas (violenta ou prosocial). De forma consistente com as predições estabelecidas, verificou-se que os participantes que desempenharam a função violenta no jogo o percebiam como mais violento $(M d n=5,00)$ do que os que desempenharam a função prosocial $(M d n=1,00), U=40,00, z=-4,26, p<0,001$, $r=-0,69$. Para todos os outros critérios, não foi encontrada diferença significativa tanto para os critérios de avaliação do jogo quanto de exigência cognitiva das tarefas (Tabela 5). 
Tabela 5. Teste Mann-Whitney para comparação das avaliações de jogo e da percepção de carga das tarefas de acordo com a função jogada - violenta ou prosocial $(\mathrm{N}=38)$.

\begin{tabular}{lcccccc}
\hline \hline & $U$ & $z$ & $p$ & $r$ & \multicolumn{2}{c}{ Medianas } \\
\cline { 6 - 7 } Variável & & & & & 2,00 & 3,00 \\
\hline Dificuldade do jogo & 148,50 & $-0,96$ & 0,354 & $-0,16$ & 5,00 & 6,00 \\
\hline Agradabilidade do jogo & 152,00 & $-0,86$ & 0,418 & $-0,14$ & 2,00 & 1,00 \\
\hline Frustração com o jogo & 127,50 & $-1,63$ & 0,123 & $-0,26$ & 2,00 & Prosocial \\
\hline Excitação com o jogo & 168,00 & $-0,38$ & 0,729 & $-0,06$ & 5,00 & 4,00 \\
\hline Violência do jogo & 40,00 & $-4,26$ & $<0,001$ & $-0,69$ & 5,00 & 1,00 \\
\hline Necessidade de & 150,50 & $-0,92$ & 0,385 & $-0,15$ & 4,00 & 4,00 \\
concentração & 163,00 & $-0,53$ & 0,624 & $-0,15$ & 2,00 & 2,00 \\
\hline Dificuldade das tarefas & 175,50 & $-0,15$ & 0,885 & $-0,02$ & 3,00 & 3,00 \\
\hline Desempenho nas tarefas & 17,50 & $-0,75$ & 0,506 & $-0,12$ & 2,00 & 1,00 \\
\hline Cansaço após tarefas & 157,00 & & & &
\end{tabular}

Da mesma forma, verificou-se se a avaliação do ZPG variava em função da condição jogada (com carga cognitiva ou sem carga cognitiva). Esperava-se que a percepção dos participantes somente se diferenciasse nos critérios mais relacionados a um aumento nas exigências dentro do jogo. A Tabela 6 sintetiza os resultados encontrados. De acordo com o esperado, os participantes que jogaram o ZPG nas condições onde havia a manipulação de carga cognitiva tenderam a avaliar o jogo como mais difícil $(U=41,00, z=-4,16, p<0,001$, $r=-0,67)$ e mais frustrante $(U=85,50, z=-2,82, p=0,005, r=-0,46)$ do que aqueles que experimentaram o jogo sem a tarefa concorrente. Além disso, julgaram que havia maior necessidade de concentração $(U=90,50, z=-2,90, p=0,008, r=-0,47)$, que as tarefas propostas eram mais difíceis $(U=51,50, z=-3,87, p<0,001, r=-0,63)$ e que seu desempenho foi pior $(U=96,50, z=-2,53, p=0,013, r=-0,41)$ do que aqueles que experimentaram o ZPG sem a tarefa concorrente. 
Tabela 6. Teste Mann-Whitney para comparação das avaliações de jogo e da percepção de carga das tarefas de acordo com a condição jogada no ZPG $(\mathrm{N}=38)$.

\begin{tabular}{lcccccc}
\hline \hline & $U$ & $z$ & $p$ & $r$ & \multicolumn{2}{c}{ Medianas } \\
\cline { 6 - 8 } Variável & & & & & Sem Carga & Com Carga \\
\hline Dificuldade do jogo & 41,00 & $-4,16$ & $<0,001$ & $-0,67$ & 2,00 & 5,00 \\
\hline Agradabilidade do jogo & 153,50 & $-0,80$ & 0,435 & $-0,13$ & 5,00 & 5,00 \\
\hline Frustração com o jogo & 85,50 & $-2,82$ & 0,005 & $-0,46$ & 2,00 & 4,00 \\
\hline Excitação com o jogo & 165,00 & $-0,46$ & 0,665 & $-0,07$ & 4,00 & 4,00 \\
\hline Violência do jogo & 155,00 & $-0,96$ & 0,470 & $-0,16$ & 1,00 & 1,00 \\
\hline Necessidade de & 90,50 & $-2,90$ & 0,008 & $-0,47$ & 4,00 & 5,00 \\
concentração & 51,50 & $-3,87$ & $<0,001$ & $-0,63$ & 2,00 & 4,00 \\
\hline Dificuldade das tarefas & 96,50 & $-2,53$ & 0,013 & $-0,41$ & 4,00 & 3,00 \\
\hline Desempenho nas tarefas & 141,50 & $-1,17$ & 0,258 & $-0,19$ & 2,00 & 3,00 \\
\hline Cansaço após tarefas & 14,50 & & &
\end{tabular}

Com relação às medidas de amabilidade e de empatia, não foram encontradas diferenças entre os grupos $\left(p_{s}>0,76\right)$.

\section{Análises principais}

Primeiramente, foram realizadas análises para avaliar, separadamente, os efeitos da função jogada e da carga cognitiva no comportamento de ajuda dentro do ZPG. Com relação à função jogada, observou-se que não há diferença significativa na frequência de ajuda, $(U=$ $224,00, z=1,30, p=0,212, r=-0,21)$. Quando se analisa o efeito da carga cognitiva, no entanto, observa-se que os participantes na condição sem carga cognitiva ajudaram mais $(M d n=8,00)$ do que na condição com carga cognitiva $(M d n=1,00),(U=95,00, z=-2,56, p$ $=0,012, r=-0,42)$.

Ao se analisar a interação entre as estas duas variáveis independentes, por meio da análise de Kruskall-Wallis, observa-se que a sua influência no comportamento de ajuda ainda permanece significativa, $H(3)=14,22, p=0,003$. No entanto, ao se observar as comparações pareadas, verificou-se que esta diferença ocorre somente entre as condições Violenta Com 
Carga e Prosocial Sem Carga, $p=0,002, r=-0,59$ e Prosocial Com Carga e Prosocial Sem Carga, $p=0,016, r=0,50$ (Figura 11).

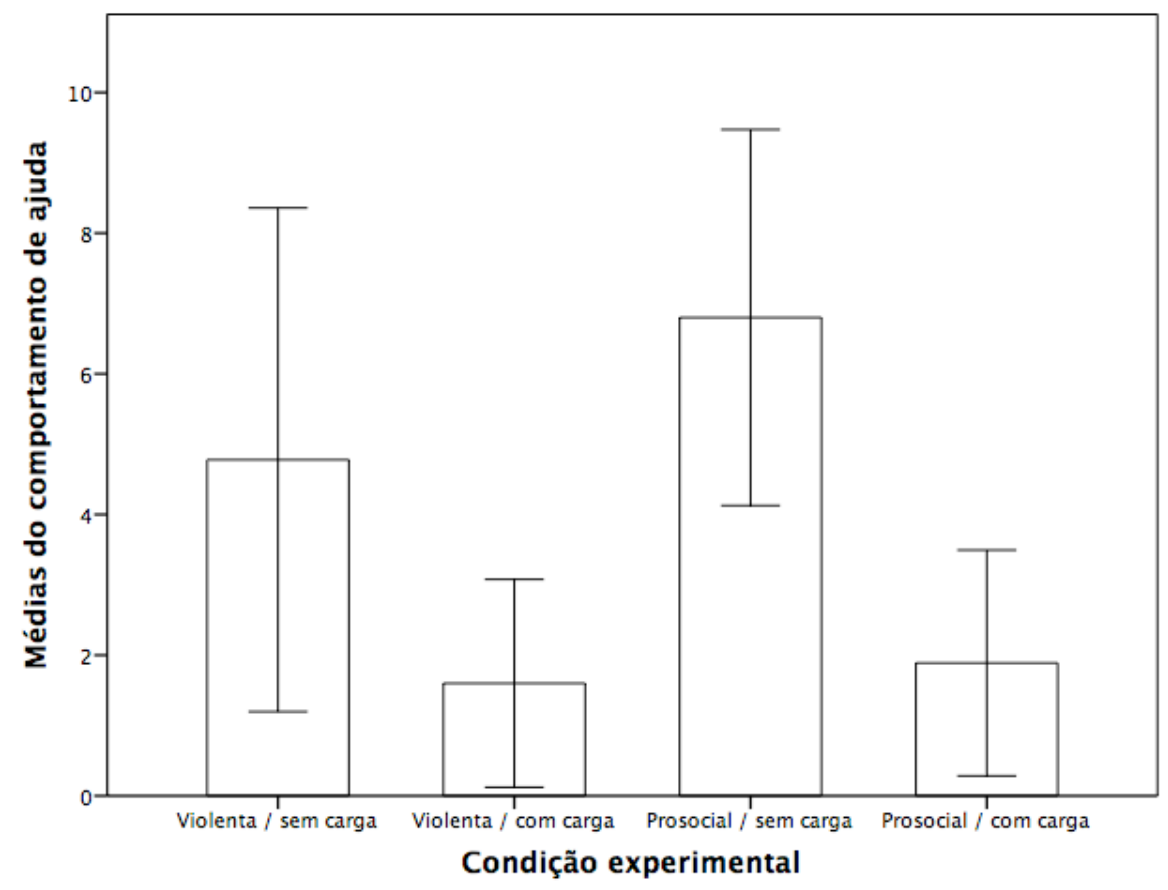

Barras de Erro: $95 \%$ IC

Figura 11. Médias do comportamento de ajuda por condição $(\mathrm{N}=38)$. As barras de erro representam o Intervalo de Confiança (95\%).

Por fim, foram realizadas análises de moderação com o intuito de verificar a influência dos traços de amabilidade e de empatia na relação entre o comportamento prosocial e as variáveis de função jogada e de carga cognitiva. Com relação à amabilidade, análises de moderação não encontraram resultados significativos considerando o efeito da função jogada, $F(3,34)=1,51, p=0,229$. Com relação à moderação na relação entre a carga cognitiva e o comportamento de ajuda, apesar de existir o efeito principal do modelo, $F(3,34)$ $=4,62, p=0,008$, este efeito se dá somente em função da carga cognitiva (conforme visto anteriormente), e não da interação com a amabilidade, $t=0,32, p=0,754$. 
Ao se considerar a medida de empatia, por meio dos fatores da IRI, todas as análises de moderação, considerando ambas as variáveis independentes, apresentaram resultados não significativos tanto para o efeito principal quanto para os efeitos de interação $\left(p_{s}>0,005\right)$.

\section{Discussão}

O presente experimento teve como objetivo principal avaliar o efeito da manipulação de carga cognitiva na relação entre a função jogada e a ocorrência do comportamento prosocial. Com isso, esperava-se encontrar evidências que pudessem contribuir para a melhor compreensão do papel de processos automáticos e controlados no efeito dos jogos sobre o comportamento prosocial.

Em consonância com os experimentos anteriores desta tese, não foram encontrados os efeitos principais relacionados à função no jogo e o comportamento prosocial. Apesar dos estudos comumente utilizarem jogos diferentes para se manipular o nível de prosocialidade e violência do jogo (Greitemeyer \& Mügge, 2014; Greitemeyer \& Osswald, 2009, 2010), era esperado que fossem encontrados efeitos semelhantes manipulando-se somente a função que o participante executa no jogo, uma vez que os objetivos, mecânica e sistema de recompensas do jogo são consonantes com a função desempenhada pelo jogador. Estes elementos são parte constituintes do jogo em si e são responsáveis pela experiência que o jogador tem com o jogo. Mais do que isso, compõem o sistema de reforçamento e treino que fundamenta a racional por trás do principal modelo explicativo utilizado atualmente, o general learning model (Barlett \& Anderson, 2013; Buckley \& Anderson, 2006; Huesmann, 2007; Prot et al., 2013). Neste sentido, considera-se a Hipótese 1 deste experimento não pôde ser sustentada pelas evidências encontradas (Indivíduos expostos ao personagem com uma função prosocial apresentarão maior comportamento prosocial quando comparados ao personagem com função violenta). 
Um ponto que diferencia este experimento dos Experimentos 1, 2 e 3 é o uso de um jogo criado especificamente para esta tese. O jogo Field of Valor, cujo desenvolvimento e pré-teste foi apresentado no Experimento 4, permitiu a manipulação da função de jogo mantendo outras características do jogo o mais similar possível dentro das condições. Apesar de ser improvável considerar as duas condições idênticas, os resultados apresentados sugerem que os participantes julgaram os dois modos do jogo (prosocial e violento) diferentes somente com relação à dimensão de violência, tendo as outras dimensões sido consideradas semelhantes. Esta análise é similar ao que é comumente feito pela literatura (por exemplo, Greitemeyer \& Osswald, 2010) e permite inferir que a manipulação da função de jogo foi feita com sucesso.

Com relação à manipulação da carga cognitiva, a checagem de manipulação utilizada - com base na diferença de desempenho ou de percepção de esforço entre as condições também é coerente com os esforços apresentados na literatura (Cavallo et al., 2012; Conway \& Gawronski, 2013; Cornelissen et al., 2011; Greene et al., 2008; Mattys \& Wiget, 2011; Suter \& Hertwig, 2011), e os resultados encontrados sugerem sucesso em sua execução. Além disso, os resultados principais indicam que, em situação de alta carga cognitiva, o comportamento prosocial tende a ter sua ocorrência reduzida, evidência coerente com achados de outros estudos (DeWall et al., 2008; Gailliot, 2010), o que sugere que esta classe de comportamentos demanda a disponibilidade de recursos cognitivos e que, em situação de escassez, comportamentos mais egoístas se manifestem mais facilmente. Considera-se, neste sentido, que as evidências encontradas dão suporte à Hipótese 2 ( $A$ situação de alta carga cognitiva resultará em menor ocorrência de comportamento prosocial).

Ao se analisar o possível efeito de interação entre as duas variáveis independentes, as evidências sugerem que o efeito da carga cognitiva foi mais expressivo na condição de jogo prosocial, uma vez que os participantes que jogaram o jogo prosocial sem a existência da 
tarefa concorrente de monitoramento apresentaram maior ocorrência de comportamento prosocial quando comparados aos participantes das condições com carga. No entanto, o mesmo não aconteceu para as condições onde a função violenta estava presente no jogo. Com isso, os resultados oferecem suporte parcial à Hipótese 3 deste estudo (Haverá uma interação entre a função desempenhada em jogo e a carga cognitiva na ocorrência de comportamentos prosociais em jogo).

Caso tais evidências estejam corretas, é possível supor a existência de um efeito de interação entre a função do jogo e a carga cognitiva, algo que não foi considerado pela maioria dos estudos anteriores (Greitemeyer \& Mügge, 2014). Sugere, de forma semelhante aos estudos acerca do efeito da dificuldade e ritmo do jogo na relação entre jogos violentos e os principais efeitos encontrados pela literatura (Adachi \& Willoughby, 2011; Elson, Breuer, Looy, Kneer, \& Quandt, 2013; Kneer, Elson, \& Knapp, 2016), a existência de outros elementos que devem ser considerados ao se investigar a relação entre jogos digitais (e suas características) e sua influência no comportamento. No caso específico relacionado ao comportamento prosocial, as evidências da literatura são escassas ao relacionar o efeito da carga cognitiva na relação entre jogos prosociais e comportamento. Os resultados encontrados neste experimento, considerando as duas variáveis independentes, apontam para uma discussão ainda não realizada na literatura acerca do general learning model acerca dos resultados dos processos de avaliação dos estímulos que compõem a experiência com os jogos digitais.

Como já explicitado anteriormente, o GLM pressupõe que a disponibilidade de recursos cognitivos influencia na forma como o comportamento (resultado do processo avaliativo do indivíduo) pode ocorrer. Quando há recursos disponíveis, as ações do indivíduo são controladas; quando não há, as ações são impulsivas (Buckley \& Anderson, 2006). Não há previsão, no modelo, de uma alteração na natureza do comportamento resultante do 
processo de interação com os estímulos do jogo digital. Contudo, o que os resultados encontrados neste experimento sugerem é a chance do comportamento prosocial ocorrer depende da quantidade de recursos que o indivíduo possui no momento em que tal comportamento é demandado.

Uma explicação possível é que, dentro do modelo, a distinção entre comportamentos controlados e impulsivos já consideraria, por exemplo, evidências de que os comportamentos prosociais dependeriam de maior controle por parte dos indivíduos, e que o comportamento egoísta seria mais intuitivo, ou impulsivo (DeWall et al., 2008). Uma explicação semelhante foi abordada pelo modelo no qual o GLM se baseia, o general aggression model. Nele, a disponibilidade de recursos cognitivos é relevante para se controlar a manifestação de comportamentos não adequados socialmente, como é o caso de comportamentos agressivos (Anderson \& Bushman, 2002). No entanto, tal hipótese não foi devidamente considerada pelos autores do GLM ao estenderem o modelo a uma gama de comportamentos além do comportamento agressivo e as relações existentes na literatura entre o comportamento prosocial e a disponibilidade de recursos cognitivos não foram abordadas.

Outra possível explicação é que os resultados existentes na literatura acerca da influência de jogos no comportamento prosocial tenha uma a carga cognitiva como uma variável interveniente, caso os jogos violentos sejam mais demandantes do ponto de vista de mecânica e complexidade do que os jogos prosociais (considerando que a literatura comumente utiliza jogos diferentes para caracterizar cada condição experimental). Se considerada factível, tal explicação pode demandar uma mudança significativa no GLM e na forma como as evidências que suportam este modelo são interpretadas. No entanto, para que esse raciocínio seja aprofundado, é fundamental que outros estudos manipulem a carga cognitiva, seja por meio da apresentação de tarefas concorrentes ou pela manipulação da dificuldade do jogo utilizando um mesmo jogo digital, sejam realizados. 
Com relação às variáveis de empatia e amabilidade, não foram encontrados efeitos, principais ou de moderação, associados a essas variáveis, o que contradiz evidências da literatura tanto na área de comportamento prosocial (DeWall et al., 2008; Gailliot, 2010; Graziano et al., 2007; Hilbig et al., 2014; Xu et al., 2012) quanto na área de influência de jogos digitais (Greitemeyer, 2013a; Greitemeyer et al., 2010; Prot et al., 2013). No entanto, esses resultados são condizentes com os encontrados pelos experimentos 1, 2 e 3 desta tese, o que pode indicar, como hipóteses alternativas, idiossincrasias relacionadas às amostras utilizadas ou aos instrumentos utilizados para se aferir tais construtos. Observa-se que, apesar dos índices de confiabilidade encontrados para as medidas terem se mostrado aceitáveis, não foram realizadas análises fatoriais com o intuito de verificar a validade de conteúdo dos fatores constituintes de cada medida. Neste sentido, e considerando que as Hipóteses 4 ( $A$ empatia atuará como moderadora entre a função desempenhada e o comportamento prosocial) e 5 ( $A$ amabilidade atuará como moderadora entre a função desempenhada e o comportamento prosocial) não tiveram suporte a partir dos resultados encontrados, novas investigações que considerem a utilização desses constructos (a partir dessas ou outras medidas utilizadas pela literatura) devem ser realizadas a fim de verificar de forma mais aprofundada a relação entre tais medidas disposicionais e o fenômeno de interesse.

O presente experimento, conforme apresentado anteriormente, foi estruturado de forma a se reduzir a chance de problemas com a manipulação das variáveis ou da existência de variáveis intervenientes. Contudo, ele não está isento de limitações. A principal delas diz respeito ao tamanho da amostra utilizada, o que reduziu o poder estatístico associado à manipulação e a possibilidade de se detectar o efeito, caso ele de fato exista. Esta limitação deve ser levada em conta, principalmente quando se pretende realizar replicações ou testar evidências encontradas anteriormente pela literatura (Brandt et al., 2014; Open Science Collaboration, 2014). Neste sentido, é fundamental que novos experimentos sejam realizados 
para se testar o efeito da carga cognitiva, utilizando amostras de tamanho adequado de forma a se aumentar a garantia da detecção dos efeitos.

Outro ponto que merece maior atenção diz respeito ao jogo desenvolvido para a manipulação da função prosocial/violenta. Considerando que diversas características do jogo podem estar associadas à ocorrência dos efeitos investigados (Barlett et al., 2009) e que deve haver uma relação bem estabelecida entre o jogo e o fenômeno que se deseja estudar (McMahan et al., 2011), considera-se que mais estudos devem ser feitos com o intuito de verificar a adequação do FoV enquanto jogo a ser utilizado em experimentos, apesar dos resultados apresentarem evidências que sugerem que a manipulação foi bem-sucedida.

Este experimento encerra o conjunto de estudos que compõem esta tese e traz contribuições para a análise da influência de jogos digitais no comportamento prosocial. A seguir, são discutidas as evidências de todos os experimentos realizados até o momento, bem como as implicações decorrentes tanto para a compreensão de modelos teóricos vigentes quanto para a construção de uma agenda de pesquisa focada em aspectos como o desenvolvimento de jogos digitais específicos e a consideração da dimensão cognitiva como variável independente em estudos que investiguem o impacto de jogos digitais no comportamento.

\section{Discussão geral}

A presente tese teve como objetivo principal avaliar o papel dos recursos cognitivos na relação entre a função desempenhada no jogo e o comportamento prosocial. Para isso, foi desenvolvida uma série de experimentos que buscavam verificar evidências anteriormente encontradas na literatura acerca da relação entre a natureza do jogo e: comportamentos prosociais (Experimentos 1, 2 e 6), intenção de ajuda (Experimentos 1, 2 e 3), acessibilidade a conteúdos prosociais (Experimento 2), ativação implícita de conteúdos relacionados a 
autoconceito (Experimento 3). Além disso, e considerando as evidências encontradas nos primeiros experimentos, buscou-se desenvolver e testar um jogo que permitisse a manipulação da função de jogo (Jogo FoV, Experimento 4) e adaptar uma medida em formato de jogo digital para o comportamento prosocial (Jogo ZPG, Experimento 5). Com base nisso, investigou-se a influência dos recursos cognitivos na relação entre a função desempenhada no jogo e o comportamento de ajuda (Experimento 6).

Ao se considerar estudos anteriores acerca da relação entre jogos digitais e comportamento humano, grande parte da literatura sustenta a existência de uma influência entre a natureza do jogo experimentado pelos participantes (por exemplo, violento ou prosocial) e o comportamento em situações após o jogo (comportamentos agressivos ou prosociais) em contextos digitais ou em situações reais (Anderson et al., 2010; Anderson \& Bushman, 2001; Barlett et al., 2009; Fischer et al., 2011; Greitemeyer \& Mügge, 2014; Prot, McDonald, Anderson, \& Gentile, 2012). Em consonância com esta suposição, é possível encontrar evidências diversas que sustentam que a natureza do jogo levaria a uma maior ocorrência de comportamentos congruentes com ela. Jogos violentos, por exemplo, tenderiam a aumentar a ocorrência de comportamentos agressivos e reduzir a ocorrência de comportamentos prosociais (Anderson \& Dill, 2000; Carnagey \& Anderson, 2005; DeWall \& Anderson, 2011; J. Fischer, Aydin, Kastenmüller, Frey, \& Fischer, 2012; Greitemeyer, 2013b; Hasan et al., 2012, 2013; Hollingdale \& Greitemeyer, 2014; Krahé \& Möller, 2011; Mößle, Kliem, \& Rehbein, 2014; Sestir \& Bartholow, 2010). Jogos de natureza prosocial, por sua vez, teriam o efeito oposto (Gentile et al., 2009; Greitemeyer et al., 2011; Greitemeyer \& Mügge, 2014; Greitemeyer \& Osswald, 2010; Jin, 2011; Peng et al., 2010; Prot et al., 2013; Saleem et al., 2012a). Além do efeito sobre o comportamento, a natureza do jogo também estaria relacionada a um efeito semelhante na acessibilidade a cognições congruentes com ela (Anderson \& Dill, 2000; Bastian et al., 2012; Carnagey \& Anderson, 2005; Greitemeyer et 
al., 2011; Greitemeyer \& Mügge, 2014; Greitemeyer \& Osswald, 2009; Sestir \& Bartholow, 2010; Uhlmann \& Swanson, 2004; Velez, Mahood, Ewoldsen, \& Moyer-gusé, 2014;

Zumbach, Seitz, \& Bluemke, 2015) e em afetos positivos e negativos (Anderson \& Bushman, 2001; Bailey et al., 2011; Buckley \& Anderson, 2006; Greitemeyer, 2013a; Greitemeyer \& Mügge, 2014; Greitemeyer et al., 2010; Huesmann, 2007; Jeong et al., 2012; Prot et al., 2013; Prot, Anderson, Gentile, Brown, \& Swing, 2014; Saleem et al., 2012b). No entanto, não foi possível observar, considerando o conjunto de estudos que compõem esta tese, resultados consonantes com tais evidências.

Com relação à influência da função jogada (violenta ou prosocial) no comportamento prosocial, nos experimentos relatados nesta tese não foram encontrados efeitos significativos, indicando que (ao menos considerando as amostras e medidas utilizadas) o fato do participante executar uma função violenta ou prosocial no jogo não afeta o comportamento posterior de ajuda. Tais resultados suportam uma visão crítica sobre o fenômeno em questão, sugerindo que os resultados encontrados pela literatura podem advir da existência de outras variáveis, mais importantes do que a natureza do jogo, para a manifestação do comportamento prosocial, como a dificuldade ou o ritmo de jogo (Adachi \& Willoughby, 2011; Elson et al., 2013; Kneer et al., 2016). Apesar da maior parte dos estudos citados aqui manipularem o tipo de jogo (por meio da seleção de jogos distintos) e não a função jogada diretamente, é razoável supor que a mudança do tipo de jogo altera também a sua função. No caso dos experimentos realizados nesta tese, a escolha pela manipulação da função de jogo se deu exatamente como forma de controlar outras características do jogo digital, permitindo uma análise mais refinada do fenômeno. Considera-se que este fator traz uma contribuição relevante para a área, mesmo que seus resultados venham de encontro à compreensão mais comumente estabelecida pela literatura. Ainda, reforça os argumentos acerca da inexistência do efeito (Ferguson \& Kilburn, 2010; Tear \& Nielsen, 2013; Valadez \& Ferguson, 2012) ou 
da fragilidade das medidas utilizadas por estudos anteriores (Elson \& Ferguson, 2013; Elson et al., 2014).

Esta discussão deve considerar, também, críticas que sugerem que determinados procedimentos de análise de dados (comumente utilizados pela literatura) podem aumentar a chance de se divulgar falsos positivos em publicações acadêmicas (Ioannidis, 2005). Em psicologia, diversos autores criticam o uso de determinadas estratégias de coleta e análise de dados que aumentam a ocorrência de falsos positivos e de um viés de publicação em que estudos não significativos simplesmente não são publicados (Simmons, Nelson, \& Simonsohn, 2011; Simonsohn, Nelson, \& Simmons, 2014; van Assen, van Aert, Nuijten, \& Wicherts, 2014). Tais críticas demandam que os pesquisadores examinem evidências de estudos anteriores com a perspectiva não necessariamente de refutação, mas principalmente de considerar hipóteses alternativas e a interpretação de resultados não significativos. A título de exemplo, ao se considerar evidências acerca do priming em psicologia social, resultados não significativos podem ocorrer devido à existência de variáveis moderadoras ou mediadoras não previstas (Dijksterhuis, van Knippenberg, \& Holland, 2014). O presente trabalho contribui para esta discussão ao apresentar evidências acerca de outras variáveis relevantes para a compreensão da relação entre jogos digitais e comportamento prosocial além da natureza do jogo propriamente dita.

Da mesma forma, não foram encontrados resultados significativos para a relação entre a função jogada e a acessibilidade cognitiva a conteúdos congruentes, seja por meio da mensuração por meio do Teste de Decisão Lexical (Experimento 2), seja por meio do Teste de Associação Implícita de autoconceito (Experimento 3). A influência do tipo de jogo na acessibilidade cognitiva é uma evidência que vem sendo apresentada por diversos estudos na literatura (Anderson et al., 2010; Anderson \& Bushman, 2001; Anderson \& Dill, 2000; Barlett et al., 2009; Buckley \& Anderson, 2006; Greitemeyer \& Mügge, 2014), 
principalmente enfocando sua importância enquanto possível variável mediadora na relação entre a natureza do jogo e o comportamento agressivo ou prosocial (Anderson \& Dill, 2000; Carnagey \& Anderson, 2005; Greitemeyer et al., 2011; Greitemeyer \& Osswald, 2010, 2011). Apesar de não se questionar neste estudo a importância da cognição como elemento explicativo para diversas manifestações do comportamento humano, a ausência de resultados significativos reforça a necessidade de se aprofundar a investigação de como a ativação de conteúdos específicos na memória pode mediar a relação entre a natureza do estímulo apresentado e o comportamento decorrente dele. Neste sentido, estudos futuros devem se debruçar sobre a natureza das medidas utilizadas, bem como de sua adequação, considerando que a qualidade das medidas é uma das críticas mais comuns associadas a área de jogos digitais e comportamento (Elson \& Ferguson, 2013; Ferguson, 2009a; Ferguson \& Kilburn, 2010). No caso da cognição, é possível que a exposição a jogos digitais (considerando sua natureza complexa) pode ativar conteúdos tanto agressivos quanto prosociais, e as evidências da literatura poderiam ser um impacto da ferramenta que se utiliza para aferir tal relação (Bösche, 2010).

Com relação à variáveis de cunho afetivo, os Experimentos 1, 2 e 3 não encontraram evidências acerca do impacto da função jogada em afetos positivos e negativos, mais uma vez contrariando as evidências apontadas por meta-análises e revisões sistemáticas (Anderson \& Bushman, 2001; Greitemeyer \& Mügge, 2014). No entanto, encontra suporte em estudos anteriores que falharam em encontrar tais relações (Greitemeyer \& Osswald, 2010; Valadez \& Ferguson, 2012). Um aspecto negativo que deve ser considerado nos experimentos desta tese é a utilização de uma medida que depende de uma resposta explícita do participante acerca de seus estados afetivos, o que pode gerar problemas de qualidade da medida. Neste sentido, sugere-se que sejam estudos com o interesse direto na avaliação de estados afetivos 
utilizem medidas menos suscetíveis à processos de julgamento, como medidas de variáveis fisiológicas (Bailey et al., 2011).

Além dos pontos apresentados até o momento, este trabalho buscou investigar o papel da disponibilidade de recursos cognitivos na relação entre a função experimentada no jogo digital e o comportamento prosocial. Esta decisão partiu de uma análise crítica do general learning model, atualmente o modelo mais utilizado para se explicar a influência de jogos digitais sobre o comportamento humano (Barlett \& Anderson, 2013; Buckley \& Anderson, 2006; Prot \& Anderson, 2013; Prot et al., 2014). De acordo com este modelo, as características constituintes do jogo digital, bem como aspectos situacionais e disposicionais, influenciam o comportamento por meio de três rotas distintas - cognitiva, afetiva e de alerta (arousal). A ativação de conteúdos específicos em cada uma das dimensões influencia como o indivíduo interpreta as situações em que se encontra e como ele age em situações posteriores à exposição ao jogo. Ainda, de acordo com Buckley e Anderson (2006), o tipo de comportamento decorrente deste processo avaliativo pode ser impulsivo ou controlado, a depender da quantidade de recursos cognitivos disponíveis e do resultado da experiência com o jogo. Conforme ressaltado anteriormente, este pressuposto do modelo sugere que o comportamento após a experiência de jogo depende também do fato de recursos cognitivos estarem mais ou menos disponíveis no momento da avaliação das situações. Apesar dos autores não apresentarem evidência empíricas específicas para este pressuposto dentro do modelo, ele é coerente com as perspectivas que compreendem a existência de um modelo duplo de processamento de informações (Hassin et al., 2005), e que a existência de recursos cognitivos pode resultar em processos mais ou menos controlados pelos indivíduos o que, em sua vez, resultaria em ações mais ou menos controladas por eles (Baumeister et al., 1998). Um dos pontos críticos relacionados a este pressuposto - e a ausência de evidências empíricas específicas sobre ele dentro do contexto de investigação de jogos digitais - é que 
várias manifestações de comportamentos comumente estudados pela área de jogos também são afetadas, por si só, pela disponibilidade de recursos cognitivos. O caso do comportamento prosocial, foco desta tese, não é exceção, e vários estudos sugerem que comportamentos de ajuda tendem a reduzir sua ocorrência em função da escassez de recursos cognitivos, indicando que esta classe de comportamentos pode demandar de uma gestão maior por parte do indivíduo para que a ajuda possa ocorrer (DeWall et al., 2008; Fennis, 2011; Xu et al., 2012). Caso tais evidências de fato se sustentem empiricamente, é factível supor que pode haver um viés nos estudos sobre a influência de jogos no comportamento quando tal variável não é considerada, principalmente quando se utilizam jogos diferentes como estratégia de manipulação do tipo de jogo.

Jogos digitais variam drasticamente em termos de seus atributos principais. Mecânica, elementos gráficos e sonoros, animações, sistemas de recompensa e narrativa, entre outros fatores, podem ser completamente diferentes de um jogo para outro (Gentile, 2011). Além disso, jogos mais comercialmente rentáveis tendem a ser mais complexos em termos de tecnologia, dinâmica e elementos gráficos e sonoros. A utilização de jogos distintos pode resultar em influências diferentes com relação a estes aspectos, gerando um fator de interveniência não previsto pelo pesquisador. As estratégias mais comuns para checar se há diferença nestes elementos consiste em perguntar ao participante como ele avalia o jogo em termos de dificuldade, diversão, frustração, entre outras dimensões. No entanto, o fato do pesquisador não encontrar diferença significativa na percepção dos participantes dos estudos não garante, per se, que estes atributos foram adequadamente controlados. Um exemplo disso são estudos em que, ao se manipular diretamente a dificuldade do jogo, o efeito relacionado à natureza do jogo (violenta, neutra ou prosocial) tende a desaparecer (Adachi \& Willoughby, 2011; Engelhardt et al., 2015; Kneer et al., 2016). Neste caso específico, uma explicação é que a dificuldade afeta a disponibilidade de recursos disponíveis para o indivíduo julgar as 
situações posteriores ao jogo, influenciando na forma como ele se comporta (no caso de interesse desta tese, mais ou menos prosocialmente).

Os resultados do Experimento 6 fornecem, ao menos parcialmente, suporte à interpretação de que a disponibilidade de recursos cognitivos responde mais pela ocorrência de comportamentos prosociais do que a função desempenhada no jogo. Ao se analisar os efeitos principais das variáveis função no jogo e carga cognitiva, observou-se um efeito considerável desta última sobre o comportamento de ajuda, mas não da primeira. No entanto, uma análise mais aprofundada sugeriu a possibilidade de um efeito de interação, principalmente ao se considerar a função prosocial no jogo, sugerindo que a disponibilidade de recursos cognitivos contribui mais para a explicação sobre a ocorrência do comportamento prosocial no ZPG quando a função que serve de estímulo (priming) no jogo anterior tem natureza prosocial. Tal interpretação, por si só, sugere uma agenda de pesquisa que pode auxiliar a área de estudos sobre a influência de jogos digitais no aprofundamento e melhor compreensão dos elementos envolvidos na interação com este tipo de mídia.

No entanto, os experimentos que compõem esta tese apresentaram limitações que restringem o impacto das inferências feitas até o momento e que devem ser solucionadas em estudos futuros. No caso dos Experimentos 1, 2 e 3, a ausência da checagem de manipulação da função jogada reduz o potencial interpretativo dos resultados, uma vez que não há como garantir que os participantes compreenderam as funções de forma coerente com o especulado pelo pesquisador. Os resultados encontrados no Experimento 1, curiosamente incompatíveis com o descrito pela literatura, sugere uma incompatibilidade da função prosocial que não pôde ser devidamente testada com os dados disponíveis. O mesmo obstáculo se estende aos outros estudos. Além disso, foram utilizadas nestes experimentos escalas que ou não apresentaram índices de confiabilidade adequados (por exemplo, a adaptação para o Brasil da Bateria de Personalidade Prosocial - BPP) ou medidas que dependem de uma resposta direta 
do participante acerca de seus estados afetivos (como a PANAS utilizada neste trabalho). São necessários novos estudos para se testar, a partir de escalas psicometricamente consistentes, a influência de características disposicionais na relação entre jogos digitais e comportamento. Os resultados relacionados ao fator de amabilidade do Big 5, na versão de Andrade (2008), apresentaram tendências promissoras acerca do efeito de moderação na relação entre a função no jogo e o comportamento prosocial, algo que estudos anteriores sugerem (Greitemeyer, 2013a; Prot et al., 2013), até mesmo pela relação entre a amabilidade e a ocorrência de comportamentos de ajuda (Graziano et al., 2007; Hilbig et al., 2014). No entanto, os estudos aqui descritos foram insuficientes para se investigar de forma detalhada esta relação.

Outra limitação importante diz respeito ao tamanho da amostra utilizada no Experimento 6, o que pode resultar em um baixo poder e, consequentemente, em uma maior dificuldade em se encontrar o efeito caso ele de fato exista. Apesar dos tamanhos de efeito encontrados estarem longe de serem considerados tímidos $\left(r_{s}>0,40\right)$, a realização do mesmo experimento com uma amostra maior traria maior solidez às análises e interpretações realizadas.

Apesar das limitações apontadas acima, considera-se que este trabalho resultou em um conjunto de contribuições para a área de estudo da influência de jogos digitais. O desenvolvimento de um jogo específico para a manipulação das variáveis de interesse, por exemplo, mostrou-se um caminho promissor de investigação. Apesar dos custos inerentes a esta decisão (de pessoal e de tempo, principalmente), a possibilidade de controle de possíveis variáveis intervenientes e de manipulação mais fina das variáveis independentes traz benefícios significativos ao processo investigativo, e faz coro com autores que sustentam esta estratégia (McMahan et al., 2011) ou a modificação (modding) de jogos comerciais que permitem tal ação (Elson et al., 2013; Elson \& Quandt, 2014). 
Além disso, esta tese trouxe, do ponto de vista teórico, evidências sobre o papel da disponibilidade de recursos cognitivos como moderador da relação entre o tipo de jogo e o comportamento de ajuda. Compreender este papel pode ajudar a esclarecer, por exemplo, como determinadas características dos jogos podem, por meio da carga cognitiva imposta por eles, influenciar os diferentes resultados (às vezes contraditórios) encontrados na literatura.

Por fim, este estudo contribui com a indústria de desenvolvimento que buscam conceber jogos cujo objetivo vai além do entretenimento (Baldwin \& Dandeneau, 2009; McGonigal, 2011). Tais iniciativas podem fazer uso das evidências produzidas por estudos como os propostos neste trabalho, aumentando a chance de se mostrarem efetivas ferramentas de mudança atitudinal e comportamental.

\section{Considerações finais}

O estudo do conjunto de comportamentos que caracterizam o comportamento prosocial, comportamentos cuja finalidade é o benefício de terceiros (Mikulincer \& Shaver, 2010) envolve compreender não só os contextos onde eles ocorrem, mas principalmente os fatores que levam um indivíduo a auxiliar o outro mesmo que isso signifique um prejuízo para si mesmo. Neste sentido, são comumente estudados fatores individuais, situacionais e grupais na tentativa de compreender quem ajuda, em quais situações e por quais razões (Penner et al., 2005). Os jogos digitais surgem, dentro do escopo desta tese, como um dos elementos cujas características poderiam influenciar a probabilidade do comportamento prosocial ocorrer. Foram apresentadas, no decorrer deste trabalho, evidências que sustentam uma forte relação entre características de um jogo digital e o comportamento de ajuda (Anderson \& Bushman, 2001; Bushman \& Huesmann, 2014; Fischer et al., 2011; Greitemeyer \& Mügge, 2014; Huesmann, 2007) e que questionam sua existência (Elson \& Ferguson, 2013; Ferguson, 2007, 2009a, 2015; Ferguson, Garza, Jerabeck, Ramos, \& Galindo, 2013). Por fim, os resultados dos experimentos apresentados sugerem uma 
perspectiva mais complexa de compreensão do fenômeno, e que a natureza do jogo pode ter um papel mais tímido do que outras características na compreensão de sua influência no comportamento de jogadores.

A existência de resultados como os encontrados aqui somente reforça, na opinião dos autores, a necessidade e importância deste ramo de investigação e, principalmente, o papel da psicologia social na compreensão deste fenômeno. Conforme apontado anteriormente, a indústria de jogos digitais vem crescendo de forma vertiginosa anualmente e não há perspectivas de desaceleração (McGonigal, 2011). Os jogos cada vez mais são utilizados em outros contextos além do entretenimento; a criação de jogos sérios e a utilização de princípios de game design em outros processos têm aberto caminhos promissores em diversos campos, como na educação em geral e no treinamento corporativo (Laamarti, Eid, \& Saddik, 2014; Morford, Witts, Killingsworth, \& Alavosius, 2014; Robson, Plangger, Kietzmann, McCarthy, \& Pitt, 2015). Assim como outros tipos de mídia, sua inserção no cotidiano da sociedade tem ocorrido de forma mais acelerada do que a produção de conhecimento científico sobre seus efeitos e, neste sentido, é fundamental que este ramo de investigação apresente uma produção cada vez mais consistente, não só do ponto de vista quantitativo mas também (e principalmente) do ponto de vista da qualidade dos estudos e das análises realizadas. Mais do que isso, é fundamental que o interesse em descobrir modelos explicativos mais parcimoniosos vá além do interesse pessoal dos pesquisadores, algo que ainda não tem ocorrido neste ramo de investigação (Krahé, 2014). 


\section{Referências}

Adachi, P. J. C., \& Willoughby, T. (2011). The effect of violent video games on aggression: Is it more than just the violence? Aggression and Violent Behavior, 16(1), 55-62. http://doi.org/10.1016/j.avb.2010.12.002

Anderson, C. A., \& Bushman, B. J. (2001). Effects of violent video games on aggressive behavior, aggressive cognition, aggressive affect, physiological arousal, and prosocial behavior: A meta-analytic review of the scientific literature. Psychological Science, 12(5), 353-359. Retrieved from http://www.ncbi.nlm.nih.gov/pubmed/11554666

Anderson, C. A., \& Bushman, B. J. (2002). Human aggression. Annual Review of Psychology, 53, 27-51.

Anderson, C. A., \& Dill, K. E. (2000). Video games and aggressive thoughts, feelings, and behavior in the laboratory and in life. Journal of Personality and Social Psychology, 78(4), 772-790. http://doi.org/10.1037//O022-3514.78.4.772

Anderson, C. A., Shibuya, A., Ihori, N., Swing, E. L., Bushman, B. J., Sakamoto, A., ... Saleem, M. (2010). Violent video game effects on aggression, empathy, and prosocial behavior in eastern and western countries: A meta-analytic review. Psychological Bulletin, 136(2), 151-73. http://doi.org/10.1037/a0018251

Andrade, J. M. (2008). Evidências de validade do inventário dos cinco grandes fatores de personalidade para o Brasil (Tese de doutorado). Universidade de Brasília.

Bailey, K., West, R., \& Anderson, C. A. (2010). A negative association between video game experience and proactive cognitive control. Psychophysiology, 47, 34-42. http://doi.org/10.1111/j.1469-8986.2009.00925.x

Bailey, K., West, R., \& Anderson, C. A. (2011). The influence of video games on social, cognitive, and affective information processing. In J. Decety \& J. T. Cacioppo (Eds.), The Oxford Handbook of Social Neuroscience (pp. 1001-1014). Oxford: Oxford 
University Press.

Baldaro, B., Tuozzi, G., Codispoti, M., Montebarocci, O., Barbagli, F., Trombini, E., \& Rossi, N. (2004). Aggressive and non-violent videogames: Short-term psychological and cardiovascular effects on habitual players. Stress and Health, 20, 203-208. http://doi.org/10.1002/smi.1015

Baldwin, M. W., \& Dandeneau, S. D. (2009). Putting social psychology into serious games. Social and Personality Psychology Compass, 3(4), 547-565. http://doi.org/10.1111/j.1751-9004.2009.00185.x

Bargh, J. A., Schwader, K. L., Hailey, S. E., Dyer, R. L., \& Boothby, E. J. (2012). Automaticity in social-cognitive processes. Trends in Cognitive Sciences, 16(12), 593605. http://doi.org/10.1016/j.tics.2012.10.002

Barlett, C. P., \& Anderson, C. A. (2013). Examining media effects: The general aggression and general learning models. In E. Scharrer (Ed.), The International Encyclopedia of Media Studies (1st ed., Vol. V, pp. 108-127). Blackwell Publishing Ltd.

Barlett, C. P., Anderson, C. A., \& Swing, E. L. (2009). Video game effects - confirmed, suspected, and speculative: A review of the evidence. Simulation \& Gaming, 40(3), 377-403. http://doi.org/10.1177/1046878108327539

Bastian, B., Jetten, J., \& Radke, H. R. M. (2012). Cyber-dehumanization: Violent video game play diminishes our humanity. Journal of Experimental Social Psychology, 48, 486-491. http://doi.org/10.1016/j.jesp.2011.10.009

Baumeister, R. F., Bratslavsky, E., Muraven, M., \& Tice, D. M. (1998). Ego depletion: Is the active self a limited resource? Journal of Personality and Social Psychology, 74(5), 1252-65. Retrieved from http://www.ncbi.nlm.nih.gov/pubmed/9599441

Bluemke, M., Friedrich, M., \& Zumbach, J. (2009). The influence of violent and nonviolent computer games on implicit measures of aggressiveness. Aggressive Behavior, 35, 1-13. 
http://doi.org/10.1002/ab.20329

Bösche, W. (2010). Violent video games prime both aggressive and positive cognitions. Journal of Media Psychology: Theories, Methods, and Applications, 22(4), 139-146. http://doi.org/10.1027/1864-1105/a000019

Brandt, M. J., Ijzerman, H., Dijksterhuis, A., Farach, F. J., Geller, J., Giner-sorolla, R., ... Van, A. (2014). The replication recipe: What makes for a convincing replication? Journal of Experimental Social Psychology, 50, 217-224. http://doi.org/10.1016/j.jesp.2013.10.005

Buckley, K. E., \& Anderson, C. A. (2006). A Theoretical model of the effects and consequences of playing video games. In P. Vorderer \& J. Bryant (Eds.), Playing Video Games - Motives, Responses, and Consequences (pp. 363-378). Mahwah, NJ: LEA.

Buelow, M. T., Okdie, B. M., \& Cooper, A. B. (2015). The influence of video games on executive functions in college students. Computers in Human Behavior, 45, 228-234. http://doi.org/10.1016/j.chb.2014.12.029

Bushman, B. J., \& Huesmann, L. R. (2014). Twenty-five years of research on violence in digital games and aggression revisited. European Psychologist, 19(1), 47-55. http://doi.org/10.1027/1016-9040/a000164

Cappelletti, D., Güth, W., \& Ploner, M. (2011). Being of two minds: Ultimatum offers under cognitive constraints. Journal of Economic Psychology, 32(6), 940-950. http://doi.org/10.1016/j.joep.2011.08.001

Carnagey, N. L., \& Anderson, C. a. (2005). The effects of reward and punishment in violent video games on aggressive affect, cognition, and behavior. Psychological Science, 16(11), 882-889. http://doi.org/10.1111/j.1467-9280.2005.01632.x

Cavallo, J. V, Holmes, J. G., Fitzsimons, G. M., Murray, S. L., \& Wood, J. V. (2012). Managing motivational conflict: How self-esteem and executive resources influence 
self-regulatory responses to risk. Journal of Personality and Social Psychology, 103(3), 430-51. http://doi.org/10.1037/a0028821

Chambers, J. H., \& Ascione, F. R. (2001). The effects of prosocial and aggressive videogames on children's donating and helping. Journal of Genetic Psychology, 148(4), 499-505.

Conway, P., \& Gawronski, B. (2013). Deontological and utilitarian inclinations in moral decision making: A process dissociation approach. Journal of Personality and Social Psychology, 104(2), 216-35. http://doi.org/10.1037/a0031021

Cornelissen, G., Dewitte, S., \& Warlop, L. (2011). Are social value orientations expressed automatically? Decision making in the dictator game. Personality \& Social Psychology Bulletin, 37(8), 1080-90. http://doi.org/10.1177/0146167211405996

DeWall, C. N., \& Anderson, C. A. (2011). The general aggression model. In M. Mikulincer and P. R. Shaver (Eds.), Understanding and reducing aggression, violence, and their consequences (pp. 15-33). Washington, DC: American Psychological Association.

DeWall, C. N., Baumeister, R. F., Gailliot, M. T., \& Maner, J. K. (2008). Depletion makes the heart grow less helpful: Helping as a function of self-regulatory energy and genetic relatedness. Personality \& Social Psychology Bulletin, 34(12), 1653-62. http://doi.org/10.1177/0146167208323981

Dijksterhuis, A., \& Aarts, H. (2010). Goals, attention, and (un)consciousness. Annual Review of Psychology, 61, 467-90. http://doi.org/10.1146/annurev.psych.093008.100445

Dijksterhuis, A., van Knippenberg, A., \& Holland, R. W. (2014). Evaluating behavior priming research: Three observations and a recommendation. Social Cognition, 32(Supplement), 196-208. http://doi.org/10.1521/soco.2014.32.supp.196

Dobrowolski, P., Hanusz, K., Sobczyk, B., Skorko, M., \& Wiatrow, A. (2015). Cognitive enhancement in video game players: The role of video game genre. Computers in 
Human Behavior, 44, 59-63. http://doi.org/10.1016/j.chb.2014.11.051

Dunfield, K. A. (2014). A construct divided: prosocial behavior as helping, sharing, and comforting subtypes. Frontiers in Psychology, 5, 1-13. http://doi.org/10.3389/fpsyg.2014.00958

Elson, M., Breuer, J., Looy, J. Van, Kneer, J., \& Quandt, T. (2013). Comparing apples and oranges? Evidence for pace of action as a confound in research on digital games and aggression. Psychology of Popular Media Culture, 4(2), 1-14.

http://doi.org/10.1037/ppm0000010

Elson, M., \& Ferguson, C. J. (2013). Twenty-five years of research on violence in digital games and aggression. European Psychologist, 19(1), 33-46. http://doi.org/10.1027/1016-9040/a000147

Elson, M., Mohseni, M. R., Breuer, J., Scharkow, M., \& Quandt, T. (2014). Press CRTT to measure aggressive behavior: The unstandardized use of the competitive reaction time task in aggression research. Psychological Assessment, 26(2), 419-32. http://doi.org/10.1037/a0035569

Elson, M., \& Quandt, T. (2014). Digital games in laboratory experiments: Controlling a complex stimulus through modding. Psychology of Popular Media Culture, (JUNE). http://doi.org/10.1037/ppm0000033

Engelhardt, C. R., Hilgard, J., \& Bartholow, B. D. (2015). Acute exposure to difficult (but not violent) video games dysregulates cognitive control. Computers in Human Behavior, 45, 85-92. http://doi.org/10.1016/j.chb.2014.11.089

Epley, N., Morewedge, C. K., \& Keysar, B. (2004). Perspective taking in children and adults: Equivalent egocentrism but differential correction. Journal of Experimental Social Psychology, 40, 760-768.

Evans, J. S. B. T. (2008). Dual-processing accounts of reasoning, judgment, and social 
cognition. Annual Review of Psychology, 59, 255-78.

http://doi.org/10.1146/annurev.psych.59.103006.093629

Fennis, B. M. (2011). Can't get over me : Ego depletion attenuates prosocial effects of perspective taking. European Journal of Social Psychology, 41, 580-585.

http://doi.org/10.1002/ejsp.828

Ferguson, C. J. (2007). Evidence for publication bias in video game violence effects

literature: A meta-analytic review. Aggression and Violent Behavior, 12, 470-482.

http://doi.org/10.1016/j.avb.2007.01.001

Ferguson, C. J. (2008). The school shooting/violent video game link: Causal relationship or moral panic? Journal of Investigative Psychology and Offender Profiling, 5(1-2), 2537. http://doi.org/10.1002/jip.76

Ferguson, C. J. (2009a). Is psychological research really as good as medical research? Effect size comparisons between psychology and medicine. Review of General Psychology, $13(2), 130-136$.

Ferguson, C. J. (2009b). Media violence effects: Confirmed truth or just another X-File? Journal of Forensic Psychology Practice, 9(2), 103-126. http://doi.org/10.1080/15228930802572059

Ferguson, C. J. (2015). Do angry birds make for angry children? A meta-analysis of video game influences on children's and adolescents' aggression, mental health, prosocial behavior, and academic performance. Perspectives on Psychological Science, 10(5), 646-666. http://doi.org/10.1177/1745691615592234

Ferguson, C. J., Cruz, A. M., \& Rueda, S. M. (2007). Gender, video game playing habits and visual memory tasks. Sex Roles, 58(3-4), 279-286. http://doi.org/10.1007/s11199-0079332-z

Ferguson, C. J., \& Dyck, D. (2012). Paradigm change in aggression research: The time has 
come to retire the general Aggression Model. Aggression and Violent Behavior, 17(3), 220-228. http://doi.org/10.1016/j.avb.2012.02.007

Ferguson, C. J., Garza, A., Jerabeck, J., Ramos, R., \& Galindo, M. (2013). Not worth the fuss after all? Cross-sectional and prospective data on violent video game influences on aggression, visuospatial cognition and mathematics ability in a sample of youth. Journal of Youth and Adolescence, 42(1), 109-22. http://doi.org/10.1007/s10964-012-9803-6

Ferguson, C. J., \& Kilburn, J. (2010). Much ado about nothing: The misestimation and overinterpretation of violent video game effects in eastern and western nations: comment on Anderson et al. (2010). Psychological Bulletin, 136(2), 174-8-7. http://doi.org/10.1037/a0018566

Fischer, J., Aydin, N., Kastenmüller, A., Frey, D., \& Fischer, P. (2012). The delinquent media effect: Delinquency-reinforcing video games increase players attitudinal and behavioral inclination toward delinquent behavior. Psychology of Popular Media Culture, 1(3), 201-205. http://doi.org/10.1037/a0028114

Fischer, P., Greitemeyer, T., Kastenmüller, A., Vogrincic, C., \& Sauer, A. (2011). The effects of risk-glorifying media exposure on risk-positive cognitions, emotions, and behaviors: A meta-analytic review. Psychological Bulletin, 137(3), 367-90. http://doi.org/10.1037/a0022267

Fiske, S. T., \& Taylor, S. E. (2008a). Behavior and Cognition. In Social Cognition. From Brains to Culture (pp. 361-396). New York: McGraw-Hill Higher Education.

Fiske, S. T., \& Taylor, S. E. (2008b). Dual Modes In Social Cognition. In Social Cognition. From Brains to Culture (pp. 25-50). New York: McGraw-Hill Higher Education.

Gailliot, M. T. (2010). The effortful and energy demanding nature of prosocial behavior. In M. Mikulincer \& P. R. Shaver (Eds.), Prosocial Motives, Emotions, and Behavior. The Better Angels of Our Nature (pp. 169-180). Washington, DC: American Psychological 
Association.

Galinha, I. C., \& Pais-Ribeiro, J. L. (2005). Contribuição para o estudo da versão portuguesa da Positive and Negative Affect Schedule ( PANAS ): II - Estudo psicométrico (*). Análise Psicológica, 2, 219-227.

Gawronski, B., \& Creighton, L. A. (2006). Dual-process theories. In D. E. Carlston (Ed.), The Oxford handbook of Social Cognition (pp. 1-35). New York: Oxford University Press.

Gentile, D. A. (2011). The multiple dimensions of video game effects. Child Development Perspectives, 5(2), 75-81. http://doi.org/10.1111/j.1750-8606.2011.00159.x

Gentile, D. A., \& Anderson, C. A. (2006). Video games: Origin and growth of the video game industry. In N. J. Salkind (Ed.), Encyclopedia of Human Development (Vol. 3, pp. 1303-1307). Thousand Oaks, CA: Sage Publications.

Gentile, D. A., Anderson, C. a, Yukawa, S., Ihori, N., Saleem, M., Ming, L. K., ... Sakamoto, A. (2009). The effects of prosocial video games on prosocial behaviors: International evidence from correlational, longitudinal, and experimental studies. Personality \& Social Psychology Bulletin, 35(6), 752-763. http://doi.org/10.1177/0146167209333045

Gollwitzer, M., \& Melzer, A. (2012). Macbeth and the joystick: Evidence for moral cleansing after playing a violent video game. Journal of Experimental Social Psychology, 48(6), 1356-1360. http://doi.org/10.1016/j.jesp.2012.07.001

Graziano, W. G., Habashi, M. M., Sheese, B. E., \& Tobin, M. (2007). Agreeableness, empathy, and helping : A person $\Upsilon$ situation perspective. Journal of Personality and Social Psychology, 93(4), 583-599. http://doi.org/10.1037/0022-3514.93.4.583

Green, C. S., Sugarman, M., Medford, K., Klobusicky, e., \& Bavelier, D. (2012). The effect of action video game experience on task switching. Computers in Human Behavior, 28(3), 984-994. http://dx.doi.org/10.1016/j.chb.2011.12.020 
Greene, J. D., Morelli, S. a, Lowenberg, K., Nystrom, L. E., \& Cohen, J. D. (2008).

Cognitive load selectively interferes with utilitarian moral judgment. Cognition, 107(3), 1144-54. http://doi.org/10.1016/j.cognition.2007.11.004

Greenwald, A. G., McGhee, D. E., \& Schwartz, J. L. (1998). Measuring individual differences in implicit cognition: The implicit association test. Journal of Personality and Social Psychology, 74(6), 1464-80. http://doi.org/10.1037/0022-3514.74.6.1464

Greenwald, A. G., Nosek, B. A., \& Banaji, M. R. (2003). Understanding and using the Implicit Association Test: I. An improved scoring algorithm. Journal of Personality and Social Psychology, 85(2), 197-216. http://doi.org/10.1037/0022-3514.85.2.197

Greitemeyer, T. (2011). Effects of prosocial media on social behavior: When and why does media exposure affect helping and aggression? Current Directions in Psychological Science, 20(4), 251-255. http://doi.org/10.1177/0963721411415229

Greitemeyer, T. (2013a). Playing video games cooperatively increases empathic concern. Social Psychology, 44(6), 408-413. http://doi.org/10.1027/1864-9335/a000154

Greitemeyer, T. (2013b). Playing Violent Video Games Increase Intergroup Bias. Personality and Social Psychology Bulletin, 1-9. http://doi.org/10.1177/0146167213505872

Greitemeyer, T. (2014). Intense acts of violence during video game play make daily life aggression appear innocuous: A new mechanism why violent video games increase aggression. Journal of Experimental Social Psychology, 50, 52-56.

http://doi.org/10.1016/j.jesp.2013.09.004

Greitemeyer, T., Agthe, M., Turner, R., \& Gschwendtner, C. (2011). Acting prosocially reduces retaliation: Effects of prosocial video games on aggressive behavior. European Journal of Social Psychology, 42(2), 235-242. http://doi.org/10.1002/ejsp.1837

Greitemeyer, T., \& Mügge, D. O. (2014). Video games do affect social outcomes: A metaanalytic review of the effects of violent and prosocial video game play. Personality \& 
Social Psychology Bulletin, 40(5), 578-589. http://doi.org/10.1177/0146167213520459

Greitemeyer, T., \& Mügge, D. O. (2015). When Bystanders Increase Rather Than Decrease Intentions to Help. Social Psychology, 46(2), 116-119. http://doi.org/10.1027/18649335/a000215

Greitemeyer, T., \& Osswald, S. (2009). Prosocial video games reduce aggressive cognitions. Journal of Experimental Social Psychology, 45, 896-900. http://doi.org/10.1016/j.jesp.2009.04.005

Greitemeyer, T., \& Osswald, S. (2010). Effects of prosocial video games on prosocial behavior. Journal of Personality and Social Psychology, 98(2), 211-221. http://doi.org/10.1037/a0016997

Greitemeyer, T., \& Osswald, S. (2011). Playing prosocial video games increases the accessibility of prosocial thoughts. The Journal of Social Psychology, 151, 121-128.

Greitemeyer, T., Osswald, S., \& Brauer, M. (2010). Playing prosocial video games increases empathy and decreases schadenfreude. Emotion, 10(6), 796-802. http://doi.org/10.1037/a0020194

Gunter, W. D., \& Daly, K. (2012). Causal or spurious: Using propensity score matching to detangle the relationship between violent video games and violent behavior. Computers in Human Behavior, 28(4), 1348-1355. http://doi.org/10.1016/j.chb.2012.02.020

Hasan, Y., Bègue, L., \& Bushman, B. J. (2012). Viewing the world through "blood-red tinted glasses": The hostile expectation bias mediates the link between violent video game exposure and aggression. Journal of Experimental Social Psychology, 48, 953-956. http://doi.org/10.1016/j.jesp.2011.12.019

Hasan, Y., Bègue, L., Scharkow, M., \& Bushman, B. J. (2013). The more you play, the more aggressive you become: A long-term experimental study of cumulative violent video game effects on hostile expectations and aggressive behavior. Journal of Experimental 
Social Psychology, 49(2), 224-227. http://doi.org/10.1016/j.jesp.2012.10.016

Hassin, R. R., Uleman, J. S., \& Bargh, J. A. (2005). The New Unconscious. New York, NY:

Oxford University Press. http://doi.org/10.1093/acprof:oso/9780195307696.001.0001

Hilbig, B. E., Glöckner, A., \& Zettler, I. (2014). Personality and prosocial behavior: Linking basic traits and social value orientations. Journal of Personality and Social Psychology, 107(3), 529-539. http://doi.org/10.1037/a0036074

Hollingdale, J., \& Greitemeyer, T. (2014). The Effect of Online Violent Video Games on Levels of Aggression. PLoS ONE, 9(11), e111790.

http://doi.org/10.1371/journal.pone.0111790

Huesmann, L. R. (2007). The impact of electronic media violence: Scientific theory and research. The Journal of Adolescent Health, 41, S6-13. http://doi.org/10.1016/j.jadohealth.2007.09.005

Ioannidis, J. P. A. (2005). Why most published research findings are false. PLoS Medicine, 2(8), e124. http://doi.org/10.1371/journal.pmed.0020124

Jeong, E. J., Biocca, F. A., \& Bohil, C. J. (2012). Sensory realism and mediated aggression in video games. Computers in Human Behavior, 28(5), 1840-1848. http://doi.org/10.1016/j.chb.2012.05.002

Jin, S. A. A. (2011). "My avatar behaves well and this feels right": Ideal and ought selves in video gaming. Social Behavior and Personality, 39(9), 1175-1182.

Jonides, J., \& Irwin, D. E. (1981). Capturing attention. Cognition, 10, 145-150.

Kahneman, D. (2011). Thinking fast and slow. New York, NY: Farrar, Straus and Giroux.

Keltner, D., Kogan, A., Piff, P. K., \& Saturn, S. R. (2014). The sociocultural appraisals, values, and emotions (SAVE) framework of prosociality: Core processes from gene to meme. Annual Review of Psychology, 65, 425-60. http://doi.org/10.1146/annurevpsych-010213-115054 
Kneer, J., Elson, M., \& Knapp, F. (2016). Fight fire with rainbows: The effects of displayed violence, difficulty, and performance in digital games on affect, aggression, and physiological arousal. Computers in Human Behavior, 54, 142-148. http://doi.org/10.1016/j.chb.2015.07.034

Krahé, B. (2014). Restoring the spirit of fair play in the debate about violent video games. European Psychologist, 19(1), 56-59. http://doi.org/10.1027/1016-9040/a000165

Krahé, B., \& Möller, I. (2011). Links between self-reported media violence exposure and teacher ratings of aggression and prosocial behavior among German adolescents. Journal of Adolescence, 34(2), 279-287.

http://doi.org/10.1016/j.adolescence.2010.05.003

Laamarti, F., Eid, M., \& Saddik, A. El. (2014). An overview of serious games. Intenational Journal of Computer Games Technology, 2014.

Leiberg, S., Klimecki, O., \& Singer, T. (2011). Short-term compassion training increases prosocial behavior in a newly developed prosocial game. PloS One, 6(3), e17798. http://doi.org/10.1371/journal.pone.0017798

Maclin, E. L., Mathewson, K. E., Low, K. A., Boot, W. R., Kramer, A. F., Fabiani, M., \& Gratton, G. (2011). Learning to multitask: Effects of video game practice on electrophysiological indices of attention and resource allocation. Psychophysiology, 48(9), 1173-83. http://doi.org/10.1111/j.1469-8986.2011.01189.x

Mattys, S. L., \& Wiget, L. (2011). Effects of cognitive load on speech recognition. Journal of Memory and Language, 65(2), 145-160. http://doi.org/10.1016/j.jml.2011.04.004

Mäyrä, F. (2008). An introduction to game studies. Thousand Oaks, CA: Sage Publications. Mccullough, M. E., \& Tabak, B. A. (2010). Prosocial behavior. In R. F. Baumeister \& E. J. Finkel (Eds.), Advanced Social Psychology (pp. 263-302). New York: Oxford University Press. 
McGonigal, J. (2011). Reality is broken. Why games makes us better and how they can change the world. New York, NY: The Penguin Press.

McMahan, R. P., Ragan, E. D., Leal, A., Beaton, R. J., \& Bowman, D. A. (2011).

Considerations for the use of commercial video games in controlled experiments. Entertainment Computing, 2(1), 3-9. http://doi.org/10.1016/j.entcom.2011.03.002

Mikulincer, M., \& Shaver, P. R. (2010). Introduction. In M. Mikulincer \& P. R. Shaver (Eds.), Prosocial motives, emotions, and behavior. The better angels of our nature (pp. 3-11). Washington, DC: American Psychological Association.

Morford, Z. H., Witts, B. N., Killingsworth, K. J., \& Alavosius, M. P. (2014). Gamification: The intersection between behavior analysis and game design technologies. Behavior Analyst, 37(1), 25-40. http://doi.org/10.1007/s40614-014-0006-1

Mößle, T., Kliem, S., \& Rehbein, F. (2014). Longitudinal effects of violent media usage on aggressive behavior-The significance of empathy. Societies, 4(1), 105-124. http://doi.org/10.3390/soc4010105

Murias, K., Kwok, K., Castillejo, A. G., Liu, I., \& Iaria, G. (2016). The effects of video game use on performance in a virtual navigation task. Computers in Human Behavior, 58, 398-406. http://doi.org/10.1016/j.chb.2016.01.020

Nosek, B. A., Greenwald, A. G., \& Banaji, M. R. (2005). Understanding and using the Implicit Association Test: II. Method variables and construct validity. Personality \& Social Psychology Bulletin, 31(2), 166-180. http://doi.org/10.1177/0146167204271418

Oei, A. C., \& Patterson, M. D. (2013). Enhancing cognition with video games: A multiple game training study. PLoS ONE, 8(3), e58546. http://doi.org/10.1371/journal.pone.0058546

Open Science Collaboration. (2014). Maximizing the reproducibility of your research. Psychological Science Under Scrutiny: Recent Challenges and Proposed Solutions, 1- 
26.

Peng, W., Lee, M., \& Heeter, C. (2010). The effects of a serious game on role-taking and willingness to help. Journal of Communication, 60, 723-742. http://doi.org/10.1111/j.1460-2466.2010.01511.x

Penner, L. A., Fritzsche, B. A., Craiger, J. P., \& Freifeld, T. S. (1995). Measuring the prosocial personality. In J. N. Butcher \& C. D. Spielberger (Eds.), Advances in personality assessment, (Vol. 12). Hillsdale, NJ: Erlbaum.

Penner, L. A., Dovidio, J. F., Piliavin, J. A., \& Schroeder, D. A. (2005). Prosocial behavior: multilevel perspectives. Annual Review of Psychology, 56(1), 365-392. http://doi.org/10.1146/annurev.psych.56.091103.070141

Perugini, M., Conner, M., \& Gorman, R. O. (2011). Automatic activation of individual differences : A test of the gatekeeper model in the domain of spontaneous helping. European Journal of Personality, 25, 465-476. http://doi.org/10.1002/per

Pilati, R., Iglesias, F., Lima, B. R., \& Simone, C. V. (2010). Experimentos de campo em comportamento prosocial: Sexo, densidade e grupo cultural. Psicologia: Teoria e Pesquisa, 26(2), 361-370.

Prot, S., \& Anderson, C. A. (2013). Research methods, design, and statistics in media psychology. In K. Dill (Ed.), The Oxford handbook of media psychology (pp. 109-136). New York: Oxford University Press.

Prot, S., Anderson, C. A., Gentile, D. A., Brown, S. C., \& Swing, E. L. (2014). The positive and negative effects of video game play. In A. Jordan \& D. Romer (Eds.) Children and Media, 109-128. New York: Oxford University Press.

Prot, S., Gentile, D. a., Anderson, C. a., Suzuki, K., Swing, E., Lim, K. M., ... Lam, B. C. P. (2013). Long-term relations among prosocial-media use, empathy, and prosocial behavior. Psychological Science, 25(2), 358-368. 
http://doi.org/10.1177/0956797613503854

Prot, S., McDonald, K. A., Anderson, C. A., \& Gentile, D. A. (2012). Video games: Good, bad, or other? Pediatric Clinics of North America, 59(3), 647-58, viii. http://doi.org/10.1016/j.pcl.2012.03.016

Rabelo, A. L. A., \& Pilati, R. (2013). Adaptação e evidências de validade da Bateria de Personalidade Prosocial no Brasil. Psico-USF, 18(3), 455-468.

Robson, K., Plangger, K., Kietzmann, J. H., McCarthy, I., \& Pitt, L. (2015). Is it all a game? Understanding the principles of gamification. Business Horizons. http://doi.org/10.1016/j.bushor.2015.03.006

Saleem, M., Anderson, C. A., \& Gentile, D. A. (2012a). Effects of prosocial, neutral, and violent video games on children's helpful and hurtful behaviors. Aggressive Behavior, 38(4), 281-287. http://doi.org/10.1002/ab.21428

Saleem, M., Anderson, C. A., \& Gentile, D. A. (2012b). Effects of prosocial, neutral, and violent video games on college students' affect. Aggressive Behavior, 38(January), 263271. http://doi.org/10.1002/ab.21427

Sampaio, L. R., Guimarães, P. R. B., Camino, C. P. S., Formiga, N. S., \& Menezes, I. G. (2011). Estudos sobre a dimensionalidade da empatia: tradução e adaptação do Interpersonal Reactivity Index (IRI). Psico, 42(1), 67-76.

Sestir, M. A., \& Bartholow, B. D. (2010). Violent and nonviolent video games produce opposing effects on aggressive and prosocial outcomes. Journal of Experimental Social Psychology, 46, 934-942. http://doi.org/10.1016/j.jesp.2010.06.005

Sherman, J. W., Lee, A. Y., Bessenoff, G. R., \& Frost, L. A. (1998). Stereotype efficiency reconsidered: Encoding flexibility under cognitive load? Journal of Personality and Social Psychology, 75(3), 589-606. Retrieved from http://www.ncbi.nlm.nih.gov/pubmed/9781404 
Simmons, J. P., Nelson, L. D., \& Simonsohn, U. (2011). False-positive psychology:

Undisclosed flexibility in data collection and analysis allows presenting anything as significant. Psychological Science, 22(11), 1359-66.

http://doi.org/10.1177/0956797611417632

Simonsohn, U., Nelson, L. D., \& Simmons, J. P. (2014). P-curve and effect size : Correcting for publication bias using only significant results. Perspectives on Psychological Science, 9(6), 666-681. http://doi.org/10.1177/1745691614553988

Stürmer, S., \& Snyder, M. (2010). The psychology of prosocial behavior. West Sussex: Wiley-Blackwell. http://doi.org/10.1002/9781444307948

Suter, R. S., \& Hertwig, R. (2011). Time and moral judgment. Cognition, 119(3), 454-458. http://doi.org/10.1016/j.cognition.2011.01.018

Swing, E. L., Gentile, D. A., \& Anderson, C. A. (2009). Learning processes and violent video games. In R. E. Ferdig (Ed.), Handbook of Research on Effective Electronic Gaming in Education (Vol. II, pp. 876-892). New York: Information Science Reference.

Tear, M. J., \& Nielsen, M. (2013). Failure to demonstrate that playing violent video vames diminishes prosocial behavior. PLoS ONE, 8(7), e68382. http://doi.org/10.1371/journal.pone.0068382

Tear, M. J., \& Nielsen, M. (2014). Video games and prosocial behavior: A study of the effects of non-violent, violent and ultra-violent gameplay. Computers in Human Behavior, 41, 8-13. http://doi.org/10.1016/j.chb.2014.09.002

Uhlmann, E., \& Swanson, J. (2004). Exposure to violent video games increases automatic aggressiveness. Journal of Adolescence, 27(1), 41-52.

http://doi.org/10.1016/j.adolescence.2003.10.004

Unsworth, N., Redick, T. S., McMillan, B. D., Hambrick, D. Z., Kane, M. J., \& Engle, R. W. (2015). Is playing video games related to cognitive abilities? Psychological Science, 
26(6), 759-774. http://doi.org/10.1177/0956797615570367

Valadez, J. J., \& Ferguson, C. J. (2012). Just a game after all: Violent video game exposure and time spent playing effects on hostile feelings, depression, and visuospatial cognition. Computers in Human Behavior, 28, 608-616. http://doi.org/10.1016/j.chb.2011.11.006

Vallett, D. B., Lamb, R. L., \& Annetta, L. A. (2013). The gorilla in the room: The impacts of video-game play on visual attention. Computers in Human Behavior, 29(6), 2183-2187. http://doi.org/10.1016/j.chb.2013.05.001

van Assen, M. A. L. M., van Aert, R. C. M., Nuijten, M. B., \& Wicherts, J. M. (2014). Why publishing everything is more effective than selective publishing of statistically significant results. PLoS ONE, 9(1), e84896. http://doi.org/10.1371/journal.pone.0084896

Van Boven, L., \& Robinson, M. D. (2012). Boys don't cry: Cognitive load and priming increase stereotypic sex differences in emotion memory. Journal of Experimental Social Psychology, 48(1), 303-309. http://doi.org/10.1016/j.jesp.2011.09.005

Van Gog, T., Kester, L., \& Paas, F. (2011). Effects of concurrent monitoring on cognitive load and performance as a function of task complexity. Applied Cognitive Psychology, $25,584-587$.

Velez, J. A., Mahood, C., Ewoldsen, D. R., \& Moyer-gusé, E. (2014). Ingroup versus outgroup conflict in the context of violent video game play: The effect of cooperation on increased helping and decreased aggression. Communication Research, 41(5), 607-626. http://doi.org/10.1177/0093650212456202

Xu, H., Bègue, L., \& Bushman, B. J. (2012). Too fatigued to care: Ego depletion, guilt, and prosocial behavior. Journal of Experimental Social Psychology, 48(5), 1183-1186. http://doi.org/10.1016/j.jesp.2012.03.007 
Yao, M. Z., Mahood, C., \& Linz, D. (2010). Sexual priming, gender stereotyping, and likelihood to sexually harass: Examining the cognitive effects of playing a sexuallyexplicit video game. Sex Roles, 62(1-2), 77-88. http://doi.org/10.1007/s11199-0099695-4

Zumbach, J., Seitz, C., \& Bluemke, M. (2015). Impact of violent video game realism on the self-concept of aggressiveness assessed with explicit and implicit measures. Computers in Human Behavior, 53, 278-288. http://doi.org/10.1016/j.chb.2015.07.018 


\section{Apêndice A. Questionário contendo questões sobre avaliação do jogo e PANAS}

Caro(a) Participante:

Este instrumento tem como objetivo avaliar o jogo que você acabou de jogar. Para tanto, solicitamos a sua colaboração para responder este formulário, que contém perguntas sobre suas impressões acerca do jogo. Pedimos que você seja o mais sincero possível em suas respostas e garantimos que os dados coletados serão tratados de forma anônima e sigilosa. Por isso, não é necessário se identificar.

\begin{tabular}{|l|l|}
\hline 1. Classe Jogada & ( ) Aldeão ( ) Arqueiro ( ) Clérigo \\
\hline & ( ) Guerreiro ( ) Mago ( ) Trabalhador \\
\hline
\end{tabular}

2. Na sua opinião, qual é o nível de dificuldade do jogo? Marque na escala abaixo a opção mais apropriada:

\begin{tabular}{|c|c|c|c|}
\hline Muito fácil & 1 & 2 & \\
\hline
\end{tabular}

3. Quanto o jogo foi agradável para você?

\begin{tabular}{|l|l|l|l|l|l|l|l|l|}
\hline Muito desagradável & 1 & 2 & 3 & 4 & 5 & 6 & 7 & Muito agradável \\
\hline
\end{tabular}

4. Com base na sua opinião, o quão frustrante é o jogo?

\begin{tabular}{|l|l|l|l|l|l|l|l|l|} 
Nada frustrante & 1 & 2 & 3 & 4 & 5 & 6 & 7 & Muito frustrante \\
\hline
\end{tabular}

5. O quanto o jogo foi excitante para você?

\begin{tabular}{|l|l|l|l|l|l|l|l|l} 
Nada excitante & 1 & 2 & 3 & 4 & 5 & 6 & 7 & Muito excitante
\end{tabular}

6. Quão violento você considera o jogo que experimentou?

\begin{tabular}{|l|l|l|l|l|l|l|l|l} 
Nada violento & 1 & 2 & 3 & 4 & 5 & 6 & 7 & Muito violento
\end{tabular}

7. Analise os itens abaixo. Eles expressam diferentes sentimentos e emoções. Avalie, com base na escala abaixo, o quanto cada um representa a forma como você se sentiu após terminar de jogar:

\begin{tabular}{|c|c|c|c|c|}
\hline 1 & 2 & 3 & 4 & 5 \\
\hline Nada & Um pouco & Moderadamente & Bastante & Extremamente \\
\hline \multicolumn{3}{|c|}{ Interessado } & \multicolumn{2}{|l|}{ __ Orgulhoso } \\
\hline \multicolumn{3}{|c|}{ __ Perturbado } & \multicolumn{2}{|l|}{ __ Irritado } \\
\hline \multicolumn{3}{|c|}{ __ Excitado } & \multicolumn{2}{|l|}{ ___ Encantado } \\
\hline \multicolumn{3}{|c|}{ __ Atormentado } & \multicolumn{2}{|l|}{ __ Remorsos } \\
\hline \multirow{2}{*}{\multicolumn{3}{|c|}{$\begin{array}{l}\text { Agradavelmente Surpreendido } \\
\text { Culpado }\end{array}$}} & \multicolumn{2}{|l|}{ ___ Inspirado } \\
\hline & & & \multirow{2}{*}{\multicolumn{2}{|c|}{$\begin{array}{l}\text { _- Nervoso } \\
\text { _- Determinado }\end{array}$}} \\
\hline \multicolumn{3}{|c|}{ Assustado } & & \\
\hline \multicolumn{3}{|c|}{ _Caloroso } & \multicolumn{2}{|l|}{ __ Trêmulo } \\
\hline \multicolumn{3}{|c|}{ _ Repulsa } & \multicolumn{2}{|l|}{$\ldots$ Ativo } \\
\hline \multicolumn{3}{|c|}{ _ Entusiasmado } & \multicolumn{2}{|l|}{ __ Amedrontado } \\
\hline
\end{tabular}




\section{Apêndice B. Questionário contendo questões demográficas e de hábitos de jogo,}

\section{BPP e Intenção de ajuda}

\section{Caro(a) Participante:}

Este instrumento tem como objetivo coletar alguns dados sobre você e seus hábitos com jogos, que servirão como elementos de comparação entre os participantes da pesquisa. Pedimos que você seja o mais sincero possível em suas respostas e garantimos que os dados coletados serão tratados de forma anônima e sigilosa. Por isso, não é necessário se identificar.

Desde já, muito obrigado pela colaboração.

1. Idade: anos

2. Gênero: ( ) Masculino ( ) Feminino

3. Nível de Escolaridade

( ) $1^{\circ}$ grau incompleto

( ) $1^{\circ}$ grau completo

( ) $2^{\circ}$ grau incompleto

( ) $2^{\circ}$ grau completo

( ) Superior incompleto

( ) Superior completo

( ) Mestrado

( ) Doutorado

Caso tenha marcado Superior completo ou incompleto: Curso:

4. Você joga jogos eletrônicos (videogames, jogos de computador, jogos de celular, etc)?:

( ) Não - passe para a questão 11

( ) Sim - Continue respondendo abaixo

5. Quantas horas de jogo por semana, aproximadamente:

6. Em qual período? a) da semana: ( ) dias de semana ( ) fins de semana

b) do dia: ( ) manhã ( ) tarde ( ) Noite

9. Quais consoles utiliza? Numere do mais frequente (1) ao menos frequente (5):

( ) Computador ( ) PS2 ( ) PS3 ( ) Xbox360 ( ) Nintendo Wii

( ) Nintendo DS ( ) PSP/Vita ( ) Celular ( ) Tablet ( ) Outro:

10. Cite até 3 jogos mais jogados por você no último mês

10 mais jogado:

$2^{\circ}$ mais jogado:

$3^{\circ}$ mais jogado: 
11. Por fim, utilize a escala abaixo e atribua, para cada afirmativa apresentada, o quanto você concorda com ela.

\begin{tabular}{|c|c|c|c|c|}
\hline 1 & 2 & 3 & 4 & 5 \\
\hline $\begin{array}{c}\text { Discordo } \\
\text { totalmente }\end{array}$ & $\begin{array}{c}\text { Discordo em } \\
\text { parte }\end{array}$ & $\begin{array}{c}\text { Nem concordo } \\
\text { nem discordo }\end{array}$ & $\begin{array}{c}\text { Concordo em } \\
\text { parte }\end{array}$ & $\begin{array}{c}\text { Concordo } \\
\text { totalmente }\end{array}$ \\
\hline
\end{tabular}

\begin{tabular}{|l|l|}
\hline ( ) & Eu já ajudei a carregar os pertences de um estranho (ex. Livros, pacotes, etc.) \\
\hline ( ) & $\begin{array}{l}\text { Eu permiti que alguém passasse na minha frente em uma fila (ex. } \\
\text { supermercado, fotocopiadora, etc.) }\end{array}$ \\
\hline ( ) & $\begin{array}{l}\text { Eu já emprestei um item de algum valor para um vizinho que não conhecia bem } \\
\text { (ex. ferramentas, um prato, etc.) }\end{array}$ \\
\hline ( ) & $\begin{array}{l}\text { Eu já me ofereci para cuidar dos animais de estimação ou crianças de um } \\
\text { vizinho sem ser remunerado por isso. }\end{array}$ \\
\hline ( ) & $\begin{array}{l}\text { Eu já me ofereci para ajudar um deficiente ou idoso desconhecido a } \\
\text { atravessar a rua. }\end{array}$ \\
\hline ( ) & Geralmente sou muito eficiente ao lidar com emergências. \\
\hline ( ) & Tenho tendência a perder o controle durante emergências. \\
\hline ( ) & $\begin{array}{l}\text { Quando vejo alguém que precisa muito de ajuda em uma situação de } \\
\text { emergência, eu fico perdido. }\end{array}$ \\
\hline
\end{tabular}

13. Você teria interesse e disponibilidade para participar de outras pesquisas de nosso grupo?

( ) Não

( ) $\operatorname{Sim}$

Em caso afirmativo, quantas horas por semana você poderia dispor? horas 


\section{Apêndice C. Lista de estímulos do Teste de Decisão Lexical}

\section{Palavras-alvo}

- Altruísta;

- Benevolente;

- Caridoso;

- Cooperativo;

- Filantropo;

- Generoso;

- Prestativo;

- Solidário.

\section{Palavras neutras}

- Filmadora;

- Computador

- Microondas;

- Televisão;

- Telefone;

- Amplificador;

- Liquidificador;

- Ventilador.

\section{Pseudopalavras}

- Tamembola;

- Caltruvisto;

- Pertiversado;

- Cantrolesmo;

- Loúcetário;

- Antrovismo;

- Bulólico;

- Amblinômico;

- Tadeirama;

- Bedeloquente;

- Meriótico;

- Vedidade;

- Patacace;

- Tanesta;

- Propluteno;

- Nacéptico. 


\section{Apêndice D. Escala de Amabilidade do Big Five (Andrade, 2008)}

A seguir, há uma lista com adjetivos que completam a frase "Eu sou uma pessoa...". Esses adjetivos representam características comuns a diversas pessoas. Leia cada um deles e assinale o quanto descrevem você. Quanto maior o número, mais adequada a descrição.

\begin{tabular}{|c|c|c|c|c|}
\hline 1 & 2 & 3 & 4 & 5 \\
\hline $\begin{array}{c}\text { Discordo } \\
\text { totalmente }\end{array}$ & $\begin{array}{c}\text { Discordo em } \\
\text { parte }\end{array}$ & $\begin{array}{c}\text { Nem concordo } \\
\text { nem discordo }\end{array}$ & $\begin{array}{c}\text { Concordo em } \\
\text { parte }\end{array}$ & $\begin{array}{c}\text { Concordo } \\
\text { totalmente }\end{array}$ \\
\hline
\end{tabular}
( ) Amável
( ) Gentil
( ) Simpática
( ) Bondosa
( ) Compreensiva 
Apêndice E. Lista de estímulos utilizada no Teste de Associação Implícita de autoconceito

\begin{tabular}{|c|c|}
\hline $\begin{array}{l}\text { Categoria Alvo - Prosocial: } \\
\begin{array}{l}\text { - Altruísta; } \\
\text { - Benevolente; } \\
\text { - Caridoso; } \\
\text { - Cooperativo; } \\
\text { - Filantropo; } \\
\text { - Generoso; } \\
\text { - Prestativo; } \\
\text { - Solidário. }\end{array}\end{array}$ & $\begin{array}{l}\text { Categoria Alvo - Antissocial: } \\
\text { - Antipático; } \\
\text { - Descortês; } \\
\text { - Desrespeitoso; } \\
\text { - Detestável; } \\
\text { - Grosseiro; } \\
\text { - Indelicado; } \\
\text { - Insensível; } \\
\text { - Rude. }\end{array}$ \\
\hline $\begin{array}{l}\text { Categoria Atributo - Eu: } \\
\text { - Eu; } \\
\text { - Mim; } \\
\text { - Meu; } \\
\text { - Minha; } \\
\text { - Comigo; } \\
\text { - Me; } \\
\text { - Próprio. }\end{array}$ & $\begin{array}{l}\text { Categoria Atributo - Outros: } \\
\text { - Alheio; } \\
\text { - Eles; } \\
\text { - Deles; } \\
\text { - Outros; } \\
\text { - Seu; } \\
\text { - Consigo; } \\
\text { - Lhe. }\end{array}$ \\
\hline
\end{tabular}




\section{Apêndice F. Instruções gerais do Zurich Prosocial Game - ZPG}

\section{Objetivo do jogo}

Durante este jogo, você deverá alcançar tesouros o mais rápido possível. Usando o mouse do computador, você deverá tentar guiar sue personagem por um caminho dentro do tempo fixado. Cada tesouro vale 50 pontos. Esses pontos serão trocados por dinheiro entregue a você ao final do jogo.

\section{Instruções}

O jogo será jogado por dois jogadores simultaneamente. Por isso, você será conectado com outro jogador em nossa rede ao começo de cada rodada. Para cada rodada do jogo, você será conectado com um jogador diferente.

Antes de iniciar o jogo, você será solicitado a inserir um código. Esse código deve ser formado a partir das iniciais de seu nome e o ano de seu nascimento. Por exemplo, para João Ubaldo Ribeiro, nascido em 1930, o código será JUR1930. Esse código será utilizado garantir o anonimato na análise dos dados.

Vocês dois jogarão no mesmo campo, porém você tentará alcançar o seu próprio tesouro independentemente. Isso significa que os dois podem ganhar cada rodada. Seu personagem sempre será a carinha vermelha, e a cor da carinha do outro jogador vai mudar a cada rodada.

As imagens da tela a seguir mostram o campo no inicio de uma rodada

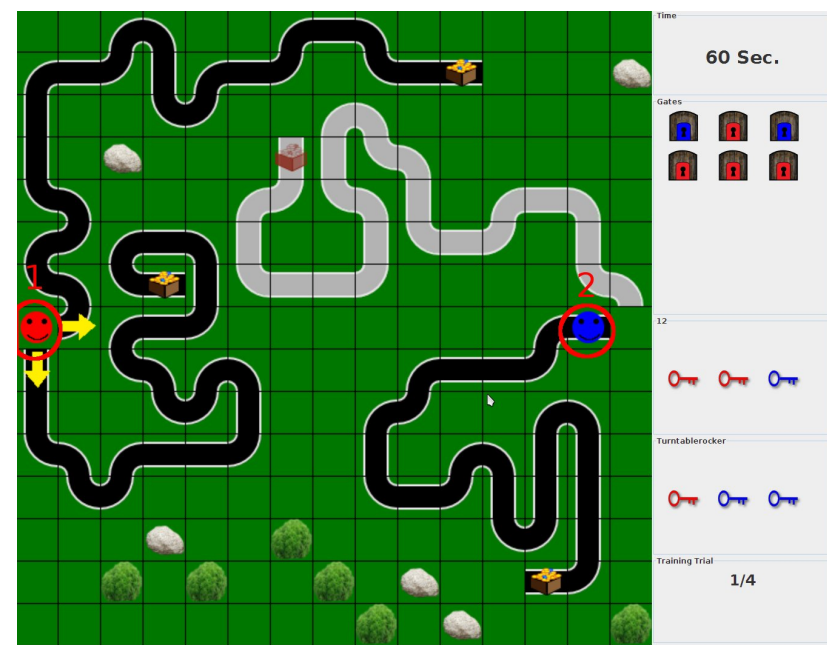

Fig. 1. Campo de jogo no início de uma rodada: (1) você, (2) segundo jogador

Quando o jogo começar, você terá que decidir entre dois caminhos possíveis para seu personagem (a carinha vermelha). Para fazer isso, por favor, clique com o botão esquerdo do mouse em uma das duas setas amarelas. O outro caminho ficará cinza. Assim que os dois jogadores escolherem seus caminhos para o tesouro, o tempo começa. Você tem um limite de tempo para alcançar o tesouro. O tempo restante está visível no alto do canto direito da tela. 
Para mover seu personagem adiante, clique rapidamente nas setas amarelas que aparecem no caminho em frente a sua carinha.

Durante cada rodada, portões vermelhos e azuis vão cair aleatoriamente no caminho, impedindo os jogadores de seguirem em frente. Os portões podem cair no seu caminho, no caminho do outro jogador ou no caminho cinza, que ninguém escolheu. Para abrir um portão, você precisa de uma chave que tenha a mesma cor do portão. Durante cada rodada, o lado direito da tela listará suas chaves disponíveis abaixo do seu nome, e as chaves disponíveis para o outro jogador abaixo do nome dele(a). Você também verá os seis portões que podem aparecer durante cada rodada.

Por exemplo, se um portão azul cai no seu caminho, clique na chave azul abaixo do seu nome na tela. Esse clique vai abrir o portão. Por favor, mantenha em mente que portões azuis só podem ser abertos por chaves azuis e portões vermelhos apenas podem ser abertos por chaves vermelhas. Depois de abrir o portão, tanto o portão quanto a chave desaparecem e você não pode usar a chave novamente. Se o portão bloqueia um jogador e não é aberto, o jogador bloqueado morrerá em alguns segundos. $\mathrm{O}$ uso da chave é independente dos caminhos. Isso significa que tanto você quanto o outro jogador podem abrir tanto o próprio caminho quanto o caminho do outro. Você pode usar chaves enquanto você não tiver alcançado o tesouro, mesmo que seu personagem já esteja morto.

Por favor, familiarize-se com a tela no começo do jogo (antes de escolher seu caminho!) e estude a distribuição de portões e chaves.

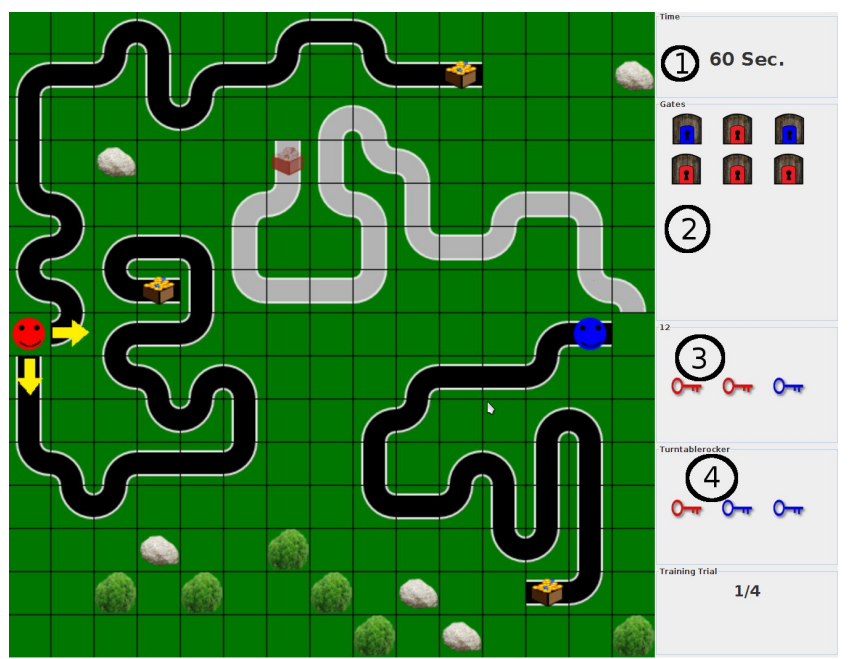

Fig. 2. Campo de jogo no início de uma rodada: (1) tempo restante, (2) portões restantes, (3) suas chaves, (4) chaves do outro jogador.

Às vezes durante o jogo, estrelas vermelhas irão aparecer em seu caminho ou no caminho do outro jogador. Se você clicar na estrela rapidamente, você ganhará 20 pontos adicionais.

De início, você jogará 4 rodadas de teste para treinar. Depois jogará 11 rodadas. 


\section{Questões de compreensão}

\section{Código do participante:}

Olhe para a figura e responda as questões abaixo:

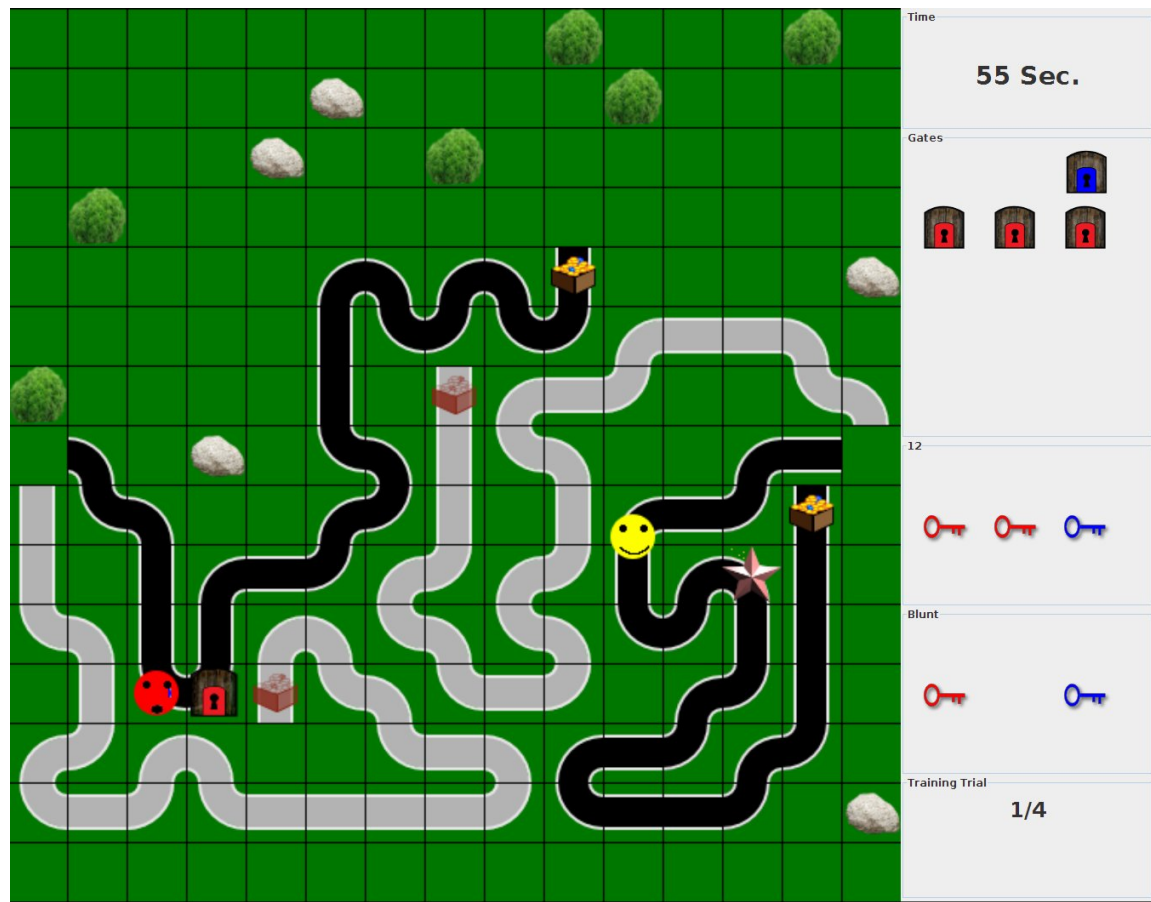

Fig. 1. Situação durante o jogo: Você foi bloqueado por um portão vermelho.

1. Eu serei apto a abrir o portão que está me bloqueando nessa situação?
( ) $\operatorname{Sim}$
( ) Não 


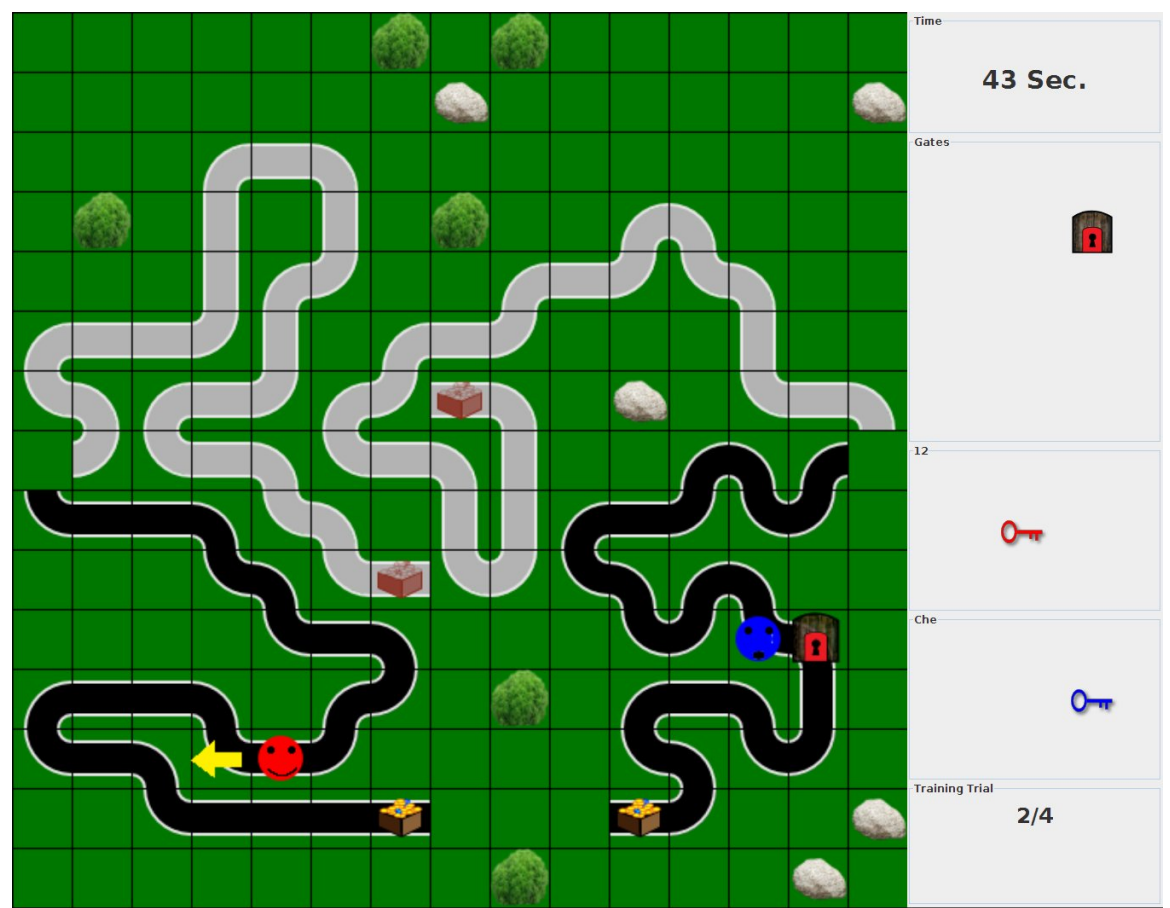

Fig. 2. Situação durante o jogo: O outro jogador foi bloqueado por um portão vermelho.

2. O outro jogador está apto a abrir esse portão?
( ) $\mathrm{Sim}$
( ) Não

3. Quantos portões ainda irão aparecer?
( ) Nenhum
( ) Um
( ) Dois

4. Se eu abrir o portão do outro jogador, o que pode acontecer?
( ) Eu com certeza alcançarei o tesouro.
( ) Eu não vou alcançar mais o tesouro.
( ) Eu poderei ser bloqueado por outro portão vermelho.

5. Qual a probabilidade de alcançar meu tesouro se eu ajudar o outro jogador?
( ) $10 \%$
( ) $25 \%$
( ) $50 \%$ 


\section{Apêndice G. Itens da Interpersonal Reactivity Index (adaptado por Sampaio,}

\section{Guimarães, Camino, Formiga \& Menezes, 2011)}

A seguir, você lerá uma série de afirmações quanto a características pessoais. Marque a opção que melhor te descreve na escala abaixo das afirmações. Quanto mais à esquerda for a opção que você selecionou, menos a característica te descreve bem; quanto mais à direita, melhor aquela característica te descreve:

\begin{tabular}{|r|l|l|l|l|l|l|}
\hline $\begin{array}{r}\text { Não me descreve } \\
\text { bem }\end{array}$ & 1 & 2 & 3 & 4 & 5 & $\begin{array}{l}\text { Descreve-me muito } \\
\text { bem }\end{array}$ \\
\hline
\end{tabular}

- Tenho facilidade de assumir a posição de um personagem de filme.

- Sinto emoções de um personagem de filme como se fossem minhas próprias emoções.

- Depois de ver uma peça de teatro ou um filme sinto-me envolvido com seus personagens.

- Habitualmente me envolvo emocionalmente com filmes e/ou livros.

- Sou neutro quando vejo filmes.

- Costumo fantasiar com coisas que poderiam me acontecer.

- Quando vejo uma história interessante, imagino como me sentiria se ela estivesse acontecendo comigo.

- Preocupo-me com as pessoas que não têm uma boa qualidade de vida.

- Sinto compaixão quando alguém é tratado injustamente.

- Incomodo-me com as coisas ruins que acontecem aos outros.

- Fico comovido com os problemas dos outros.

- Quando vejo que se aproveitam de alguém, sinto necessidade de protegê-lo.

- Costumo me emocionar com as coisas que vejo acontecer aos outros.

- Descrevo-me como uma pessoa de "coração mole" (muito sensível).

- Habitualmente fico nervoso quando vejo pessoas feridas.

- Fico apreensivo em situações emergenciais.

- Fico tenso em situações de fortes emoções.

- Tendo a perder o controle durante emergências.

- Sinto-me indefeso numa situação emotiva.

- Perco o controle quando vejo alguém que esteja precisando de muita ajuda.

- Tento compreender meus amigos imaginando como eles vêem as coisas.

- Escuto os argumentos dos outros, mesmo estando convicto de minha opinião.

- Antes de tomar alguma decisão procuro avaliar todas as perspectivas.

- Tento compreender o argumento dos outros.

- Imagino como as pessoas se sentem quando eu as critico.

- Coloco-me no lugar do outro se eu me preocupo com ele. 


\section{Apêndice H. Questionário de avaliação do jogo e de esforço cognitivo}

Código do participante:

Caro(a) Participante:

Este instrumento tem como objetivo avaliar o jogo que você foi solicitado a jogar nesta etapa. Para tanto, solicitamos a sua colaboração para responder este formulário, que contém perguntas sobre suas impressões. Pedimos que você seja o mais sincero possível em suas respostas e garantimos que os dados coletados serão tratados de forma anônima e sigilosa.

1. Na sua opinião, como você avalia o nível de dificuldade para desempenhar as tarefas do jogo? Marque na escala abaixo a opção mais apropriada:

\begin{tabular}{l|l|l|l|l|l|l|l|l|l} 
Muito fácil & 1 & 2 & 3 & 4 & 5 & 6 & 7 & Muito difícil
\end{tabular}

2. Quanto o jogo foi agradável para você?

\begin{tabular}{|l|l|l|l|l|l|l|l|l|}
\hline Muito desagradável & 1 & 2 & 3 & 4 & 5 & 6 & 7 & Muito agradável \\
\hline
\end{tabular}

3. Com base na sua opinião, o quão frustrante foi jogar este jogo?

\begin{tabular}{|r|l|l|l|l|l|l|l|l|}
\hline Nada frustrante & 1 & 2 & 3 & 4 & 5 & 6 & 7 & Muito frustrante \\
\hline
\end{tabular}

4. 0 quanto o jogo foi excitante para você?

\begin{tabular}{|l|l|l|l|l|l|l|l|l|} 
Nada excitante & 1 & 2 & 3 & 4 & 5 & 6 & 7 & Muito excitante \\
\hline
\end{tabular}

5. Quão violento você considera o jogo que experimentou?

\begin{tabular}{|l|l|l|l|l|l|l|l|l|}
\hline Nada violento & 1 & 2 & 3 & 4 & 5 & 6 & 7 & Muito violento \\
\hline
\end{tabular}

6. Analise os itens abaixo. Eles contemplam diferentes afirmações acerca da experiência em jogar. Avalie, com base na escala abaixo, o quanto você concorda com cada uma delas:

\begin{tabular}{|c|c|c|c|c|}
\hline 1 & 2 & 3 & 4 & 5 \\
\hline $\begin{array}{c}\text { Discordo } \\
\text { Totalmente }\end{array}$ & $\begin{array}{c}\text { Discordo em } \\
\text { Parte }\end{array}$ & $\begin{array}{c}\text { Nem concordo } \\
\text { nem discordo }\end{array}$ & $\begin{array}{c}\text { Concordo em } \\
\text { parte }\end{array}$ & $\begin{array}{c}\text { Concordo } \\
\text { totalmente }\end{array}$ \\
\hline
\end{tabular}

( ) Jogar este jogo exigiu muito de minha concentração

( ) Tive dificuldade em realizar as tarefas propostas no jogo

( ) Considero que tive um desempenho excelente no jogo que acabei de jogar

( ) Jogar este jogo me deixou mais cansado do que quando as iniciei 